\title{
Cochrane
}

Library

Cochrane Database of Systematic Reviews

\section{Ureteral stent versus no ureteral stent for ureteroscopy in the management of renal and ureteral calculi (Review)}

Ordonez M, Hwang EC, Borofsky M, Bakker CJ, Gandhi S, Dahm P

Ordonez M, Hwang EC, Borofsky M, Bakker CJ, Gandhi S, Dahm P.

Ureteral stent versus no ureteral stent for ureteroscopy in the management of renal and ureteral calculi. Cochrane Database of Systematic Reviews 2019, Issue 2. Art. No.: CD012703.

DOI: 10.1002/14651858.CD012703.pub2.

www.cochranelibrary.com

Ureteral stent versus no ureteral stent for ureteroscopy in the management of renal and ureteral calculi (Review) Copyright $\odot 2019$ The Cochrane Collaboration. Published by John Wiley \& Sons, Ltd. 
TABLE OF CONTENTS

HEADER 1

ABSTRACT

PLAIN LANGUAGE SUMMARY ....

SUMMARY OF FINDINGS

BACKGROUND

OBJECTIVES

METHODS

RESULTS

Figure 1.

Figure 2.

Figure 3.

DISCUSSION

AUTHORS' CONCLUSIONS

ACKNOWLEDGEMENTS

REFERENCES

CHARACTERISTICS OF STUDIES

DATA AND ANALYSES

Analysis 1.1. Comparison 1 URS with stent placement vs URS with no stent placement, Outcome 1 Unplanned return visit to emergency/urgent care department.

Analysis 1.2. Comparison 1 URS with stent placement vs URS with no stent placement, Outcome 2 Postoperative pain day 0 . ..

Analysis 1.3. Comparison 1 URS with stent placement vs URS with no stent placement, Outcome 3 Postoperative pain day 1 to day 3.

Analysis 1.4. Comparison 1 URS with stent placement vs URS with no stent placement, Outcome 4 Postoperative pain day 4 to day 30 .

Analysis 1.5. Comparison 1 URS with stent placement vs URS with no stent placement, Outcome 5 Secondary interventions. .. Analysis 1.6. Comparison 1 URS with stent placement vs URS with no stent placement, Outcome 6 Narcotic requirement. ..... Analysis 1.7. Comparison 1 URS with stent placement vs URS with no stent placement, Outcome 7 UTI (positive urine culture as well as symptoms) up to 90 days.

Analysis 1.8. Comparison 1 URS with stent placement vs URS with no stent placement, Outcome 8 Operating room time (in minutes).

Analysis 1.9. Comparison 1 URS with stent placement vs URS with no stent placement, Outcome 9 Ureteral stricture up to 90 days.

Analysis 1.10. Comparison 1 URS with stent placement vs URS with no stent placement, Outcome 10 Quality of life. ...............

Analysis 1.11. Comparison 1 URS with stent placement vs URS with no stent placement, Outcome 11 Hospital admission. ...... ADDITIONAL TABLES

APPENDICES

CONTRIBUTIONS OF AUTHORS

DECLARATIONS OF INTEREST

SOURCES OF SUPPORT

DIFFERENCES BETWEEN PROTOCOL AND REVIEW

NOTES

INDEX TERMS 
[Intervention Review]

\section{Ureteral stent versus no ureteral stent for ureteroscopy in the management of renal and ureteral calculi}

Maria Ordonez ${ }^{1}$, Eu Chang Hwang², Michael Borofsky¹, Caitlin J Bakker³, Shreyas Gandhi ${ }^{4}$, Philipp Dahm

1Department of Urology, University of Minnesota, Minneapolis, Minnesota, USA. 2Department of Urology, Chonnam National University Medical School, Chonnam National University Hwasun Hospital, Hwasun, Korea, South. ${ }^{3}$ Health Sciences Libraries, University of Minnesota, Minneapolis, Minnesota, USA. ${ }^{4}$ Dalhousie University, Halifax, Canada. 5 Urology Section, Minneapolis VA Health Care System, Minneapolis, Minnesota, USA

Contact address: Maria Ordonez, Department of Urology, University of Minnesota, 420 Delaware Street SE, MMC 394, Minneapolis, Minnesota, USA. mordonez@umn.edu.

Editorial group: Cochrane Urology Group.

Publication status and date: New, published in Issue 2, 2019.

Citation: Ordonez M, Hwang EC, Borofsky M, Bakker CJ, Gandhi S, Dahm P. Ureteral stent versus no ureteral stent for ureteroscopy in the management of renal and ureteral calculi. Cochrane Database of Systematic Reviews 2019, Issue 2. Art. No.: CD012703. DOI: 10.1002/14651858.CD012703.pub2.

Copyright () 2019 The Cochrane Collaboration. Published by John Wiley \& Sons, Ltd.

\section{A B S T R A C T}

\section{Background}

Ureteroscopy combined with laser stone fragmentation and basketing is a common approach for managing renal and ureteral stones. This procedure is associated with some degree of ureteral trauma. Ureteral trauma may lead to swelling, ureteral obstruction, and flank pain and may require subsequent interventions such as hospital admission or secondary ureteral stent placement. To prevent such issues, urologists often place temporary ureteral stents prophylactically, but the value of doing so remains unclear.

\section{Objectives}

To assess the effects of postoperative ureteral stent placement after uncomplicated ureteroscopy.

\section{Search methods}

We performed a comprehensive search using multiple databases (the Cochrane Library, MEDLINE, Embase, Scopus, Google Scholar, and Web of Science), trials registries, other sources of grey literature, and conference proceedings, up to 01 February 2019. We applied no restrictions on publication language or status.

\section{Selection criteria}

We included trials in which researchers randomised participants undergoing uncomplicated ureteroscopy to placement of a ureteral stent versus no ureteral stent.

\section{Data collection and analysis}

Two review authors independently classified studies and abstracted data from the included studies. We performed statistical analyses using a random-effects model. We rated the certainty of evidence (CoE) according to the GRADE approach.

\section{Main results}

\section{Primary outcomes}

Stenting may slightly reduce the number of unplanned return visits (16 trials with 1970 participants; very low CoE), but we are very uncertain of this finding. 
Pain on the day of surgery as measured on a visual analogue scale (scale 0 to 10; higher values reflect more pain) is probably similar (mean difference (MD) 0.32 higher, $95 \%$ confidence interval (CI) 0.13 lower to 0.78 higher; 4 trials with 346 participants; moderate CoE). Pain on postoperative days 1 to 3 may show little to no difference (standardised mean difference (SMD) 0.25 higher, $95 \% \mathrm{Cl} 0.32$ lower to 0.82 higher; 8 trials with 683 participants; low $\mathrm{COE}$ ). On postoperative days 4 to 30, stented participants may experience more pain ( 8 trials with 903 participants; very low $\mathrm{CoE}$ ), but we are very uncertain of this finding.

Stenting may result in little to no difference in the need for secondary interventions (risk ratio (RR) 1.15, $95 \% \mathrm{Cl} 0.39$ to 3.33 ; 10 studies with 1435 participants; low $\mathrm{CoE}$ ); this corresponds to three more interventions per 1000 participants ( $95 \% \mathrm{Cl} 13$ fewer to 48 more).

\section{Secondary outcomes}

Stenting may reduce the need for narcotics ( 7 trials with 830 participants; very low CoE), but we are very uncertain of this finding.

Rates of urinary tract infection (UTI) up to 90 days are probably not substantially different (RR $0.94,95 \% \mathrm{Cl} 0.59$ to $1.51 ; 10$ trials with 1207 participants; moderate $\mathrm{CoE}$ ); this corresponds to three fewer infections per 1000 participants ( $95 \% \mathrm{Cl} 23$ fewer to 29 more).

Ureteral stricture rates up to 90 days may be slightly reduced (14 trials with 1625 participants; very low CoE), but we are very uncertain of this finding.

Rates of hospital admission may be slightly reduced (RR $0.70,95 \% \mathrm{Cl} 0.32$ to $1.55 ; 13$ studies with 1647 participants; low CoE). This corresponds to 15 fewer admissions per 1000 participants ( $95 \% \mathrm{Cl} 33$ fewer to 27 more).

\section{Authors' conclusions}

Findings of this review illustrate the trade-offs of risks and benefits faced by urologists and their patients when it comes to decision-making about stent placement after uncomplicated ureteroscopy for stone disease. We noted that both desirable and undesirable effects were small in absolute terms, with findings based mostly on low and very low $\mathrm{CoE}$. The main issues reducing our confidence in research findings were study limitations (mostly risk of performance and detection bias) and imprecision. We were unable to conduct any of the preplanned subgroup analyses, in particular those based on stone size, stone location, and use of ureteral dilation, which may be important effect modifiers. Given the importance of this question, higher-quality and sufficiently large trials are needed to better inform decision-making.

\section{PLAIN LANGUAGE SUMMARY}

\section{Should we place a stent or not after stone removal?}

\section{Review question}

For patients with stones in the kidney or in the tube draining urine from the kidney to the bladder that have been removed from the inside by a ureteroscope (a very thin scope), how does placing a stent (a small plastic tube in the ureter) compare to not using a stent?

\section{Background}

Urologists use small scopes and other tools to find, break up, and remove stones. Afterwards, swelling and blockage of the ureter can cause discomfort. To prevent that from happening, urologists often leave a temporary stent. It is unclear whether a stent makes things better or worse.

\section{Study characteristics}

We included 23 trials with 2656 people who either had a stent or not. Whether they received a stent or not was decided by chance.

\section{Key results}

A stent may make people come back to the hospital for problems less often, but we are very uncertain of this finding. Pain on the day of surgery and on days one to three after surgery may be similar. People with a stent may have more pain in the long term (days four to 30), but we are also very uncertain about this. The need for another procedure may be similar.

People with a stent may be less likely to need narcotics (strong pain medications that can cause addiction), but we are very uncertain about this. There may be no difference in the risk of a urinary tract infection. Stenting may make people a little less likely to develop a narrowing of the ureter because of scarring and may make them slightly less likely to be admitted to the hospital. However, we are very uncertain of both findings.

\section{Certainty of the evidence}

The certainty of evidence ranged from moderate to very low depending on the outcome, meaning that we have moderate, low, or very low confidence in the study results. 


\section{SUMMARY OF FINDINGS}

Summary of findings for the main comparison. URS with stent placement compared to URS with no stent placement for ureteroscopy in the management of renal and ureteral calculi

URS with stent placement compared to URS with no stent placement for ureteroscopy in the management of renal and ureteral calculi

Participants: participants underwent ureteroscopy due to renal and ureteral calculi

Setting: inpatient or outpatient

Intervention: stent placement

Comparator: no stent placement

\begin{tabular}{|c|c|c|c|c|c|}
\hline \multirow[t]{2}{*}{ Outcomes } & \multirow{2}{*}{$\begin{array}{l}\text { No. of partici- } \\
\text { pants } \\
\text { (studies) } \\
\text { Follow-up }\end{array}$} & \multirow{2}{*}{$\begin{array}{l}\text { Certainty of the } \\
\text { evidence } \\
\text { (GRADE) }\end{array}$} & \multirow{2}{*}{$\begin{array}{l}\text { Relative effect } \\
(95 \% \mathrm{CI})\end{array}$} & \multicolumn{2}{|c|}{ Anticipated absolute effects ${ }^{\star}(95 \% \mathrm{Cl})$} \\
\hline & & & & $\begin{array}{l}\text { Risk with URS } \\
\text { with no stent } \\
\text { placement }\end{array}$ & $\begin{array}{l}\text { Risk difference with URS with } \\
\text { stent placement }\end{array}$ \\
\hline Unplanned return visit to emergency/urgent & 1970 & $\oplus \ominus \ominus \ominus$ & RR 0.69 & \multicolumn{2}{|l|}{ Study population } \\
\hline Follow-up: 2 weeks to 49 months & & & & 67 per 1000 & $\begin{array}{l}21 \text { fewer per } 1000 \\
\text { ( } 40 \text { fewer to } 14 \text { more) }\end{array}$ \\
\hline $\begin{array}{l}\text { Postoperative pain day } 0 \\
\text { Assessed with visual analogue scale (range } 0 \\
\text { to } 10 \text { ): } 4 \text { studies }\end{array}$ & $\begin{array}{l}346 \\
\text { (4 RCTs) }\end{array}$ & $\begin{array}{l}\oplus \oplus \oplus \ominus \\
\text { MODERATE } a\end{array}$ & - & $\begin{array}{l}\text { Mean postopera- } \\
\text { tive pain day } 0 \\
\text { ranged from } 2.3 \text { to } \\
4.82\end{array}$ & $\begin{array}{l}\text { MD } 0.32 \text { higher } \\
\text { ( } 0.13 \text { lower to } 0.78 \text { higher) }\end{array}$ \\
\hline $\begin{array}{l}\text { Postoperative pain day } 1 \text { to day } 3 \\
\text { Assessed with visual analogue scale (range } 0 \\
\text { to } 10 \text { ): } 7 \text { studies; pain questionnaire (range } 0 \\
\text { to } 100 \text { ): } 1 \text { study }\end{array}$ & $\begin{array}{l}683 \\
\text { (8 RCTs) }\end{array}$ & $\begin{array}{l}\oplus \oplus \ominus \ominus \\
\text { LOW a,d,e }\end{array}$ & - & - & $\begin{array}{l}\text { SMD } 0.25, \text { SD higher } \\
\text { ( } 0.32 \text { lower to } 0.82 \text { higher) }\end{array}$ \\
\hline $\begin{array}{l}\text { Postoperative pain day } 4 \text { to day } 30 \\
\text { Assessed with visual analogue scale (range } 0 \\
\text { to } 10 \text { ): } 5 \text { studies; pain questionnaire (range } 0 \\
\text { to } 100 \text { ): } 1 \text { study }\end{array}$ & $\begin{array}{l}903 \\
\text { (8 RCTs) }\end{array}$ & $\begin{array}{l}\oplus \ominus \ominus \ominus \\
\text { VERY LOW a,b,d }\end{array}$ & - & - & $\begin{array}{l}\text { SMD } 0.62, \text { SD higher } \\
\text { ( } 0.08 \text { higher to } 1.16 \text { higher) }\end{array}$ \\
\hline Other: 2 studies & & & & & \\
\hline Secondary interventions & $\begin{array}{l}1435 \\
\text { (10 RCTs) }\end{array}$ & $\begin{array}{l}\oplus \oplus \ominus \ominus \\
\text { LOW a,f }\end{array}$ & $\begin{array}{l}\text { RR } 1.15 \\
\text { (0.39 to } 3.33)\end{array}$ & Study population & \\
\hline
\end{tabular}




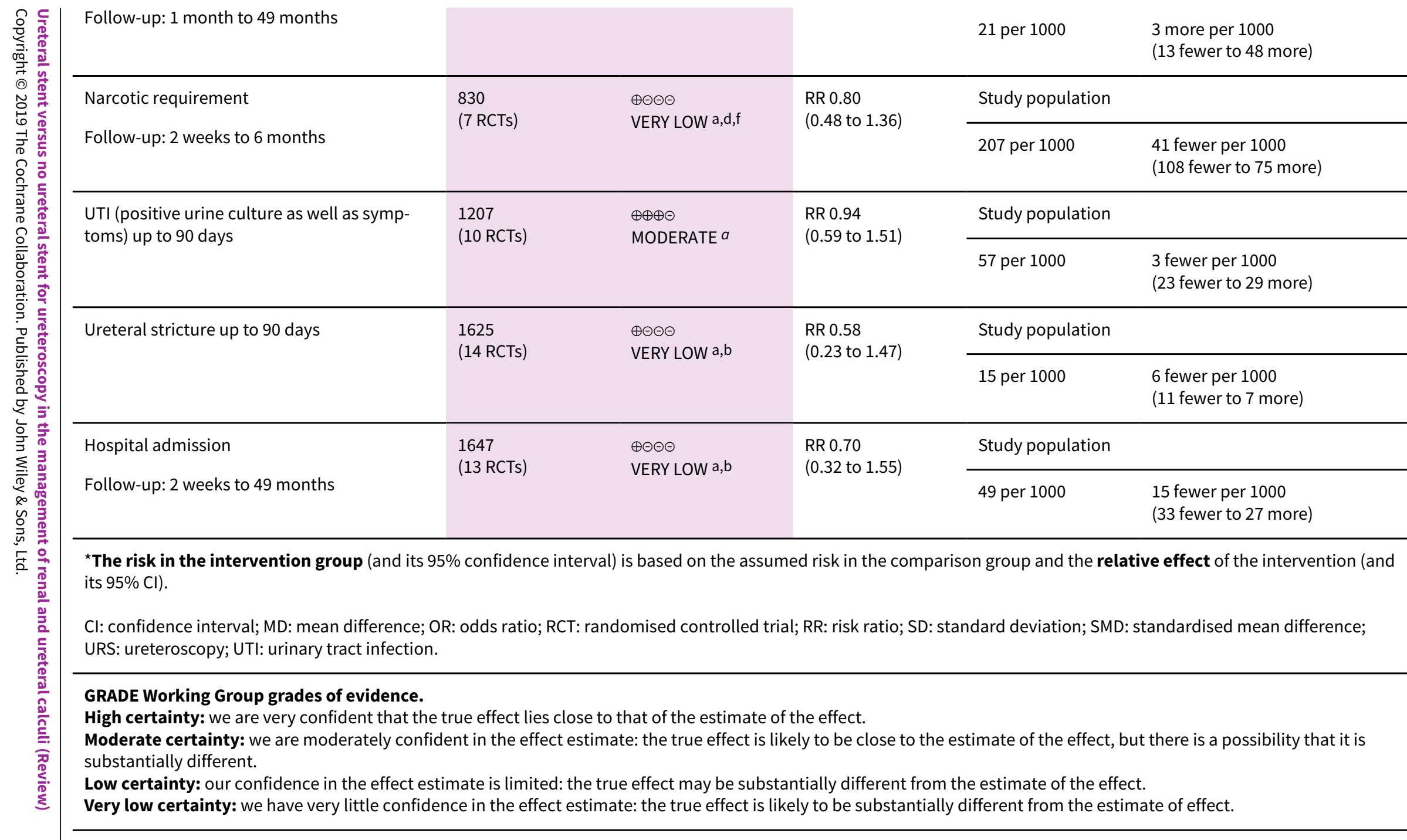

aDowngraded by one level for study limitations mainly due to concerns about performance bias across studies.

bDowngraded by two levels for imprecision: wide confidence interval.

cDowngraded by one level for publication bias: funnel plot asymmetry.

$d$ Downgraded by one level for inconsistency: clinically relevant heterogeneity.

eWe did not downgrade for imprecision because it resulted from inconsistency.

fDowngraded by one level for imprecision: confidence interval crosses the line of no difference and the assumed threshold of a clinically important difference. 


\section{B A C K G R O U N D}

\section{Description of the condition}

Urolithiasis is one of the most common urological diseases with increasing prevalence worldwide. In the United States, the prevalence has increased to nearly $8.8 \%$ over the past 40 years (Scales 2012). In the United Kingdom, lifetime prevalence of nephrolithiasis has increased from $7.14 \%$ to $14 \%$, and in Japan, the incidence has been rising over the past 40 years as well (Rukin 2017; Turney 2011; Yasui 2008). Although intrarenal stones may be asymptomatic, many ultimately migrate and become obstructive. Ureteral and renal calculi can lead to symptoms involving severe abdominal and flank pain, nausea, and urinary tract problems.

American Urological Association (AUA) and European Association of Urology (EAU) guidelines suggest a trial of passage for stones that are $1 \mathrm{~cm}$ or smaller through symptom management. Medical expulsive therapy may facilitate stone passage (Campschroer 2018; Hollingsworth 2016; Vermandere 2018). If a stone has not passed after a period of four to six weeks (or as determined by shared decision-making), patients are offered an intervention to clear the stones (AUA Guideline Surgical Management of Stones 2016; EAU Guidelines on Urolithiasis 2016, EAU Guidelines on Urolithiasis 2018). Clinicians may offer surgical intervention for larger stones (AUA Guideline Surgical Management of Stones 2016).

In the past, shockwave lithotripsy represented the mainstay of treatment for renal and proximal ureteral stones and was used for distal ureteral stones at some centres. With the advent of smaller and more agile instruments, ureteroscopy has become one of the most common procedures for treatment of patients with ureteral and renal calculi. This is reflected in an expanded indication for ureteroscopy in current evidence-based clinical practice guidelines, such as those provided by the AUA (AUA Guideline Surgical Management of Stones 2016). So-called semirigid ureteroscopes, which are used mainly for distal and midureteral stones, as well as flexible ureteroscopes that can access the entire upper tract collecting system including the renal calyces are used in conjunction with lasers for stone 'dusting' or fragmentation and basketing (AUA Guideline Surgical Management of Stones 2016; EAU Guidelines on Urolithiasis 2016; EAU Guidelines on Urolithiasis 2018).

Ureteral stents are very commonly placed after ureteroscopy and are indicated in the setting of infection, renal failure, ureteral injury, or severe oedema. One evaluation of stent placement revealed that stents are placed in $60 \%$ of patients after treatment for ureteral stones and in $80 \%$ of patients after treatment for renal stones (Muslumanoglu 2017). Postoperative ureteral stenting is thought to decrease renal obstruction due to postoperative ureteral oedema or small stone fragments. It is also thought to mitigate the effects of instrumentation and the sequelae of subsequent oedema and to prevent ureteral stricture formation. Stents, however, are not used without costs. Side effects from ureteral stents, including urinary frequency and urgency, haematuria, dysuria, flank pain, and pelvic pain, are the most common source of postoperative morbidity (Joshi 2003). These side effects can lead to office and emergency department visits, and yet omitting the stent can lead to further intervention and additional visits as well (Rapoport 2007).

Ureteral stents are placed routinely in the ureter if ureteroscopy is complicated by a ureteral injury, the most severe of which may extend through the ureteral wall. Ureteroscopy is also considered complicated when patients show concomitant urinary tract infection or evidence of acute renal failure. However, no standard definition of a 'complicated' ureteroscopy is available. Investigators have developed a ureteral lesion scale for ureteroscopy that grades the severity of injury, but it has not yet found widespread use (Schoenthaler 2012; Traxer 2013).

\section{Description of the intervention}

Ureteral stent placement involves placement of a small, flexible tube from the kidney to the bladder. Most commonly, stents have a so-called double ' $J$ ' design that results in a curl in the renal collecting system and a curl in the bladder, both of which hold the stent in place. Stents allow urine to move from the kidney to the bladder even if obstruction of the ureter follows the ureteroscopic procedure. Stents differ in design, material, and surface coating (Mosayyebi 2018). They are typically placed under fluoroscopic guidance over a wire after the ureteroscopic procedure, which only takes a few minutes to perform.

\section{How the intervention might work}

Ureteral stent placement is thought to facilitate drainage of the kidney after obstruction due to ureteral mucosal oedema, while decreasing intrarenal pressure and facilitating passage of small residual stone fragments, but some reviews show that these outcomes are not necessarily improved by ureteral stent placement in the time frame during which oedema or stone fragments would be an issue (Netto 2001).

\section{Why it is important to do this review}

It is important to do this review to examine whether postoperative ureteral stent placement is required after uncomplicated ureteroscopy. Stents themselves may cause significant discomfort and morbidity in patients after ureteroscopy. Several systematic reviews have summarised the body of evidence on benefits and harms of placing a ureteral stent (Haleblian 2008; Makarov 2008; Nabi 2007; Pais 2016; Pengfei 2011; Picozzi 2013; Tang 2011; Wang 2017). However, none has adhered to the methodological standards of Cochrane, including application of GRADE and generation of 'Summary of findings' tables. The only related Cochrane Review explored the use of ureteral stents in patients undergoing renal transplantation (Wilson 2005); this involved a very different patient population with different reasons for stent placement and different expected results.

\section{O B JECT IVES}

To assess the effects of postoperative ureteral stent placement after uncomplicated ureteroscopy.

\section{METHODS}

\section{Criteria for considering studies for this review}

\section{Types of studies}

We included randomised trials. We included studies regardless of their publication status or language of publication.

\section{Types of participants}

We included participants over the age of 18 who underwent ureteroscopy for stone clearance. 
We excluded studies conducted in children, pregnant women, patients with systemic signs of infection (sepsis), patients with a solitary kidney, patients undergoing bilateral stone procedures, patients with anatomical abnormalities (horseshoe kidney, pelvic kidney, etc.), and transplant patients. We excluded studies in which ureteroscopy was complicated by perforation of the ureter or gross bleeding. In the absence of a standard definition of what constitutes complicated ureteroscopy and the challenge of applying any criteria retrospectively to a given trial, this determination will hinge on the judgement of the trial authors. We also excluded studies in patients who had a pre-existing ureteral stent at the time of ureteroscopy.

Should we have identified studies in which only a subset of participants were relevant to this review, we included such studies if data were available separately for the relevant subset.

\section{Types of interventions}

We investigated the following comparisons of outcomes based on stent placement versus no stent placement. Concomitant interventions must be the same in experimental and comparator groups to establish fair comparisons. We included studies in which ureteral dilation or placement of an access sheath (as needed) is part of the ureteroscopic procedure.

\section{Experimental interventions}

- Ureteroscopy with stent placement

\section{Comparator interventions}

- Ureteroscopy with no stent placement

\section{Comparisons}

- Ureteral stent placement versus no ureteral stent placement

\section{Types of outcome measures}

We did not use measurement of the outcomes assessed in this review as an eligibility criterion.

\section{Primary outcomes}

- Unplanned return visit to emergency/urgent care department

- Postoperative discomfort (pain or irritative voiding complaints, or both) as measured by visual analogue scale

- Secondary interventions (e.g. stent placement/exchange, percutaneous nephrostomy tube placement, secondary ureteroscopy)

\section{Secondary outcomes}

- Requirement for narcotics

- Urinary tract infection (defined as clinical symptoms and positive urine culture)

- Operating room time (in minutes)

- Ureteral stricture (defined as need for dilation, incision, or surgical repair or radiographic appearance)

- Quality of life

- Postoperative hospital admission

We had initially planned to assess the outcome of narcotic requirements in morphine equivalents as per our protocol
(Ordonez 2017), but we revised this to requirement for narcotics (see Differences between protocol and review).

\section{Method and timing of outcome measurement}

We assessed postoperative discomfort based on information captured by visual analogue scales (VASs).

We included outcome data up to three months after randomisation for all outcomes except ureteral stricture formation; for this outcome, we also considered longer-term data when available.

\section{Main outcomes for 'Summary of findings' table}

We presented a 'Summary of findings' table reporting the following outcomes listed according to priority.

- Unplanned return visit to emergency/urgent care department.

- Postoperative pain on day 0.

- Postoperative pain on days 1 to 3 .

- Postoperative pain on days 4 to 30 .

- Secondary interventions (e.g. stent placement/exchange, percutaneous nephrostomy tube (PCN) placement, secondary ureteroscopy).

- Narcotic requirement (in morphine equivalents).

- Urinary tract infection (defined as clinical symptoms and positive urine culture).

- Ureteral stricture up to 90 days.

- Postoperative hospital admission.

\section{Search methods for identification of studies}

We performed a comprehensive search with no restrictions on the language of publication or publication status. We repeated searches within three months before anticipated publication of the review.

\section{Electronic searches}

We searched the following sources from inception of each database.

- The Cochrane Library (Appendix 1).

* Cochrane Database of Systematic Reviews (CDSR).

* Cochrane Central Register of Controlled Trials (CENTRAL).

* Database of Abstracts of Reviews of Effects (DARE).

* Health Technology Assessment Database (HTA).

- MEDLINE (via OVID; Appendix 2).

- Embase (via OVID; Appendix 3).

- Western Pacific Region Index Medicus.

We also searched the following.

- ClinicalTrials.gov (www.clinicaltrials.gov/).

- World Health Organization (WHO) International Clinical Trials Registry Platform (ICTRP) search portal (apps.who.int/ trialsearch/).

If we detected additional relevant key words during any electronic or other searches, we modified electronic search strategies to incorporate these terms and document the changes. 


\section{Searching other resources}

We tried to identify other potentially eligible trials or ancillary publications by searching the reference lists of retrieved included trials, reviews, meta-analyses, and health technology assessment reports. When applicable, we contacted study authors of included trials to identify studies that we may have missed. When applicable, we contacted drug/device manufacturers for ongoing or unpublished trials. We searched abstract proceedings for the years 2013 to 2018 from the following meetings.

- American Urological Association.

- European Association of Urology.

- Société Internationale d'Urologie.

- World Congress of Endourology.

\section{Data collection and analysis}

\section{Selection of studies}

We used reference management software (EndNote) to identify and remove potential duplicate records, then imported the references into Covidence (www.covidence.org). Three review authors (MO, $M B, S G$ ) independently scanned the abstract, title, or both, of remaining records retrieved, to determine which studies should be assessed further. Three review authors (MO, MB, SG) then investigated all potentially relevant records as full text and map records to studies and classified studies as included studies, excluded studies, studies awaiting classification, or ongoing studies, in accordance with the criteria for each provided in the Cochrane Handbook for Systematic Reviews of Interventions (Higgins 2011a). We resolved discrepancies through consensus or recourse to a fourth review author (PD). If resolution of a disagreement was not possible, we designated the study as 'awaiting classification' and contacted study authors for clarification. We documented reasons for exclusion of studies that may have reasonably been expected to be included in the review in a Characteristics of excluded studies table. We presented an adapted PRISMA flow diagram showing the process of study selection (Liberati 2009).

\section{Data extraction and management}

We developed a dedicated data abstraction form that we pilottested ahead of time.

For studies that fulfil inclusion criteria, three review authors (MO, MB, SG) independently abstracted the following information, which we provided in the Characteristics of included studies table.

- Study design.

- Study dates (if dates are not available, then this will be reported as such).

- Study settings and country.

- Participant inclusion and exclusion criteria.

- Participant details and baseline demographics (e.g. age, gender, stone location, stone size).

- Numbers of participants by study and by study arm.

- Details of relevant experimental and comparator interventions (e.g. type of stent, time until stent removal).

- Definitions of relevant outcomes, method and timing of outcome measurement, as well as any relevant subgroups.

- Study funding sources.
- Declarations of interest by primary investigators.

We extracted outcome data relevant to this Cochrane Review as needed for calculation of summary statistics and measures of variance. For dichotomous outcomes, we attempted to obtain numbers of events and totals for populations from a $2 \times 2$ table, as well as summary statistics with corresponding measures of variance. For continuous outcomes, we attempted to obtain means and standard deviations or data necessary to calculate this information.

We resolved disagreements by discussion or, if required, by consultation with a fourth review author (PD).

We provided information, including trial identifier, from potentially relevant ongoing studies in the Characteristics of ongoing studies table.

We attempted to contact authors of included studies to obtain key missing data as needed.

\section{Dealing with duplicate and companion publications}

In the event of duplicate publications, companion documents, or multiple reports of a primary study, we maximised the yield of information by mapping all publications to unique studies and collating all available data. We used the most complete data-set aggregated across all known publications. In case of doubt, we gave priority to the publication reporting the longest follow-up associated with our primary or secondary outcomes.

\section{Assessment of risk of bias in included studies}

Three review authors (MO, MB, SG) independently assessed the risk of bias of each included study. We resolved disagreements by consensus, or by consultation with a fourth review author (PD).

We assessed risk of bias using Cochrane's 'Risk of bias' assessment tool (Higgins 2011b), along with Covidence (www.covidence.org). We assessed the following domains.

- Random sequence generation (selection bias).

- Allocation concealment (selection bias).

- Blinding of participants and personnel (performance bias).

- Blinding of outcome assessment (detection bias).

- Incomplete outcome data (attrition bias).

- Selective reporting (reporting bias).

- Other sources of bias.

We judged risk of bias domains as having 'low risk', 'high risk', or 'unclear risk', and we evaluated individual bias items as described in the Cochrane Handbook for Systematic Reviews of Interventions (Higgins 2011b). We presented a 'Risk of bias' summary figure to illustrate these findings.

For selection bias (random sequence generation and allocation concealment), we evaluated risk of bias at a trial level.

For performance bias (blinding of participants and personnel), we assumed that all outcomes are similarly susceptible to performance bias. We therefore defined all endpoints as subjective outcomes (performance bias). 
For detection bias (blinding of outcome assessment), we evaluated the risk of bias separately for each outcome but grouped outcomes according to whether they are likely or unlikely to be affected by detection bias.

We defined the following endpoints as subjective outcomes (detection bias).

- Postoperative discomfort (pain and/or irritative voiding complaints).

- Urinary tract infection.

- Ureteral stricture.

- Quality of life

We defined the following endpoints as objective outcomes (detection bias).

- Unplanned return visit to emergency/urgent care department.

- Secondary interventions.

- Analgesia requirement.

- Operating room time.

- Hospital admission.

We also assessed attrition bias (incomplete outcome data) for all outcomes.

We further summarised risk of bias across domains for each outcome in each included study, as well as across studies and domains for each outcome, in accordance with the approach for summary assessments of risk of bias presented in the Cochrane Handbook for Systematic Reviews of Interventions (Higgins 2011b).

\section{Measures of treatment effect}

We expressed dichotomous data as risk ratios (RRs) with 95\% confidence intervals (Cls). We expressed continuous data as mean differences (MDs) with 95\% Cls unless different studies used different measures to assess the same outcome, in which case we re-expressed data as standardised mean differences (SMDs) with $95 \% \mathrm{Cls}$.

\section{Unit of analysis issues}

The unit of analysis was the individual participant. If we identified cross-over trials, cluster-randomised trials, or trials with more than two intervention groups for inclusion in the review, we handled these in accordance with guidance provided in the Cochrane Handbook for Systematic Reviews of Interventions (Higgins 2011c).

\section{Dealing with missing data}

We obtained missing data from study authors, if feasible, and performed intention-to-treat (ITT) analyses if data were available. Otherwise we performed available case analyses. We investigated attrition rates (e.g. dropouts, losses to follow-up, withdrawals) and the critically appraised issues of missing data. We did not impute missing data.

\section{Assessment of heterogeneity}

In the event of excessive heterogeneity unexplained by subgroup analyses, we reported outcome results as the pooled effect estimate in a meta-analysis but provided a narrative description of the results of each study.
We identified heterogeneity (inconsistency) through (a) visual inspection of forest plots to assess the amount of overlap of Cls; and (b) consideration of the $\mathrm{I}^{2}$ statistic, which quantifies inconsistency across studies to assess the impact of heterogeneity on the metaanalysis (Higgins 2002; Higgins 2003); we interpreted the $\mathrm{I}^{2}$ statistic as follows (Deeks 2011).

- $0 \%$ to $40 \%$ : may not be important.

- $30 \%$ to $60 \%$ : may indicate moderate heterogeneity.

- $50 \%$ to $90 \%$ : may indicate substantial heterogeneity.

- $75 \%$ to $100 \%$ : shows considerable heterogeneity.

When we found heterogeneity, we attempted to determine possible reasons for it by examining individual study and subgroup characteristics.

\section{Assessment of reporting biases}

We attempted to obtain study protocols to assess for selective outcome reporting.

We included 10 or more studies investigating a particular outcome, and we used funnel plots to assess small-study effects. Several explanations can be offered for the asymmetry of a funnel plot, including true heterogeneity of effect with respect to trial size, poor methodological design (and hence bias of small trials), and publication bias. We therefore interpreted results carefully.

\section{Data synthesis}

Unless we found good evidence for homogeneous effects across studies, we summarised data using a random-effects model. We interpreted random-effects meta-analyses with due consideration of the whole distribution of effects. In addition, we performed statistical analyses according to the statistical guidelines provided in the Cochrane Handbook for Systematic Reviews of Interventions (Higgins 2011a). For dichotomous outcomes, we used the MantelHaenszel method; for continuous outcomes, we used the inverse variance method. We used Review Manager 2014 software to perform analyses.

\section{Subgroup analysis and investigation of heterogeneity}

We expected the following characteristics to introduce clinical heterogeneity, and we carried out subgroup analyses with investigation of interactions.

- Patient age (40 or younger vs over 40 years of age).

- Patient gender (male vs female).

- Ureteroscope type (flexible vs semi-rigid).

- Stone location (renal vs proximal and mid vs distal ureteral).

- Stone size ( $\leq 5 \mathrm{~mm}$ vs $5 \mathrm{~mm}$ to $10 \mathrm{~mm}$ vs $>10 \mathrm{~mm}$ ).

- Ureteral dilation including access sheath use or balloon dilation, or both (yes vs no).

We used the test for subgroup differences in Review Manager 2014 to compare subgroup analyses.

\section{Sensitivity analysis}

We performed sensitivity analyses to explore the influence of the following factors (when applicable) on effect sizes. 
- Restricting the analysis by taking into account risk of bias, by excluding studies at 'high risk' or 'unclear risk'.

- Restricting the analysis to studies with a minimal stent duration of three days.

\section{'Summary of findings' table}

We presented the overall quality of the evidence for each outcome according to the GRADE approach, which takes into account five criteria related not only to internal validity (risk of bias, inconsistency, imprecision, publication bias), but also to external validity (e.g. directness of results) (Guyatt 2008). For each comparison, three review authors (MO, MB, ECH) independently rated the certainty of the evidence (COE) for each outcome as 'high', 'moderate', 'low', or 'very low' using GRADEpro GDT. We resolved discrepancies by consensus or, if needed, by arbitration by a third review author (PD). For each comparison, we presented a summary of the evidence for the main outcomes in Summary of findings for the main comparison, which provides key information about the best estimate of the magnitude of effect in relative terms and absolute differences for each relevant comparison of alternative management strategies; numbers of participants and studies addressing each important outcome; and the rating of overall confidence in effect estimates for each outcome (Guyatt 2011; Schünemann 2011).

\section{RES U L T S}

\section{Description of studies}

\section{Results of the search}

Our search of multiple electronic databases yielded 5527 references, to which we added an additional two references that we identified by searching abstract proceedings and reference lists (Figure 1). After exclusion of duplicates, we screened 2631 references at the title/abstract stage. Of these 41 references, mapping to 38 unique studies entered the full-text screening stage. We ultimately included 23 studies in the quantitative analyses. We summarised reasons for exclusion at the full-text stage in the PRISMA flow diagram (Figure 1), and we provided further details Characteristics of excluded studies. 
Figure 1. Study flow diagram.

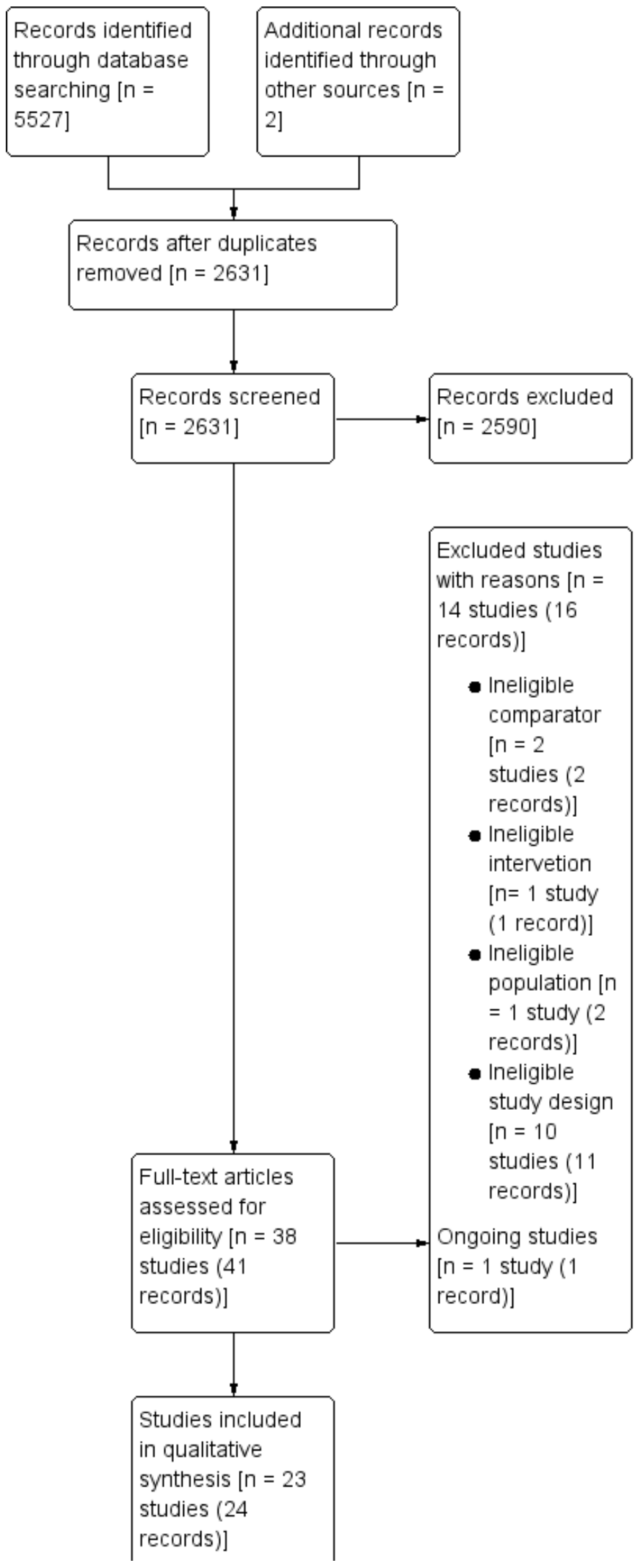


Figure 1. (Continued)

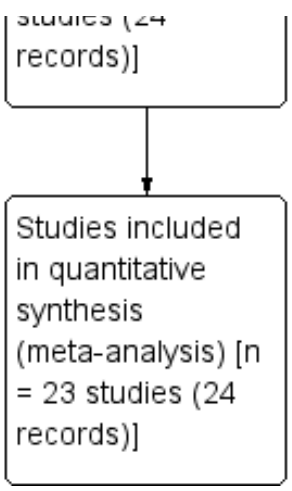

\section{Included studies}

We presented details of included studies in the Characteristics of included studies table and in Table 1 and Table 2.

\section{Source of data}

We included 20 published studies and three abstract proceedings (Benrabah 2014; Hosseini 2009; Yari 2010). All studies were published in English. We attempted to contact all corresponding authors of included trials to obtain additional information on study methods and results, and we received replies from three (Bolat 2017; Sirithanaphol 2017; Wang 2009; see Appendix 4).

\section{Study design and settings}

All studies were parallel randomised controlled trials (RCTs). Most were single-centre trials (17/23); only 6 were multi-centre trials. Accrual periods ranged from 1997 to 2014. Three trials did not report any information on their enrolment period (Benrabah 2014; Denstedt 2001; Hosseini 2009).

\section{Participants}

We included 2656 randomised participants, of whom 2275 completed the trials. However, four studies did not report the number of participants who completed the trial in each group (Benrabah 2014; Grossi 2006; Hosseini 2009; Yari 2010). Mean stone size ranged from 5.3 to $13.28 \mathrm{~mm}$, and five studies did not report stone size (Benrabah 2014; Denstedt 2001; Hosseini 2009; Sirithanaphol 2017; Yari 2010). Most studies (10/23) included upper, mid, and distal stones; three studies included mid and distal stones (Cevik 2010; Shao 2008; Xu 2009); and one study included distal stones only (Benrabah 2014). Nine studies did not report stone location (Borboroglu 2001; ElHarrech 2014; Hosseini 2009; Ibrahim 2008; Isen 2008; Sirithanaphol 2017; Srivastava 2003; Yari 2010; Zaki 2011). Three studies did not report on stent type (Başeskioğlu 2011; Netto 2001; Yari 2010). The remaining studies used a $4.8 \mathrm{Fr}$ to $7 \mathrm{Fr}$ double $\mathrm{J}$ stent or ureteral stent $(\mathrm{Fr}=1$ French $(\mathrm{Fr})$ is equivalent to $0.33 \mathrm{~mm}$ of diameter).

\section{Interventions, comparators, and comparisons}

A total of 21 studies performed ureteral stenting after ureteroscopy as an intervention and used no stent placement, with URS as a comparator. ElHarrech 2014 and Wang 2009 compared three groups (i.e. DJ stent placement vs ureteral stent placement vs no stent placement for ElHarrech 2014; and DJ stent placement vs no stent placement vs sham (named 'control') for Wang 2009); therefore, we selected one pair of interventions to create a single pair-wise comparison (i.e. DJ stent placement vs no stent placement). Followup duration ranged two weeks to one year.

\section{Outcomes}

Each study reported our predefined primary and secondary outcomes. Please refer to Analysis 1.1 through Analysis 1.11.

\section{Funding sources and conflicts of interest}

Two studies reported no funding source (Başeskioğlu 2011; Cevik 2010), and one reported the funding source (Denstedt 2001). The remaining trials did not mention a funding source. Three studies reported no conflicts of interest (Başeskioğlu 2011; Cevik 2010; ElHarrech 2014), and one reported a conflict of interest (Denstedt 2001). The remaining studies did not mention conflicts of interest.

\section{Excluded studies}

We excluded 14 studies (16 records) out of 38 studies ( 41 records) after evaluation of the full-text publications. One study reported an ineligible intervention (Byrne 2002), and one included an ineligible population (Hussein 2006). Ten studies used an ineligible study design (Ali 2001; Clayman 2005; Manu 2015; Mittakanti 2018; Muslumanoglu 2017; Schoenthaler 2013; Tu 2015; Turker 2009; Wang 2017; Zhang 2014). Two studies described an ineligible comparator (Bolat 2017; Chauhan 2015). We presented details of excluded studies in the Characteristics of excluded studies table.

\section{Studies awaiting classification and ongoing trials}

We identified no studies awaiting classification. We found one ongoing study that has not provided usable outcome data at this time (NCT03130907; see Characteristics of ongoing studies).

\section{Risk of bias in included studies}

For details, please refer to the Characteristics of included studies section, the 'Risk of bias' table, Summary of findings for the main comparison for the main comparison, and Figure 2. 
Figure 2. Risk of bias summary: review authors' judgements about each risk of bias item for each included study.

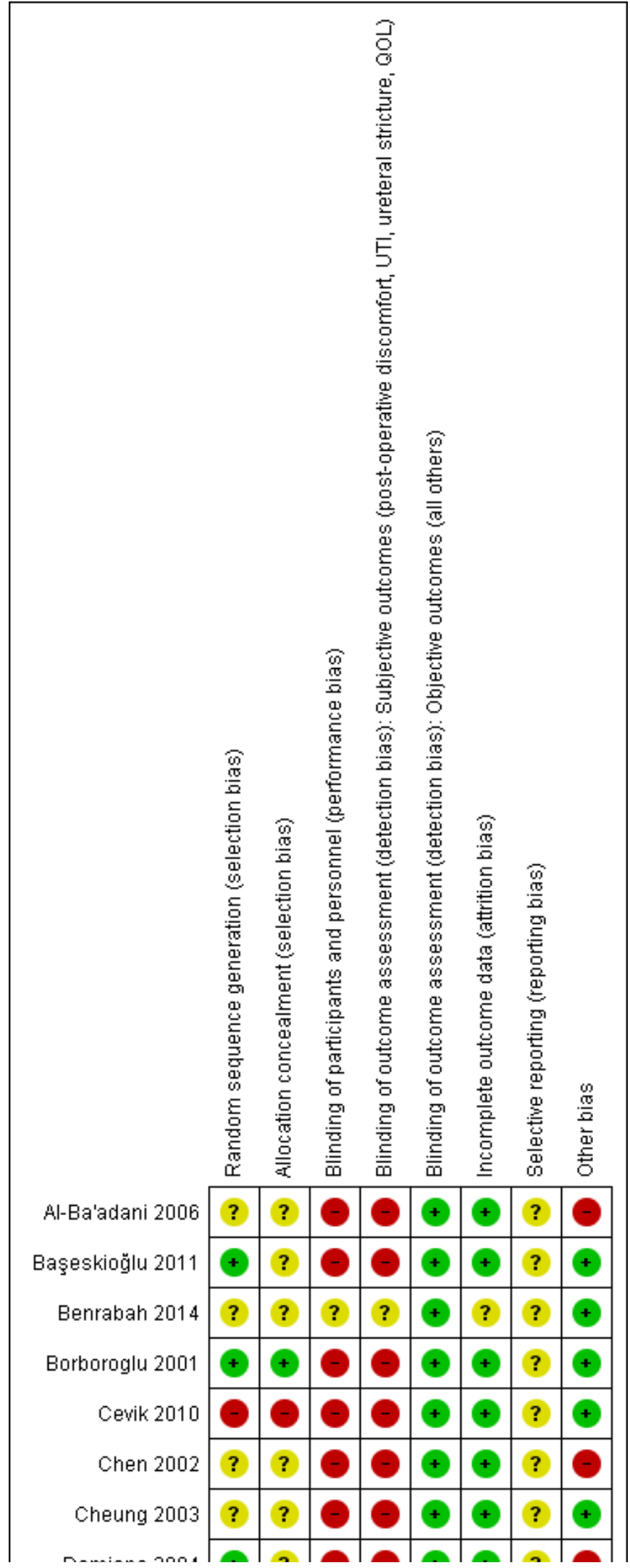


Figure 2. (Continued)

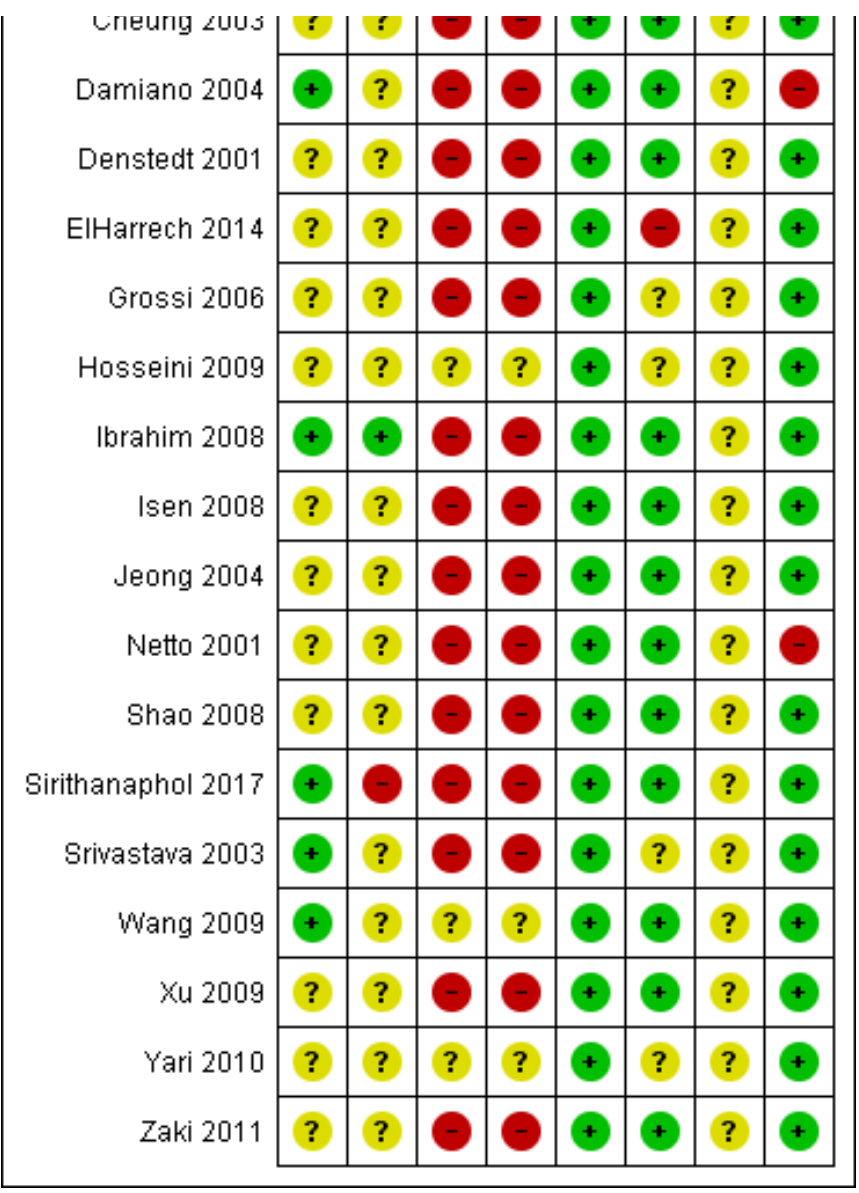

\section{Allocation}

\section{Random sequence generation}

Most studies (15/23) failed to reported sufficient detail to provide assurance of an adequate method of sequence generation, and we rated them as having unclear risk of bias. Seven studies reported an appropriate method, and we rated them as low risk. One study indicated use of alternation (quasi-randomisation), and we rated it as having high risk of bias (Cevik 2010).

\section{Allocation concealment}

Allocation concealment was rated as unclear in all but four studies (19/23). Borboroglu 2001 and Ibrahim 2008 documented an appropriate method by concealing allocation until participants were physically in the operating room. In two studies (Cevik 2010; Sirithanaphol 2017), it was apparent that allocation was not concealed.

\section{Blinding}

\section{Blinding of participants and personnel}

We judged all except four studies as high risk (19/23). Three studies were presented in abstract form only (Benrabah 2014; Hosseini 2009; Yari 2010); due to lack of information we rated risk of bias as unclear. Based on personal communication with the corresponding author of Wang 2009, review authors determined that patients and personnel were blinded, but based on the published report, it is unclear how that had been accomplished; therefore, we also rated this risk of bias as unclear.

\section{Blinding of outcome assessment}

We distinguished between outcomes for which blinding of outcome assessors appears relevant ('subjective' outcomes) versus those for which it does not.

Subjective outcomes were postoperative discomfort for the three selected time intervals, urinary tract infection defined as a composite outcome of a positive urine culture and clinical symptoms, quality of life, and ureteral stricture. We rated all but four studies (19/23) as high risk (Benrabah 2014; Hosseini 2009; Wang 2009; Yari 2010); we rated these four studies as having unclear risk for the same reasons as provided above for performance bias.

Objective outcomes were unplanned return visits, secondary interventions, analgesia requirements, operating room time, and hospital admission. We rated all (23/23) studies at low risk for bias with regards to these four outcomes because their measurement did not include any subjective judgement.

\section{Incomplete outcome data}

A majority of studies (17/23) reported low levels of attrition that permitted a low risk of bias judgement. We rated five studies as having unclear risk of bias; in four cases - Benrabah 2014, Grossi 2006, Hosseini 2009, Yari 2010 - because we were unable to 
ascertain what proportion of patients were included in the final analyses. One study had an attrition rate of $19 \%$ in one treatment arm, and we rated it as having unclear risk of bias (Srivastava 2003).

Reporting quality did not allow a meaningful distinction on a peroutcome basis; these ratings therefore apply to all outcomes.

\section{Selective reporting}

We found no a priori written protocol for any of the included studies; therefore we rated all studies (23/23) as having unclear risk of bias because we have no assurance that all measured outcomes were reported and analysed as intended.

\section{Other potential sources of bias}

We found no other sources of bias for most included studies (15/23), and we rated them as low risk. We rated four studies as having high risk of bias (Al-Ba'adani 2006; Chen 2002; Damiano 2004; Netto 2001); for three studies (Al-Ba'adani 2006; Chen 2002; Netto 2001), this was due to an imbalance of baseline characteristics, mainly with regard to age and stone size, and in one study, it was due to concerns about cross-over/contamination (Damiano 2004).

\section{Effects of interventions}

See: Summary of findings for the main comparison URS with stent placement compared to URS with no stent placement for ureteroscopy in the management of renal and ureteral calculi

\section{Unplanned return visit to emergency/urgent care department}

Stent placement may reduce the number of unplanned return visits slightly (risk ratio (RR) $0.69,95 \%$ confidence interval $(\mathrm{Cl}) 0.40$ to 1.21; 16 studies; 1970 participants; $I^{2}=31 \%$; very low certainty of evidence $(\mathrm{COE})$ ), but we are very uncertain of this finding. This corresponds to 21 fewer unplanned return visits per 1000 participants ( $95 \% \mathrm{Cl} 40$ fewer to 14 more). We downgraded the $\mathrm{CoE}$ for study limitations, imprecision, and suspected publication bias (Figure 3).

Figure 3. Funnel plot of comparison: 1 URS with stent placement vs URS with no stent placement, outcome: 1.1 Unplanned return visit to emergency/urgent care department.

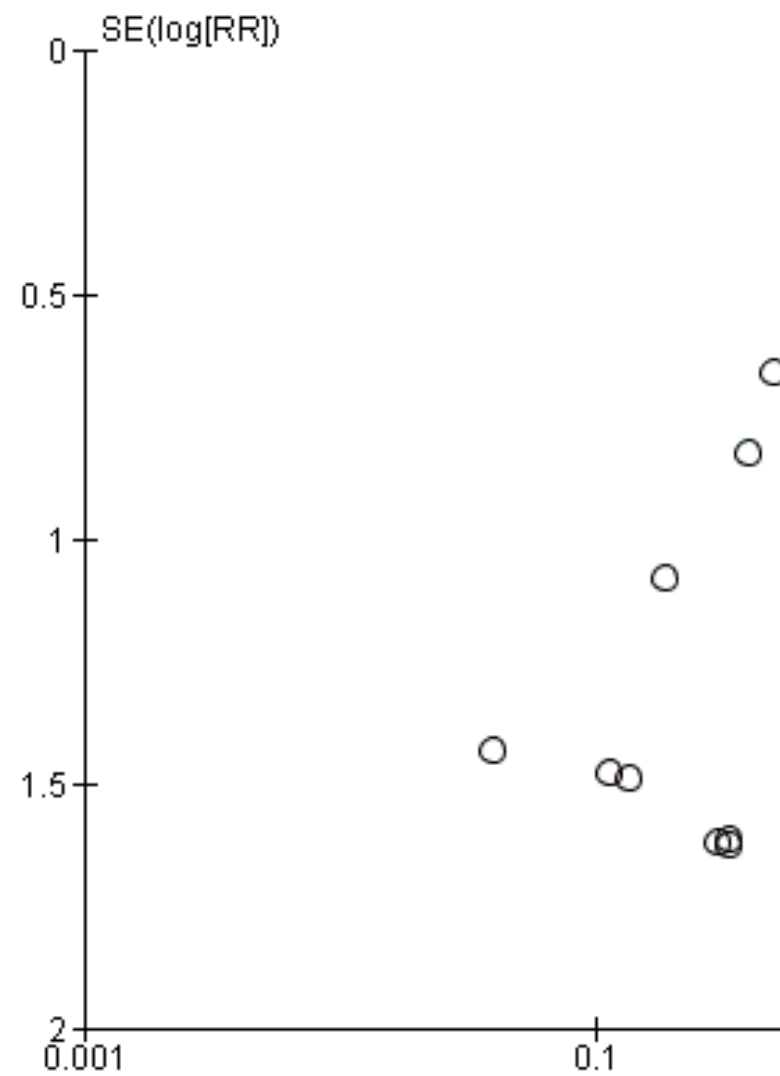

\section{Postoperative discomfort}

\subsection{Postoperative day 0}

There is probably no difference in postoperative discomfort on postoperative day 0 between stented and unstented participants (mean difference (MD) 0.32 higher, $95 \% \mathrm{Cl} 0.13$ lower to 0.78 higher; 4 studies; 346 participants; $I^{2}=0 \%$; moderate $\left.\mathrm{CoE}\right)$. The mean postoperative pain on day 0 in the non-stented group ranged from 2.3 to 4.82 . We downgraded the CoE for study limitations.

\subsection{Postoperative days 1 to 3}

There may be no difference in postoperative discomfort on postoperative days 1 to 3 between stented and unstented participants (standardised mean difference (SMD) 0.25 higher, $95 \%$ 
$\mathrm{Cl} 0.32$ lower to 0.82 higher; 8 studies; 683 participants; $1^{2}=$ 92\%; low CoE). We downgraded the CoE for study limitations and inconsistency. We also identified clinically important imprecision, but we attribute this to inconsistency and therefore did not downgrade further.

\subsection{Postoperative days 4 to 30}

Postoperative discomfort on postoperative days 4 to 30 may be greater in stented participants (SMD 0.62 higher, $95 \% \mathrm{Cl} 0.08$ higher to 1.16 higher; 8 studies; 903 participants; $I^{2}=93 \%$; very low CoE), but we are very uncertain of this finding. We downgraded the CoE for study limitations, inconsistency, and major imprecision.

\section{Secondary interventions}

There may be no difference in the number of secondary interventions between stented and unstented participants (RR $1.15,95 \% \mathrm{Cl} 0.39$ to $3.33 ; 10$ studies; 1435 participants; $\left.\right|^{2}=32 \%$; low $\mathrm{CoE})$. This corresponds to three more secondary interventions per 1000 participants ( $95 \% \mathrm{Cl} 13$ fewer to 48 more). We downgraded the CoE for study limitations and imprecision. The funnel plot shows symmetry, thereby suggesting no publication bias.

\section{Narcotic requirement}

In contrast to our protocol, we analysed this outcome to assess the number of participants who required narcotics, rather than average narcotic requirements in morphine equivalents, which was not reported in any of the studies.

Stent placement may reduce the need for narcotics (RR $0.80,95 \% \mathrm{Cl}$ 0.48 to $1.36 ; 7$ studies; 830 participants; $\left.\right|^{2}=72 \%$; very low $\mathrm{CoE}$ ), but we are very uncertain of this finding. This corresponds to 41 fewer participants requiring narcotics per 1000 participants $(95 \% \mathrm{Cl} 108$ fewer to 75 more). We downgraded the CoE for study limitations, inconsistency, and major imprecision.

\section{Urinary tract infection}

There is probably no difference in the number of urinary tract infections between stented and unstented participants (RR 0.94, $95 \% \mathrm{Cl} 0.59$ to $1.51 ; 10$ studies; 1207 participants; $\mathrm{I}^{2}=0 \%$; moderate $\mathrm{CoE}$ ). This corresponds to three fewer infections per 1000 participants ( $95 \% \mathrm{Cl} 23$ fewer to 29 more). We downgraded the $\mathrm{CoE}$ for study limitations. The funnel plot shows symmetry, thereby suggesting no publication bias.

\section{Operating room time}

Placment of a stent probably increases operating room time slightly (MD 3.72 minutes, 95\% Cl 2.30 to 5.14 minutes; 17 studies; 1981 participants; $\mathrm{I}^{2}=57 \%$; moderate $\mathrm{CoE}$ ). The average operating room time in the control group ranged from 8.7 to 45.0 minutes. We downgraded the CoE for study limitations. Despite moderate to substantial heterogeneity, we did not downgrade for inconsistency because it is not clinically relevant. The funnel plot shows small negative studies; therefore we did not downgrade for publication bias.

\section{Ureteral stricture}

Placement of a stent may slightly reduce the rate of ureteral stricture up to 90 days (RR $0.58,95 \% \mathrm{Cl} 0.23$ to $1.47 ; 14$ studies; 1625 participants; $\left.\right|^{2}=0 \%$; very low $\mathrm{CoE}$ ), but we are very uncertain of this finding. This corresponds to six fewer ureteral strictures per
1000 participants (95\% Cl 11 fewer to 7 more). We downgraded the $\mathrm{COE}$ for study limitations. The funnel plot shows symmetry, thereby suggesting no publication bias.

\section{Quality of life}

Quality of life may be reduced in stented participants with an MD 2.9 higher $(95 \% \mathrm{Cl} 2.52$ higher to 3.28 higher; 1 study; 115 participants; low $\mathrm{COE})$. We downgraded for study limitations and indirectness. The average quality of life score in the control group was 1.6.

This finding is based on a single study that used a so-called ureteral stent symptom questionnaire with a single item (range 1 to 7 ; higher values reflect worse quality of life) mapping to quality of life (Shao 2008). Given that this was based on a single item, not on a multifactorial quality of life construct as we had envisioned for this outcome, we also downgraded for indirectness.

\section{Hospital admission}

The risk of postoperative hospital readmission may be slightly lower in stented patients (RR $0.70,95 \% \mathrm{Cl} 0.32$ to $1.55 ; 13$ studies; 1647 participants; $I^{2}=29 \%$; very low $C O E$ ), but we are very uncertain of this finding. This corresponds to 15 fewer admissions per 1000 participants ( $95 \% \mathrm{Cl} 33$ fewer to 27 more). We downgraded the CoE for study limitations and imprecision. The funnel plot shows symmetry, thereby suggesting no publication bias.

\section{DISCUSSION}

\section{Summary of main results}

Findings of this systematic review indicate that stenting may reduce the number of unplanned return visits to the hospital, the need for narcotics, ureteral stricture, and hospital readmission, but these findings were derived from studies providing very low certainty of evidence (CoE).

Moderate to low CoE shows no difference in postoperative discomfort on the day of surgery (day 0 ) and in the early postoperative phase (days 1 to 3 ). Stented individuals may have more pain in the later postoperative phase (days 4 to 30 ), but we are very uncertain of this finding. There may also be no difference in the number of secondary interventions.

With regard to other outcomes, rates of urinary tract infection are probably similar but quality of life may be better in unstented participants. Stenting probably increases operating room time slightly (by approximately 4 minutes), which may not be clinically relevant.

\section{Overall completeness and applicability of evidence}

This systematic review represents the most rigorous and upto-date review on the question of ureteral stenting following ureteroscopy. Although we perceive this body of evidence to be broadly applicable to current clinical practice, the following issues deserve mention.

- All included studies chose to exclude a subset of participants for whom ureteroscopy was complicated in some manner, thereby compelling urologists to place a ureteral stent, which usually led to exclusion of participants from the trial. The summarised body of evidence therefore applies only to 'uncomplicated' ureteroscopy; however definitions of what that constitutes 
vary. Whereas post ureteroscopic lesion scales have been developed (Schoenthaler 2012; Traxer 2013), they have not found widespread use.

- At the time of protocol development, we stipulated that certain baseline characteristics might have an important impact on the effect of stenting, in particular stone size and location, and whether ureteral dilation took place. We hypothesised that ureteral stenting may become more relevant, for example, in larger stones that necessitate longer operating room time, thereby increasing the risk of (subclinical) ureteral injury with resulting oedema and potential obstruction in unstented patients. Meanwhile, available evidence did not permit any meaningful subgroup analyses; this issue therefore remains unclear.

\section{Quality of the evidence}

We rated the CoE as moderate to very low. Reasons for rating down were as follows.

- Study limitations: none of the studies blinded patients or personnel, raising concerns about performance bias. Specifically, the concern is that participants could have been treated differently, for example, with regards to pain medications, discharge instructions, and contingency plans in the setting of postoperative pain and discomfort, whether they were stented or not. This may have biased the results. In conjunction with frequent unclear allocation concealment and concerns over selective reporting, this prompted us to downgrade the CoE for all outcomes. For subjective, selfreported outcomes, there is the additional, related concern over detection bias. We recognise that blinding of surgeons is never possible and that blinding of other involved personnel would have been extremely challenging, if not impossible (e.g. requiring all patients to return for stent removal postop to maintain blinding in the control arm); therefore concerns over bias exist.

- Inconsistency: we downgraded COE in the presence of substantial to considerable heterogeneity that was clinically relevant in the context of clinical decision-making in this setting.

- Imprecision: the finding of wide confidence intervals that crossed the threshold of clinical relevance led to downgrading of the evidence. When observed imprecision could plausibly be explained by inconsistency, which prompted downgrading, we did not downgrade further.

- Publication bias: in case of the unplanned return visit, funnel plot asymmetry raised concerns about publication bias that prompted us to downgrade the CoE. This was the only outcome for which we downgraded our findings for concerns over publication bias, but it should be noted that for five outcomes, we included fewer than 10 trials (i.e. postoperative pain day 0 , days 1 to 3 , days 4 to 30 , narcotic requirement, and quality of life), thereby not permitting meaningful interpretation of funnel plots.

- Selecive reporting bias: none of the included studies was prospectively registered, raising concerns about omission of information and post hoc changes in the analytical approach that may have influenced the results in a systematic manner.

\section{Potential biases in the review process}

The study was performed based on rigorous Cochrane standards, which included a published protocol. Nevertheless, certain issues could be the source of bias.

- We performed a comprehensive literature search for eligible studies irrespective of language and publication status. Nevertheless, we may have missed studies, in particular 'negative' studies. The potential for publication bias is underscored by funnel plot asymmetry for the outcome of unplanned return to the hospital. For a majority of outcomes, too few studies were included in the meta-analysis to formally assess for publication bias.

- Included studies reported participants' degree of pain at different time points. To provide meaningful summary data that might be helpful for clinicians and patients, we grouped available data by three time periods of postoperative day 0 , days 1 through 3 , and days 4 through 30 . These categories we established with input by expert clinicians after the protocol was written and the data were abstracted, but before any quantitative analysis was performed. Neverthless, findings for these outcomes are potentially sensitively to the specific time ranges we chose, and this may be viewed as a potential source of bias.

\section{Agreements and disagreements with other studies or reviews}

To date, no review has applied the rigorous Cochrane methodology to this topic. Defining characteristics of this review include an a priori protocol, a comprehensive literature search irrespective of language and publication status, a focus on patientcentred outcomes, and the application of GRADE methodology. Furthermore, our interpretation focuses on clinically relevant (rather and statistically significant) findings and provides absolute effect size estimates for all dichotomous outcomes.

With regard to the findings of three of the more methodologically rigorous and recent published reviews:

- Tang 2011 included 14 trials. Study authors found an increase in dysuria, frequency, and haematuria in stented patients outcomes that we did not deem of critical patient importance and that we did not investigate. However, effect estimates for the number of unplanned medical visits or hospital readmissions (risk ratio (RR) $0.60,95 \%$ confidence interval ( $\mathrm{Cl}) 0.33$ to 1.11 ) and for urinary tract infection (RR $1.20,95 \% \mathrm{Cl} 0.62$ to 2.32 ) showed similar results. This study used a fixed-effect model and did not provide absolute effect size estimates, which we view as very important for interpretation;

- Pais 2016 reported a systematic review that included and pooled a total of 17 studies, both randomised and nonrandomised, using odds ratios as effect size measures (rather than the easier to interpret risk ratio in this review) and using the method described by Peto that is most useful in the setting of low event rates - a condition we did not see met in this analytical setting. The analysis was framed as comparing unstented versus stented patients. The main findings of this review were that 'unstented patients were significantly more likely to have an unplanned medical visit compared to those who received a post-ureteroscopy stent' (odds ratio (OR) $1.63,95 \% \mathrm{Cl} 1.15$ to 2.30 ). These findings were based 
on a pooled analysis of randomised and non-randomised studies. Included observational studies favoured the unstented group, whereas randomised controlled trials (RCTs) favoured the stented group; the test of interaction was significant $(P=0.04)$, thereby questioning the appropriateness of pooling. Although the pooled effect estimate for unplanned return visits across the two bodies of evidence is the only one featured in the abstract, the results section of the review provides both, namely, the OR of 0.98 ( $95 \% \mathrm{Cl} 0.54$ to 1.77 ) based on observational studies and the OR of 2.12 ( $95 \% \mathrm{Cl} 1.38$ to 3.25 ) for RCTs alone. Also, although it did not provide a formal quality of evidence rating by outcome, as we do, the Pais 2016 review stands out for its thoughtful and detailed discussion of biases that may have affected the included studies; it is equally relevant to findings of our updated review. These include:

- performance bias, given that none of the trials blinded patients and personnel;

- selective reporting bias, given that none of the included trials were prospectively registered (see Figure 2 for our review);

- selection bias through postrandomisation exclusion of study participants randomised to the non-stent group who were "suspected to be at highest risk for the adverse effect of stent omission" (Pais 2016); and

- the issue of observational studies "performed in real-world clinical settings" as potentially confounded by indication and the needed for better criteria "to objectively assess the ureter for the safety of stone omission" (Pais 2016).

- Wang 2017 reported a systematic review of 22 RCTs but included among them three trials of shockwave lithotripsy (SWL), which we perceived as sufficiently distinct as to not include them in this review. This study also reported its findings as odds ratios. One of the main findings highlighted in the abstract results and conclusion was reduced risk of unplanned readmissions (OR $0.63,95 \% \mathrm{Cl} 0.41$ to 0.97 ) in the stented group. However, these numbers do not correlate with those in the results section (OR $0.54,95 \% \mathrm{Cl} 0.34$ to 0.87 ), suggesting an error in the analysis. This particular analysis did not include any studies of SWL. Aside from the addition of four studies to this analysis, our findings mainly differ in the (routine) choice of a random-effects model, which provides the more conservative effect size estimate. A fixed-effect model analysis of this outcome based on our data yields an RR of 0.60 ( $95 \% \mathrm{Cl} 0.37$ to 0.96$)$, which comes close to the reported odds ratio. In terms of the outcome of urinary tract infection, unlike our findings, stenting increased urinary tract infection (OR $2.01,95 \% \mathrm{Cl} 1.16$ to 3.47 ), which may be attributable to the inclusion of two trials of SWL and one trial of patients with chronic inflammatory, bilharzial ureters (Hussein 2006).

None of the existing systematic reviews provided a certainty of evidence rating, which we consider critical to any systematic review.

\section{AUTHORS' CONCLUSIONS}

\section{Implications for practice}

Findings of this review illustrate the complexity of decision-making faced by urologists after uncomplicated ureteroscopy. Although stenting may offer benefits in terms of unplanned return visits, readmissions, need for narcotic, and stricture development, the effect sizes were generally small and were very uncertain (based on very low $\mathrm{CoE}$ ). Meanwhile, stented patients may experience increased pain (days 4 to 30 ) and reduced quality of life.

\section{Implications for research}

Findings of this review indicate several research priorities.

- For a total of eight outcomes, we rated the CoE as low or very low, indicating that there is considerable uncertainty of these findings. Whereas future studies may also find it unfeasible to blind patients and personnel, there nevertheless remains a need and opportunity for better designed studies, especially when the frequency of stent use in current clinical practice is considered. All future trials should be prospectively registered.

- Findings of the review raise questions over the gap between current best evidence as reflected by this review and contemporary clinical practice with most patients receiving a stent. Muslumanoglu 2017 reported the results of the Clinical Research Office of Endourological Society (CROES) Ureteroscopy Global Study Cohort and found stenting rates of approximately $80 \%$ for renal stones and $60 \%$ for ureteral stones, with overall variation from $29 \%$ to $96 \%$ across countries. Reported stenting rates in the United States were 93\%. There appears to be an important research need to better understand this discrepancy.

- This review was unable to conduct any of the preplanned subgroup analyses, given the lack of appropriate data. However, it is possible that effects of stent placement differ based on characteristics such as stone size and location, ureteral dilation, and other factors. Specifically designed, high-quality studies are necessary to elucidate these issues.

- Given the complex trade-offs involved in deciding whether or not to place a stent after uncomplicated ureteroscopy, more research on shared decision-making in this setting appears important.

\section{ACKN OWLEDGEMENTS}

We are very grateful to Naeem Bhojani, Arkadiusz Miernik, Sung Yong Cho, Olivier Traxer, Steeve Doizi, Vernon M. Pais Jr, and Christopher S. Elliott, for having served as peer reviewers. We thank Cochrane Urology, our Contact Editor Robin Vernooij, and Managing Editor Robert Lane for the support we received.

We acknowledge the support received from the authors of included and excluded studies - Chung-Jing Wang, Ekkarin Chotikawanich, and Mustafa Suat Bolat - who provided additional, unpublished data.

The ureteral stent symptom questionnaire (English version) was provided by Professor Jinsung Park, from South Korea. 


\section{R E F E R E N C E S}

\section{References to studies included in this review}

Al-Ba'adani 2006 \{published data only\}

Al-Ba'adani T, Ghilan A, El-Nono I, Alwan M, Bingadhi A. Whether post-ureteroscopy stenting is necessary or not?. Saudi Medical Journal 2006;27(6):845-8.

\section{Başeskioğlu 2011 \{published data only\}}

Başeskioğlu B, Sofikerim M, Demirtaş A, Yenilmez A, Kaya C, Can $C$. Is ureteral stenting really necessary after ureteroscopic lithotripsy with balloon dilatation of ureteral orifice? A multiinstitutional randomized controlled study. World Journal of Urology 2011;29(6):731-6.

\section{Benrabah 2014 \{published data only\}}

Benrabah R. Is ureteral stenting systematic after uncomplicated ureteroscopic for distal ureteral stone?. European Urology Supplements 2014;13(1):e929.

\section{Borboroglu 2001 \{published data only\}}

Borboroglu PG, Amling CL, Schenkman NS, Monga M, Ward JF, Piper NY, et al. Ureteral stenting after ureteroscopy for distal ureteral calculi: a multi-institutional prospective randomized controlled study assessing pain, outcomes and complications. Journal of Urology 2001;166(5):1651-7.

Cevik 2010 \{published data only\}

Cevik I, Dillioglugil O, Akdas A, Siegel Y. Is stent placement necessary after uncomplicated ureteroscopy for removal of impacted ureteral stones?. Journal of Endourology 2010;24(8):1263-7.

\section{Chen 2002 \{published data only\}}

Chen YT, Chen J, Wong WY, Yang SS, Hsieh CH, Wang CC. Is ureteral stenting necessary after uncomplicated ureteroscopic lithotripsy? A prospective, randomized controlled trial. Journal of Urology 2002;167(5):1977-80.

\section{Cheung 2003 \{published data only\}}

Cheung MC, Lee F, Leung YL, Wong BB, Tam PC. A prospective randomized controlled trial on ureteral stenting after ureteroscopic holmium laser lithotripsy. Journal of Urology 2003;169(4):1257-60.

\section{Damiano 2004 \{published data only\}}

Damiano R, Autorino R, Esposito C, Cantiello F, Sacco R, de Sio M, et al. Stent positioning after ureteroscopy for urinary calculi: the question is still open. European Urology 2004;46(3):381-7; discussion 387-8.

\section{Denstedt 2001 \{published data only\}}

Denstedt JD, Wollin TA, Sofer M, Nott L, Weir M, D'A Honey RJ. A prospective randomized controlled trial comparing nonstented versus stented ureteroscopic lithotripsy. Journal of Urology 2001;165(5):1419-22.

\section{ElHarrech 2014 \{published data only\}}

El Harrech Y, Abakka N, El Anzaoui J, Ghoundale O, Touiti D. Ureteral stenting after uncomplicated ureteroscopy for distal ureteral stones: a randomized, controlled trial. Minimally Invasive Surgery 2014;2014:892890.

\section{Grossi 2006 \{published data only\}}

Grossi FS, Ferretti S, Di Lena S, Crispino M. A prospective randomized multicentric study comparing stented vs nonstented ureteroscopic lithotripsy. Archivio Italiano di Urologia, Andrologia 2006;78(2):53-6.

\section{Hosseini 2009 \{published data only\}}

Hosseini M, Tamaddon K, Aminsharifi A, Aryafar A, Yousefi A, Hassanpour A. Ureteroscopy and lithotripsy of ureteral calculi: stented vs. non-stented, a randomized clinical trial (preliminary report). Journal of Endourology 2009;23:A68-9.

Ibrahim 2008 \{published data only\}

Ibrahim HM, Al-Kandari AM, Shaaban HS, Elshebini YH, Shokeir AA. Role of ureteral stenting after uncomplicated ureteroscopy for distal ureteral stones: a randomized, controlled trial. Journal of Urology 2008;180(3):961-5.

\section{Isen 2008 \{published data only\}}

Isen K, Bogatekin S, Em S, Ergin H, Kilic V. Is routine ureteral stenting necessary after uncomplicated ureteroscopic lithotripsy for lower ureteral stones larger than $1 \mathrm{~cm}$ ?. Urological Research 2008;36(2):115-9.

\section{Jeong 2004 \{published data only\}}

* Jeong H, Kwak C, Lee SE. Ureteric stenting after ureteroscopy for ureteric stones: a prospective randomized study assessing symptoms and complications. BJU International 2004;93(7):1032-4; discussion 1034-5.

Noh JH, Kim DK, Jeong H. Comparison of stented and unstented patients following ureteroscopy for ureter stones. Korean Journal of Urology 2002;43(1):28-31.

Netto 2001 \{published data only\}

Netto NR Jr, Ikonomidis J, Zillo C. Routine ureteral stenting after ureteroscopy for ureteral lithiasis: is it really necessary?. Journal of Urology 2001;166(4):1252-4.

\section{Shao 2008 \{published data only\}}

Shao Y, Zhuo J, Sun XW, Wen W, Liu HT, Xia SJ. Nonstented versus routine stented ureteroscopic holmium laser lithotripsy: a prospective randomized trial. Urological Research 2008;36(5):259-63.

\section{Sirithanaphol 2017 \{published data only\}}

Sirithanaphol W, Jitpraphai S, Taweemonkongsap T, Nualyong C, Chotikawanich E. Ureteral stenting after flexible ureterorenoscopy with ureteral access sheath; is it really needed? A prospective randomized study. Journal of the Medical Association of Thailand 2017;100(Suppl 3):S174-8.

\section{Srivastava 2003 \{published data only\}}

Srivastava A, Gupta R, Kumar A, Kapoor R, Mandhani A. Routine stenting after ureteroscopy for distal ureteral calculi is 
unnecessary: results of a randomized controlled trial. Journal of Endourology 2003;17(10):871-4.

Wang 2009 \{published data only\}

Wang CJ, Huang SW, Chang CH. Indications of stented uncomplicated ureteroscopic lithotripsy: a prospective randomized controlled study. Urological Research 2009;37(2):83-8.

\section{Xu 2009 \{published data only\}}

Xu Y, Wei Q, Liu LR. A prospective randomized trial comparing non-stented versus routine stented ureteroscopic holmium laser lithotripsy. Saudi Medical Journal 2009;30(10):1276-80.

Yari 2010 \{published data only\}

Yari H, Fallahnezhad M, Tavasoli Shirvan S, Faghih Nasiri S. Stented versus non-stented ureteroscopic lithotripsy in distal ureteral stones. European Urology Supplements 2010;9(6):606.

Zaki 2011 \{published data only\}

Zaki MR, Salman A, Chaudhary AH, Asif K, Rehman MU. Is DJ stenting still needed after uncomplicated ureteroscopic lithotripsy? A randomized controlled trial. Pakistan Journal of Medical and Health Sciences 2011;5(1):121-4.

\section{References to studies excluded from this review}

\section{Ali 2001 \{published data only\}}

* Ali W, Al-Bareeq R, Samiei MR, Al-Muttawa S. The evaluation of not stenting after uncomplicated ureteroscopy: a randomized prospective study. Bahrain Medical Bulletin 2001;23(1):34-6.

Ali W, Al-Durazi M, Al-Bareeq R, Samiei MR, Al-Mutawa S. The evaluation of not stenting after uncomplicated ureteroscopy: a randomized prospective study. Bahrain Medical Bulletin 2004;26(1):3-5.

\section{Bolat 2017 \{published data only\}}

Bolat MS, Akdeniz E, Asci R, Erdemir F, Cinar O, Tomak L. Ureterorenoscopy with stenting and its effect on male sexual function: a controlled randomised prospective study. Andrologia 2017;49(9):e12746.

\section{Byrne 2002 \{published data only\}}

Byrne RR, Auge BK, Kourambas J, Munver R, Delvecchio F, Preminger GM. Routine ureteral stenting is not necessary after ureteroscopy and ureteropyeloscopy: a randomized trial. Journal of Endourology 2002;16(1):9-13.

\section{Chauhan 2015 \{published data only\}}

Chauhan VS, Bansal R, Ahuja M. Comparison of efficacy and tolerance of short-duration open-ended ureteral catheter drainage and tamsulosin administration to indwelling double $\mathrm{J}$ stents following ureteroscopic removal of stones. Hong Kong Medical Journal 2015;21(2):124-30.

\section{Clayman 2005 \{published data only\}}

Clayman RV. Ureteric stenting after ureteroscopy for ureteric stones: a prospective randomized study assessing symptoms and complications. Journal of Urology 2005;173(6):2022.

\section{Hussein 2006 \{published data only\}}

Hussein A, Rifaat E, Zaki A, Abol-Nasr M. Stenting versus nonstenting after non-complicated ureteroscopic manipulation of stones in bilharzial ureters. International Journal of Urology 2006;13(7):886-90.

\section{Manu 2015 \{published data only\}}

Manu MA, Parliteanu B, Angelescu E, Prie I, Dudu C, Surcel C, et al. Ureteral stent, no stent and no stent plus methylprednisolone and alpha blockers in ureteroscopic laser lithotripsy. European Urology Supplements 2015;14(6):e1309.

Mittakanti 2018 \{published data only\} Mittakanti HR, Conti S, Pao AC, Liao J, Leppert JT, Elliott CS. Unplanned emergency department visits and hospital admissions following ureteroscopy: do ureteral stents make a difference?. Journal of Urology 2017;197(4 Suppl 1):e667.

* Mittakanti HR, Conti SL, Pao AC, Chertow GM, Liao JC, Leppert JT, et al. Unplanned emergency department visits and hospital admissions following ureteroscopy: do ureteral stents make a difference?. Urology 2018;117:44-9.

\section{Muslumanoglu 2017 \{published data only\}}

Muslumanoglu AY, Fuglsig S, Frattini A, Labate G, Nadler RB, Martov A, et al. Risks and benefits of postoperative double-J stent placement after ureteroscopy: results from the clinical research office of Endourological Society Ureteroscopy Global Study. Journal of Endourology 2017;31(5):446-51.

\section{Schoenthaler 2013 \{published data only\}}

Schoenthaler M, Wilhelm K, Adams F, Buchholz N, Bach C, Miernik A. Recommendations for postoperative ureteral stenting based on the Post-Ureteroscopic Lesion Scale (PULS) - evaluation in 734 patients. European Urology Supplements 2013;12(3):56.

\section{Tu 2015 \{published data only\}}

Tu HYV, Matsumoto E. Cost analysis of ureteral stenting after uncomplicated ureteroscopic laser lithotripsy for urolithiasis: a decision model analysis. Journal of Urology 2015;193(4S):e1023-4.

\section{Turker 2009 \{published data only\}}

Turker P, Aslan AR, Koyuncu M, Yucebas OE, Sengor F. Is routine ureteral stenting necessary after ureteroscopic pneumatic lithotripsy?. European Urology Supplements 2009;8(4):292.

\section{Wang 2017 \{published data only\}}

Wang H, Man L, Li G, Huang G, Liu N, Wang J. Meta-analysis of stenting versus non-stenting for the treatment of ureteral stones. PLOS ONE 2017;12(1):e0167670.

\section{Zhang 2014 \{published data only\}}

Zhang J, Zhang X, Liu J, Zhao D, Zhao Tao, Gao X. Study on necessity of indwelling ureteral stent after ureteroscopic lithotripsy. Chongqing Medicine 2014;43(16):2000-1. 


\section{References to ongoing studies}

NCT03130907 \{unpublished data only\}

NCT03130907. The role of ureteral stenting following uncomplicated ureteroscopy for ureteral and renal stones: a randomized, controlled trial. https://clinicaltrials.gov/ct2/show/ study/NCT03130907\#contacts (date first posted 27 April 2017).

\section{Additional references}

\section{AUA Guideline Surgical Management of Stones 2016}

Assimos D, Krambeck A, Miller NL, Monga M, Murad MH, Nelson C, et al. Surgical management of stones: American Urological Association/Endourological Society guideline. American Urological Association 2016.

\section{Campschroer 2018}

Campschroer T, Zhu X, Vernooij RW, Lock MT. Alpha-blockers as medical expulsive therapy for ureteral stones. Cochrane Database of Systematic Reviews 2018;4:CD008509.

\section{Deeks 2011}

Deeks JJ, Higgins JPT, Altman DG (editors). Chapter 9. Analysing data and undertaking meta-analyses. In: Higgins JPT, Green S (editors). Cochrane Handbook for Systematic Reviews of Interventions. Version 5.1.0 (updated March 2011). The Cochrane Collaboration, 2011. Available from handbook.cochrane.org.

\section{EAU Guidelines on Urolithiasis 2016}

Türk C, Petrik A, Sarica K, Seitz C, Skolarikos A, Straub M, et al. EAU Guidelines on Interventional Treatment for Urolithiasis. European Urology 2016;69(3):475-82.

\section{EAU Guidelines on Urolithiasis 2018}

Türk C, Neisius A, Petrik A, Seitz C, Skolarikos A, Thomas K. Urolithiasis guidelines. http://uroweb.org/guideline/ urolithiasis/ (accessed on 1/3/2019).

\section{GRADEpro GDT [Computer program]}

McMaster University. GRADEpro GDT. GRADEpro Guideline Development Tool. Hamilton, ON: McMaster University, 2015 (developed by Evidence Prime, Inc.). Available from www.gradepro.org.

\section{Guyatt 2008}

Guyatt GH, Oxman AD, Vist GE, Kunz R, Falck-Ytter Y, Schünemann HJ, et al. GRADE: what is "quality of evidence" and why is it important to clinicians?. British Medical Journal 2008;336(7651):995-8.

\section{Guyatt 2011}

Guyatt G, Oxman AD, Akl EA, Kunz R, Vist G, Brozek J, et al. GRADE guidelines: 1. Introduction - GRADE evidence profiles and summary of findings tables. Journal of Clinical Epidemiology 2011;64(4):383-94.

\section{Haleblian 2008}

Haleblian G, Kijvikai K, de la Rosette J, Preminger G. Ureteral stenting and urinary stone management: a systematic review. Journal of Urology 2008;179(2):424-30.

\section{Higgins 2002}

Higgins JPT, Thompson SG. Quantifying heterogeneity in a meta-analysis. Statistics in Medicine 2002;21(11):1539-58.

\section{Higgins 2003}

Higgins JPT, Thompson SG, Deeks JJ, Altman DG. Measuring inconsistency in meta-analyses. British Medical Journal 2003;327(7414):557-60.

\section{Higgins 2011a}

Higgins JPT, Green S (editors). Cochrane Handbook for Systematic Reviews of Interventions. Version 5.1.0 (updated March 2011). The Cochrane Collaboration, 2011. Available from handbook.cochrane.org.

\section{Higgins 2011b}

Higgins JPT, Altman DG, Sterne JAC (editors). Chapter 8. Assessing risk of bias in included studies. In: Higgins JPT, Green S (editors). Cochrane Handbook for Systematic Reviews of Interventions. Version 5.1.0 (updated March 2011). The Cochrane Collaboration, 2011. Available from handbook.cochrane.org.

\section{Higgins 2011c}

Higgins JPT, Deeks JJ, Altman DG (editors). Chapter 16. Special topics in statistics. In: Higgins JPT, Green S (editors). Cochrane Handbook for Systematic Reviews of Interventions. Version 5.1.0 (updated March 2011). The Cochrane Collaboration, 2011. Available from handbook.cochrane.org.

\section{Hollingsworth 2016}

Hollingsworth JM, Canales BK, Rogers MA, Sukumar S, Yan P, Kuntz GM, et al. Alpha blockers for treatment of ureteric stones: systematic review and meta-analysis. BMJ 2016;355:i6112.

\section{Joshi 2003}

Joshi HB, Stainthorpe RP, MacDonough RP, Keeley FX, Timoney AG. Indwelling ureteral stents: evaluation of symptoms, quality of life and utility. Journal of Urology 2003;169(3):1065-9.

\section{Liberati 2009}

Liberati A, Altman DG, Tetzlaff J, Mulrow C, Gøtzsche PC, Ioannidis JPA, et al. The PRISMA statement for reporting systematic reviews and meta-analyses of studies that evaluate health care interventions: explanation and elaboration. PLOS Medicine 2009;6(7):e1000100.

\section{Makarov 2008}

Makarov DV, Trock BJ, Allaf ME, Matlaga BR. The effect of ureteral stent placement on post-ureteroscopy complications: a meta-analysis. Urology 2008;71(5):796-800.

\section{Mosayyebi 2018}

Mosayyebi A, Manes C, Carugo D, Somani BK. Advances in ureteral stent design and materials. Current Urology Reports 2018;19(5):35. 


\section{Nabi 2007}

Nabi G, Cook J, N'Dow J, McClinton S. Outcomes of stenting after uncomplicated ureteroscopy: systematic review and metaanalysis. British Medical Journal 2007;334(7593):572.

\section{Pais 2016}

Pais VM Jr, Smith RE, Stedina EA, Rissman CM. Does omission of ureteral stents increase risk of unplanned return visit? A systematic review and meta-analysis. Journal of Urology 2016;196(5):1458-66.

\section{Pengfei 2011}

Pengfei S, Yutao L, Jie Y, Wuran W, Yi D, Hao Z, et al. The results of ureteral stenting after ureteroscopic lithotripsy for ureteral calculi: a systematic review and meta-analysis. Journal of Urology 2011;186(5):1904-9.

\section{Picozzi 2013}

Picozzi SC, Ricci C, Stubinski R, Casellato S, Ratti D, Macchi A, et al. Is stone diameter a variable in the decision process of employing a ureteral stent in patients undergoing uncomplicated ureterorenoscopy and associated intracorporeal lithotripsy?. World Journal of Urology 2013;31(6):1617-25.

\section{Rapoport 2007}

Rapoport D, Perks AE, Teichman JMH. Ureteral access sheath use and stenting in ureteroscopy: effect on unplanned emergency room visits and cost. Journal of Endourology 2007;21(9):993-8.

\section{Review Manager 2014 [Computer program]}

The Nordic Cochrane Centre, The Cochrane Collaboration. Review Manager (RevMan). Version 5.3. Copenhagen: The Nordic Cochrane Centre, The Cochrane Collaboration, 2014.

\section{Rukin 2017}

Rukin NJ, Siddiqui ZA, Chedgy EC, Somani BK. Trends in upper tract stone disease in England: evidence from the hospital episodes statistics database. Urologia Internationalis 2017;98(4):391-6.

\section{Scales 2012}

Scales CD Jr, Smith AC, Hanley JM, Saigal CS. Prevalence of kidney stones in the United States. European Urology 2012;62(1):160-5.

\section{Schoenthaler 2012}

Schoenthaler M, Wilhelm K, Kuehhas FE, Farin E, Bach C, Buchholz N, et al. Postureteroscopic lesion scale: a new management modified organ injury scale - evaluation in 435 ureteroscopic patients. Journal of Endourology 2012;26(11):1425-30.

\section{Schünemann 2011}

Schünemann HJ, Oxman AD, Higgins JPT, Vist GE, Glasziou P, Guyatt GH. Chapter 11. Presenting results and 'Summary of findings' tables. In: Higgins JPT, Green S (editors). Cochrane Handbook for Systematic Reviews of Interventions. Version 5.1.0 (updated March 2011). The Cochrane Collaboration, 2011. Available from handbook.cochrane.org.

\section{Tang 2011}

Tang L, Gao X, Xu B, Hou J, Zhang Z, Xu C, et al. Placement of ureteral stent after uncomplicated ureteroscopy: do we really need it?. Urology 2011;78(6):1248-56.

\section{Traxer 2013}

Traxer $\mathrm{O}$, Thomas A. Prospective evaluation and classification of ureteral wall injuries resulting from insertion of a ureteral access sheath during retrograde intrarenal surgery. Journal of Urology 2013;189(2):580-4.

\section{Turney 2011}

Turney BW, Reynard JM, Noble JG, Keoghane SR. Trends in urological stone disease. BJU International 2012;109(7):1082-7.

\section{Vermandere 2018}

Vermandere M, Kuijpers T, Burgers J S, Kunnamo I, van Lieshout J, Wallace E, et al. Alpha-blockers for uncomplicated ureteric stones: a clinical practice guideline. $B J U$ International 2018;122(6):924-31.

\section{Wilson 2005}

Wilson $\mathrm{CH}$, Bhatti AA, Rix DA, Manas DM. Routine intraoperative ureteric stenting for kidney transplant recipients. Cochrane Database of Systematic Reviews 2005;19(4):CD004925.

\section{Yasui 2008}

Yasui T, Igucho M, Suzuki S, Kohri K. Prevalence and epidemiological characteristics of urolithiasis in Japan: national trends between 1965 and 2005. Urology 2008;71(2):209-13.

\section{References to other published versions of this review Ordonez 2017 \\ Ordonez M, Borofsky M, Bakker CJ, Dahm P. Ureteral stent versus no ureteral stent for ureteroscopy in the management of renal and ureteral calculi. Cochrane Database of Systematic Reviews 2017, Issue 6. [DOI: 10.1002/14651858.CD012703]}

* Indicates the major publication for the study

\section{CHARACTERISTICS OF STUDIES}

Characteristics of included studies [ordered by study ID] 
Al-Ba'adani 2006 (Continued)

Setting/Country: single centre/Yemen

Dates of the study: August 2004 to April 2005

Total number of participants randomised: 85
Group 1, stented group: 40
Group 2, unstented group: 45
Stone location: distal, mid
Inclusion criteria: participants with ureteral calculi presenting for ureteroscopy
Exclusion criteria: not reported

Interventions

Group 1: stented group

Group 2: unstented group

Surgical procedure: the procedure carried out under general anaesthesia and by direct entering of the ureter without prior dilation of the ureter, using the semi-rigid ureteroscope, which is graduated between 8 and $11 \mathrm{Fr}$. For the stented group, a ureteric catheter $6 \mathrm{Fr}$ was left for 1 to 2 days in 30 patients, and 10 double $\mathrm{J}$ stents were left for 3 to 4 weeks

Stent type: ureteral stent $(n=30)$, DJ stent $(n=10)$; all 6 Fr stent (length: NR)

Time to stent removal: ureteral stent 1 to 2 days, DJ stent 3 to 4 weeks

\begin{tabular}{ll}
\hline Putcomes & Primary outcomes \\
- Ureteral dilation, stone retrieval, operative time, postoperative analgesia use, haematuria, colour \\
clearance \\
- How measured: not reported \\
- Time to measured: not reported
\end{tabular}

Secondary outcomes: not reported

Subgroup: none

\begin{tabular}{lll}
\hline Funding source & Not reported & \\
\hline Declarations of interest & Not reported & \\
\hline Notes & Language of publication: English \\
\hline Risk of bias & Authors' judgement & Support for judgement \\
\hline Bias & Unclear risk & Quote: "random" \\
\hline $\begin{array}{l}\text { Random sequence genera- } \\
\text { tion (selection bias) }\end{array}$ & $\begin{array}{l}\text { Comment: owing to insufficient information, risk of selection bias was consid- } \\
\text { ered to be unclear }\end{array}$ \\
\hline $\begin{array}{l}\text { Allocation concealment } \\
\text { (selection bias) }\end{array}$ & Unclear risk & $\begin{array}{l}\text { Insufficient information to permit judgement } \\
\text { Comment: owing to insufficient information, risk of allocation concealment } \\
\text { was considered to be unclear }\end{array}$ \\
\hline
\end{tabular}


Al-Ba'adani 2006 (Continued)
Blinding of participants
High risk
No blinding described and personnel (perfor-
Comment: study was unlikely to have used blinding
mance bias)

All outcomes

\section{Blinding of outcome as- sessment (detection bias) Subjective outcomes (post-operative discom- fort, UTI, ureteral stricture, $\mathrm{QOL})$}

High risk

No blinding of outcome assessments described

Comment: study was unlikely to have used blinding

\begin{tabular}{|c|c|c|}
\hline $\begin{array}{l}\text { Blinding of outcome as- } \\
\text { sessment (detection bias) } \\
\text { Objective outcomes (all } \\
\text { others) }\end{array}$ & Low risk & Comment: objective outcomes were not likely affected by lack of blinding \\
\hline $\begin{array}{l}\text { Incomplete outcome data } \\
\text { (attrition bias) } \\
\text { All outcomes }\end{array}$ & Low risk & Comment: all participants randomised in each group were included in analysis \\
\hline $\begin{array}{l}\text { Selective reporting (re- } \\
\text { porting bias) }\end{array}$ & Unclear risk & $\begin{array}{l}\text { Protocol was not available } \\
\text { Comment: owing to insufficient information to permit judgement, risk of re- } \\
\text { porting bias was considered to be unclear }\end{array}$ \\
\hline
\end{tabular}

Other bias

High risk

Comment: baseline imbalance in stone size; therefore risk of other bias was considered to be high

Başeskioğlu 2011

\begin{tabular}{ll} 
Methods & Study design: parallel randomised controlled trial \\
Setting/Country: single centre/Turkey \\
Dates of the study: May 2005 to January 2010 \\
\hline
\end{tabular}

Participants

\section{Total number of participants: 286}

Group 1, stented group: 144

\section{Group 2, unstented group: 142}

Stone location: distal, mid, proximal

Inclusion criteria: adult patients undergoing ureteroscopy for ureteral calculi requiring ureteral dilation for ureteroscopy

Exclusion criteria: previous ureteroscopy or stenting, evidence of active infection, pregnancy, suspicion of urothelial cancer, and age under 18 years old. Perioperative complications (defined as those causing mucosal damage, bleeding, or ureteral perforation; residual stones $>0.5 \mathrm{~cm}$; or ureteral stones $>2 \mathrm{~cm}$ in size, which mostly causes prolonged operation time $>1.5$ hours). Patients in whom ureteral orifice dilation was not indicated

$\begin{array}{ll}\text { Interventions } & \text { Group 1: stented group } \\ & \text { Group 2: unstented group }\end{array}$


Surgical procedure: procedures were done under general or spinal anaesthesia. Balloon dilation of the ureteral orifice was done in all other patients using UroMax balloon dilators $(18 \mathrm{Fr}-4 \mathrm{~cm}$ from Boston Scientific, Quincy, Massachusetts, USA) for approximately 2 or 3 minutes. Stones were completely fragmented with Sphinx holmium laser (LISA Laser Products, Lindau, Germany) or Calcusplit pneumatic lithotripsy devices (Karl Storz, Tuttlingen, Germany). Stones were extracted by grasper forceps. All patients were given a single prophylactic dose of $400 \mathrm{mg}$ ciprofloxacin intravenously

Stent type: not reported

Time point of stent removal: not reported

\begin{tabular}{ll}
\hline Outcomes & Primary outcomes \\
& - Pain, dysuria, urgency, infectious complications, unplanned visits, ureteral stricture \\
- How measured: pain score using VAS (0 to 10), record event per each visit \\
- Time to measured: 1 and 3 months \\
Secondary outcomes: not reported \\
Subgroup: not reported \\
\hline Funding source & None \\
\hline Declarations of interest & None \\
\hline Notes & Language of publication: English
\end{tabular}

\section{Risk of bias}

\begin{tabular}{lll}
\hline Bias & Authors' judgement & Support for judgement \\
\hline $\begin{array}{l}\text { Random sequence genera- } \\
\text { tion (selection bias) }\end{array}$ & Low risk & $\begin{array}{l}\text { Quote: "patients underwent ureteral orifice dilatation and were prospectively } \\
\text { randomized to be stented or not after ureteroscopic stone removal according } \\
\text { to a random number list" }\end{array}$ \\
& $\begin{array}{l}\text { Comment: this method of random sequence generation was considered to } \\
\text { have low risk of bias }\end{array}$ \\
\hline
\end{tabular}

\begin{tabular}{lll}
\hline $\begin{array}{l}\text { Allocation concealment } \\
\text { (selection bias) }\end{array}$ & Unclear risk & $\begin{array}{l}\text { Comment: owing to insufficient information, risk of allocation concealment } \\
\text { was considered to be unclear }\end{array}$ \\
\hline $\begin{array}{l}\text { Blinding of participants } \\
\text { and personnel (perfor- } \\
\text { mance bias) }\end{array}$ & High risk & No blinding described \\
All outcomes & Comment: study was unlikely to have used blinding \\
\hline
\end{tabular}

Blinding of outcome as- High risk sessment (detection bias) Subjective outcomes (post-operative discomfort, UTI, ureteral stricture, $\mathrm{QOL})$
Quote: "results at the two centers were concealed from each other until the end of study"

Comment: blinding within centre was not described; study was unlikely to have used blinding

\begin{tabular}{l} 
Blinding of outcome as- $\quad$ Low risk Comment: objective outcomes were not likely affected by lack of blinding \\
$\begin{array}{l}\text { Sessment (detection bias) } \\
\text { Objective outcomes (all } \\
\text { others) }\end{array}$ \\
\hline
\end{tabular}


Başeskioğlu 2011 (Continued)

Incomplete outcome data Low risk Comment: all participants randomised in each group were included in analysis (attrition bias)

Comment. all participants randomised in each group were included in analysis

All outcomes

\begin{tabular}{lll}
\hline $\begin{array}{l}\text { Selective reporting (re- } \\
\text { porting bias) }\end{array}$ & Unclear risk & $\begin{array}{l}\text { Protocol was not available } \\
\text { Comment: owing to insufficient information to permit judgement, risk of re- } \\
\text { porting bias was considered to be unclear }\end{array}$ \\
\hline Other bias & Low risk & $\begin{array}{l}\text { Study appears to be free of other sources of bias } \\
\text { Comment: no other sources of bias could be found; therefore risk of other bias } \\
\text { was considered to be low }\end{array}$ \\
\hline
\end{tabular}

Benrabah 2014

Study design: parallel randomised controlled trial
Setting/Country: single centre/Algeria
Dates of the study: not reported

Participants

\section{Total number of participants randomised: 200}

Group 1, stented group: 100

Group 2, unstented group: 100

Stone location: distal

Inclusion criteria: participants successfully treated with ureteroscopy for distal ureteral calculi

Exclusion criteria: not reported

\begin{tabular}{ll}
\hline Interventions & Group 1: stented group \\
Group 2: non-stented group & Surgical procedure: not reported \\
& Stent type: DJ sent: NR Fr (length: NR) \\
& Time to stent removal: 21 days \\
\hline Outcomes & Primary outcomes \\
& Pain, urinary symptoms, medical emergency department visits, hospital readmissions, secondary \\
& procedures, time to return to work \\
& How measured: VAS, use of analgesics, record of event \\
& Time to measured: not reported \\
& Secondary outcomes: not reported \\
& Subgroup: not reported \\
\hline Funding source & Not reported \\
\hline Declarations of interest & Not reported \\
\hline
\end{tabular}


Benrabah 2014 (Continued)
Notes
Abstract only

Language of publication: English

\section{Risk of bias}

\begin{tabular}{lll}
\hline Bias & Authors' judgement & Support for judgement \\
\hline $\begin{array}{l}\text { Random sequence genera- } \\
\text { tion (selection bias) }\end{array}$ & Unclear risk & $\begin{array}{l}\text { Quote: "randomized" } \\
\text { Comment: owing to insufficient information, risk of selection bias was consid- } \\
\text { ered to be unclear }\end{array}$ \\
\hline $\begin{array}{l}\text { Allocation concealment } \\
\text { (selection bias) }\end{array}$ & Unclear risk & $\begin{array}{l}\text { Comment: owing to insufficient information, risk of allocation concealment } \\
\text { was considered to be unclear; abstract only }\end{array}$ \\
\hline $\begin{array}{l}\text { Blinding of participants } \\
\text { and personnel (perfor- } \\
\text { mance bias) }\end{array}$ & Unclear risk & $\begin{array}{l}\text { Comment: owing to insufficient information, risk of performance bias was con- } \\
\text { All outcomes }\end{array}$
\end{tabular}

\begin{tabular}{|c|c|c|}
\hline $\begin{array}{l}\text { Blinding of outcome as- } \\
\text { sessment (detection bias) } \\
\text { Subjective outcomes } \\
\text { (post-operative discom- } \\
\text { fort, UTI, ureteral stricture, } \\
\text { QOL) }\end{array}$ & Unclear risk & $\begin{array}{l}\text { Comment: owing to insufficient information, risk of detection bias was consid- } \\
\text { ered to be unclear; abstract only }\end{array}$ \\
\hline
\end{tabular}

Blinding of outcome as- Low risk Comment: objective outcomes were not likely affected by lack of blinding
sessment (detection bias) Objective outcomes (all others)

\begin{tabular}{lll}
\hline $\begin{array}{l}\text { Incomplete outcome data } \\
\text { (attrition bias) } \\
\text { All outcomes }\end{array}$ & Unclear risk & $\begin{array}{l}\text { Comment: owing to insufficient information to permit judgement, risk of attri- } \\
\text { tion bias was considered to be unclear; abstract only }\end{array}$ \\
\hline $\begin{array}{l}\text { Selective reporting (re- } \\
\text { porting bias) }\end{array}$ & Unclear risk & $\begin{array}{l}\text { Comment: owing to insufficient information to permit judgement, risk of re- } \\
\text { porting bias was considered to be unclear; abstract only }\end{array}$ \\
\hline Other bias & Low risk & $\begin{array}{l}\text { Comment: no other sources of bias could be found; therefore risk of other bias } \\
\text { was considered to be low }\end{array}$ \\
\hline
\end{tabular}

\section{Borboroglu 2001}

\begin{tabular}{ll}
\hline Methods & Study design: parallel randomised controlled trial \\
Setting/Country: multi-centre/USA \\
Dates of the study: November 1998 to January 2001 \\
\hline
\end{tabular}

Participants

Total number of participants randomised: 113

\section{Group 1, stented group: 53}

Group 2, unstented group: 60

Stone location: distal 
Borboroglu 2001 (Continued)

Inclusion criteria: 18 years or older and had distal ureteral calculi amenable to ureteroscopic management

Exclusion criteria: participants had a ureteral stent placed preoperatively

Group 2: unstented group

Surgical procedure: ureteroscope size ranged from 6.0 to $9.5 \mathrm{Fr}$. Ureteroscopic baskets ranged in size from 3.0 to $4.5 \mathrm{Fr}$. The holmium:YAG laser or electrohydraulic lithotripsy was used. Intraoperative ureteral dilation was primarily done with balloon dilation (15 and $18 \mathrm{Fr}$ balloons)

Stent type: likely DJ stent; 6 Fr stent (length determined by the surgeon)

Time to stent removal: 3 to 10 days

Primary outcomes
- Postoperative pain, stone-free rates, complications, use of analgesic medication
- How measured: pain and symptom questionnaires (pain scale 0 to 100); other outcomes measure
methods not reported
- Time to measured: baseline, at 48 hours, at 1 and 4 weeks

Secondary outcomes: not reported

Subgroup: not reported

\begin{tabular}{ll}
\hline Funding source & Not reported \\
\hline Declarations of interest & Not reported \\
\hline Notes & Language of publication: English \\
\hline
\end{tabular}

\section{Risk of bias}

\begin{tabular}{lll}
\hline Bias & Authors' judgement & Support for judgement \\
\hline $\begin{array}{l}\text { Random sequence genera- } \\
\text { tion (selection bias) }\end{array}$ & Low risk & $\begin{array}{l}\text { Quote: "random number list" } \\
\text { Comment: this method of random sequence generation was considered to } \\
\text { have low risk of bias }\end{array}$ \\
\hline $\begin{array}{l}\text { Allocation concealment } \\
\text { (selection bias) }\end{array}$ & Low risk & $\begin{array}{l}\text { Quote: "patients and surgeons were blinded between stented and unstented } \\
\text { groups until the patient was in the operating room" }\end{array}$ \\
& $\begin{array}{l}\text { Comment: this method of allocation concealment was considered to have low } \\
\text { risk of bias (blinding until allocation assignment) }\end{array}$ \\
\hline
\end{tabular}

\begin{tabular}{lll}
\hline $\begin{array}{l}\text { Blinding of participants } \\
\text { and personnel (perfor- } \\
\text { mance bias) }\end{array}$ & High risk & No blinding was described \\
$\begin{array}{l}\text { All outcomes } \\
\text { Comment: study was unlikely to have used blinding }\end{array}$ \\
\hline $\begin{array}{l}\text { Blinding of outcome as- } \\
\text { sessment (detection bias) } \\
\begin{array}{l}\text { Subjective outcomes } \\
\text { (post-operative discom- }\end{array}\end{array}$ & High risk & No blinding of outcome assessments was described \\
\hline
\end{tabular}


Borboroglu 2001 (Continued) fort, UTI, ureteral stricture, QOL)

\begin{tabular}{|c|c|c|}
\hline $\begin{array}{l}\text { Blinding of outcome as- } \\
\text { sessment (detection bias) } \\
\text { Objective outcomes (all } \\
\text { others) }\end{array}$ & Low risk & Comment: objective outcomes were not likely affected by lack of blinding \\
\hline $\begin{array}{l}\text { Incomplete outcome data } \\
\text { (attrition bias) } \\
\text { All outcomes }\end{array}$ & Low risk & $\begin{array}{l}53 / 53(100 \%) \text { participants in stented group and } 54 / 60(90 \%) \text { in unstented } \\
\text { group were included in the analyses } \\
\text { Comment: owing to the small number of participants lost to follow-up, risk of } \\
\text { attrition bias was considered to be low }\end{array}$ \\
\hline $\begin{array}{l}\text { Selective reporting (re- } \\
\text { porting bias) }\end{array}$ & Unclear risk & $\begin{array}{l}\text { Protocol was not available } \\
\text { Comment: owing to insufficient information to permit judgement, risk of re- } \\
\text { porting bias was considered to be unclear }\end{array}$ \\
\hline Other bias & Low risk & $\begin{array}{l}\text { Study appears to be free of other sources of bias } \\
\text { Comment: no other sources of bias could be found; therefore risk of other bias } \\
\text { was considered to be low }\end{array}$ \\
\hline
\end{tabular}

Cevik 2010

$\begin{array}{ll}\text { Methods } & \text { Study design: parallel randomised controlled trial } \\ \text { Setting/Country: multi-centre/Turkey } \\ \text { Dates of the study: January } 2005 \text { to October } 2007 \\ \text { Total number of participants randomised: } 60 \\ \text { Group 1, stented group: } 30 \\ \text { Group 2, unstented group: } 30 \\ \text { Stone location: distal, mid } \\ \text { Inclusion criteria: patients with impacted ureteral stones } \\ \text { Exclusion criteria: patients who had non-impacted stones, upper ureteral stones, radiolucent stones } \\ \text { that made follow-up difficult, a solitary functioning kidney, significant concomitant ipsilateral renal } \\ \text { stone load that necessitated further intervention after ureteroscopy, ureteral steinstrasse, preopera- } \\ \text { tive ureteral stent placement or nephrostomy drainage, concomitant ureteral obstruction secondary to } \\ \text { other causes such as stricture, failed ureteroscopic access to the stone, and intraoperative ureteral per- } \\ \text { foration }\end{array}$

Group 2: unstented group

Surgical procedure: the procedures were performed under general anaesthesia. Patients underwent ureteroscopic pneumatic lithotripsy (Vibrolith, Elmed Lithotripsy Systems, Ankara, Turkey) for lower and middle ureteral impacted calculi. The operation was performed with a rigid $8 \mathrm{Fr}$ semi-rigid ureteroscope (Wolf Medical Instruments, Vernon Hills, Illinois, USA) without ureteral dilation. The ureteroscope was introduced just below the stone, and confirmation of its relation to the oedematous and hyperemic ureteral mucosa was obtained by $\mathrm{C}$-arm fluoroscopic imaging in cases where direct vision of the stone could not be obtained. After disintegration of the stone with the lithotripter, a safety Zebra guidewire was placed. The fragments were removed with a grasping forceps or appropriate basket 
Cevik 2010 (Continued)

catheters. After removal of the stone fragments, retrograde ureterography was performed to exclude perforation, and real-time fluoroscopic examination was performed for reassurance of the completeness of stone removal

Stent type: DJ stent, 4.8 Fr stent (length: NR)

Time to stent removal: 3 weeks

Primary outcomes
- Operative time, hospital stay, narcotic and non-narcotic analgesic use, fever, pain delaying discharge,
emergency department visit, urinary retention, stent-related irritative symptoms
- How measured: not reported
- Time to measured: not reported

Secondary outcomes: not reported

Subgroup: not reported

\begin{tabular}{ll}
\hline Funding source & None \\
\hline Declarations of interest & None \\
\hline Notes & Language of publication: English
\end{tabular}

\section{Risk of bias}

\begin{tabular}{|c|c|c|}
\hline Bias & Authors' judgement & Support for judgement \\
\hline \multirow{2}{*}{$\begin{array}{l}\text { Random sequence genera- } \\
\text { tion (selection bias) }\end{array}$} & High risk & Quote: "one with a stent and next without a stent, alternating" \\
\hline & & $\begin{array}{l}\text { Comment: quasi-randomisation - this method of random sequence generation } \\
\text { was considered to have high risk of bias }\end{array}$ \\
\hline \multirow{2}{*}{$\begin{array}{l}\text { Allocation concealment } \\
\text { (selection bias) }\end{array}$} & High risk & Quote: "alternating" \\
\hline & & $\begin{array}{l}\text { Comment: this method of allocation concealment was considered to have high } \\
\text { risk of bias }\end{array}$ \\
\hline \multirow{3}{*}{$\begin{array}{l}\text { Blinding of participants } \\
\text { and personnel (perfor- } \\
\text { mance bias) } \\
\text { All outcomes }\end{array}$} & High risk & No blinding described \\
\hline & & Comment: study was unlikely to have used blinding \\
\hline & & \\
\hline
\end{tabular}

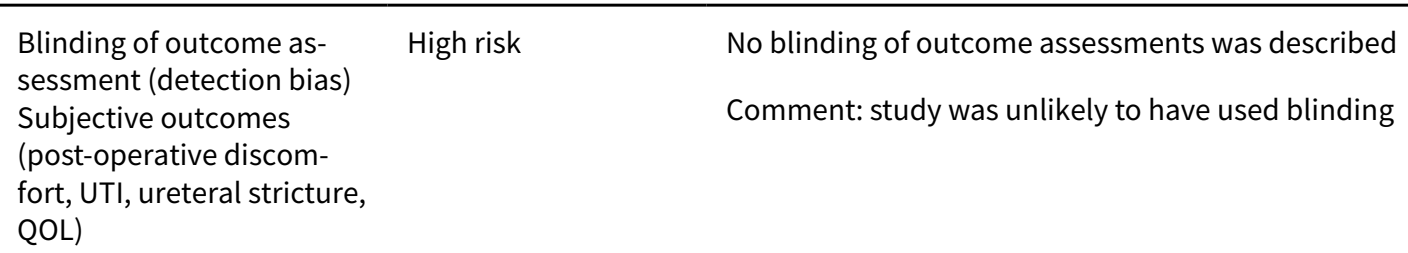

Blinding of outcome as- $\quad$ Low risk Comment: objective outcomes were not likely affected by lack of blinding
sessment (detection bias)
Objective outcomes (all
others)

Incomplete outcome data Low risk 60/64 (93.75\%) randomised participants included in analyses
(attrition bias)
All outcomes


Cevik 2010 (Continued)

Comment: owing to the small number of participants lost to follow-up, risk of attrition bias was considered to be low

\begin{tabular}{|c|c|c|}
\hline $\begin{array}{l}\text { Selective reporting (re- } \\
\text { porting bias) }\end{array}$ & Unclear risk & $\begin{array}{l}\text { Protocol was not available } \\
\text { Comment: owing to insufficient information to permit judgement, risk of re- } \\
\text { porting bias was considered to be unclear }\end{array}$ \\
\hline Other bias & Low risk & $\begin{array}{l}\text { Study appears to be free of other sources of bias } \\
\text { Comment: no other sources of bias could be found; therefore risk of other bias } \\
\text { was considered to be low }\end{array}$ \\
\hline
\end{tabular}

Chen 2002

\begin{tabular}{ll}
\hline Study design: parallel randomised controlled trial \\
Setting/Country: single centre/Taiwan \\
Dates of the study: June 2000 to October 2000 \\
\hline
\end{tabular}

Participants

Total number of participants: 60

Group 1, stented group: 30

Group 2, unstented group: 30

Stone location: distal, mid, proximal

Inclusion criteria: scheduled for ureteroscopic lithotripsy with stone 6 to $10 \mathrm{~mm}$, absence of polyp and stricture in the ureter, and no mucosal injury or perforation during operation

Exclusion criteria: not reported

Group 2: unstented group

Surgical procedure: the operation was performed with spinal anaesthesia in 42 patients and with intravenous sedation in 18, according to anaesthesiologist preference or patient request. A 6 Fr Wolf rigid ureteroscope was used in all patients with direct access to the calculi without ureteral dilation. All stones were disintegrated

Stent type: DJ stent, 7 Fr (length: NR)

Time to stent removal: 3 days

Outcomes Primary outcomes

- Pain score change (preoperative vs postoperative), postoperative pain attack, parenteral analgesic requirement, emergency room visit, pyuria, hydronephrosis, postoperative bladder symptom

- How measured: self-rated visual analogue pain scale (range 1 to 10) for pain, urine analysis for pyuria, renosonography for hydronephrosis

- Time to measured: pain: postoperative day 3; urine analysis and renal sonography: postoperative days 3,7 , and 28

- Time to reported: not reported

Secondary outcomes: not reported

Subgroup: not reported 
Chen 2002 (Continued)

\begin{tabular}{ll} 
Funding source & Not reported \\
\hline Declarations of interest & Not reported \\
\hline Notes & Language of publication: English
\end{tabular}

\section{Risk of bias}

\begin{tabular}{lll}
\hline Bias & Authors' judgement & Support for judgement \\
\hline $\begin{array}{l}\text { Random sequence genera- } \\
\text { tion (selection bias) }\end{array}$ & Unclear risk & $\begin{array}{l}\text { Quote: "random" } \\
\text { Comment: owing to insufficient information, risk of selection bias was consid- } \\
\text { ered to be unclear }\end{array}$ \\
\hline $\begin{array}{l}\text { Allocation concealment } \\
\text { (selection bias) }\end{array}$ & Unclear risk & $\begin{array}{l}\text { Insufficient information to permit judgement } \\
\text { Commnet: owing to insufficient information, risk of allocation concealment } \\
\text { was considered to be unclear }\end{array}$ \\
\hline
\end{tabular}

\begin{tabular}{|c|c|c|}
\hline $\begin{array}{l}\text { Blinding of participants } \\
\text { and personnel (perfor- } \\
\text { mance bias) }\end{array}$ & High risk & $\begin{array}{l}\text { No blinding described } \\
\text { Comment: study was unlikely to have used blinding }\end{array}$ \\
\hline
\end{tabular}

\begin{tabular}{lll}
\hline $\begin{array}{l}\text { Blinding of outcome as- } \\
\text { sessment (detection bias) }\end{array}$ & High risk & No blinding of outcome assessments was described \\
Subjective outcomes & Comment: study was unlikely to have used blinding
\end{tabular}

(post-operative discom-

fort, UTI, ureteral stricture,

$\mathrm{QOL})$

\begin{tabular}{lll}
\hline $\begin{array}{l}\text { Blinding of outcome as- } \\
\text { sessment (detection bias) } \\
\text { Objective outcomes (all } \\
\text { others) }\end{array}$ & Low risk & Comment: objective outcomes were not likely affected by lack of blinding \\
\hline $\begin{array}{l}\text { Incomplete outcome data } \\
\text { (attrition bias) } \\
\text { All outcomes }\end{array}$ & Low risk & Comment: all participants randomised in each group were included in analysis \\
\hline $\begin{array}{l}\text { Selective reporting (re- } \\
\text { porting bias) }\end{array}$ & Unclear risk & Protocol was not available \\
& $\begin{array}{l}\text { Comment: owing to insufficient information to permit judgement, risk of re- } \\
\text { porting bias was considered to be unclear }\end{array}$ \\
\hline $\begin{array}{l}\text { Other bias } \\
\text { High risk }\end{array}$ & $\begin{array}{l}\text { Comment: baseline imbalance in age; therefore risk of other bias was consid- } \\
\text { ered to be high }\end{array}$ \\
\hline
\end{tabular}

Cheung 2003

Study design: parallel randomised controlled trial
Setting/Country: single centre/Hong Kong
Dates of the study: March 2001 to February 2002


Cheung 2003 (Continued)

Participants

\section{Total number of participants randomised: 58}

Group 1, stented group: 29

Group 2, unstented group: 29

Stone location: distal, mid, and proximal

Inclusion criteria: patients with unilateral ureteral stones, irrespective of stone load and location and severity of obstruction

Exclusion criteria: patients were excluded from the study either preoperatively or intraoperatively if they had a radiolucent stone that made follow-up by plain radiograph difficult; a solitary functioning kidney; significant concomitant ipsilateral renal stone load that required further intervention after ureteroscopy, ureteral steinstrasse, preoperative ureteral stenting, or nephrostomy drainage; concomitant ureteral obstruction secondary to other causes such as stricture; failed ureteroscopic access to the stone; and intraoperative ureteral perforation

Interventions

Group 1: stented group

Group 2: unstented group

Surgical procedure: the procedure was performed with the patient under either general or spinal anaesthesia as decided by anaesthesiologists after discussion with patients. The ureteroscope was introduced without dilation of the ureteral orifice. Only semi-rigid ureteroscopes $(6.5 / 7 \mathrm{Fr})$ were used in all cases. Stones were broken by holmium laser into fragments smaller than $2 \mathrm{~mm}$, as assessed by comparison with the laser fibre (fibre size 365 micron). Basket retrieval of the fragments into the bladder was performed

Stent type: DJ stent, $6 \operatorname{Fr}(24$ or $26 \mathrm{~cm})$

Time to stent removal: 2 weeks

Primary outcomes
Outcomes
- Postoperative pain score, dysuria, loin pain, haematuria, fever, urinary tract infection, unplanned
medical visit, stone-free, stricture
- How measured: telephone interview using visual analogue scale (0 to 10$)$ for pain, IVP for ureteral
stricture
- Time to measured: postoperative days 1 and 3 for pain, postoperative 2 to 3 months for ureteral stric-
ture
- Time to reported: not reported

Secondary outcomes: not reported

Subgroup: not reported

\begin{tabular}{|c|c|c|}
\hline Funding source & \multicolumn{2}{|l|}{ Not reported } \\
\hline Declarations of interest & \multicolumn{2}{|l|}{ Not reported } \\
\hline Notes & \multicolumn{2}{|c|}{ Language of publication: English } \\
\hline \multicolumn{3}{|l|}{ Risk of bias } \\
\hline Bias & Authors' judgement & Support for judgement \\
\hline $\begin{array}{l}\text { Random sequence genera- } \\
\text { tion (selection bias) }\end{array}$ & Unclear risk & $\begin{array}{l}\text { Quote: "envelope was drawn" } \\
\text { Comment: owing to insufficient information, risk of selection bias was consid- } \\
\text { ered to be unclear }\end{array}$ \\
\hline
\end{tabular}


Cheung 2003 (Continued)

$\begin{array}{ll}\begin{array}{l}\text { Allocation concealment } \\ \text { (selection bias) }\end{array} & \text { Unclear risk } \\ & \begin{array}{l}\text { Comment: owing to insufficient information, risk of allocation concealment } \\ \text { was considered to be unclear }\end{array}\end{array}$

\begin{tabular}{|c|c|c|}
\hline $\begin{array}{l}\text { Blinding of participants } \\
\text { and personnel (perfor- } \\
\text { mance bias) }\end{array}$ & High risk & $\begin{array}{l}\text { No blinding was described } \\
\text { Comment: study was unlikely to have used blinding }\end{array}$ \\
\hline
\end{tabular}

High risk

Blinding of outcome as-
sessment (detection bias)
Subjective outcomes risk
(post-operative discom-
fort, UTI, ureteral stricture,
QOL)

Quote: "follow-up clinic on day 10, also had a plain radiograph taken and postoperative symptoms and events, was completed on the same day"

Comment: outcome assessor was not blinded; therefore risk of detection bias was considered to be high

\begin{tabular}{lll}
\hline $\begin{array}{l}\text { Blinding of outcome as- } \\
\text { sessment (detection bias) } \\
\begin{array}{l}\text { Objective outcomes (all } \\
\text { others) }\end{array}\end{array}$ & Low risk & Comment: objective outcomes were not likely affected by lack of blinding \\
\hline $\begin{array}{l}\text { Incomplete outcome data } \\
\text { (attrition bias) } \\
\text { All outcomes }\end{array}$ & Low risk & Comment: all participants randomised in each group were included in analysis \\
\hline $\begin{array}{l}\text { Selective reporting (re- } \\
\text { porting bias) }\end{array}$ & Unclear risk & Protocol was not available \\
& $\begin{array}{l}\text { Comment: owing to insufficient information to permit judgement, risk of re- } \\
\text { porting bias was considered to be unclear }\end{array}$ \\
\hline $\begin{array}{l}\text { Other bias } \\
\text { Low risk }\end{array}$ & $\begin{array}{l}\text { Study appears to be free of other sources of bias } \\
\text { Comment: no other sources of bias could be found; therefore risk of other bias } \\
\text { was considered to be low }\end{array}$
\end{tabular}

Damiano 2004

\begin{tabular}{ll} 
Methods & Study design: parallel randomised controlled trial \\
Setting/Country: multi-centre/Italy \\
Dates of the study: January 2000 to December 2002 \\
\hline Total number of participants randomised: 104 \\
Group 1, stented group: 52 \\
Group 2, unstented group: 52 \\
Stone location: proximal, mid, distal \\
Inclusion criteria: ureteroscopy for the treatment of ureteral lithiasis; absence of polyp suggestive of \\
urothelial cancer; no evidence of stricture; no mucosal perforation during the operation \\
$\begin{array}{l}\text { Exclusion criteria: stone size smaller than } 2 \text { cm; previous ureteroscopy had been performed and had } \\
\text { failed for treatment of the same stone, or there was a history of sepsis, renal failure, solitary kidney, or } \\
\text { pregnancy; presence of polyp, suggestive of urothelial cancer, and stricture in the ureter and mucosal } \\
\text { perforation during operation }\end{array}$
\end{tabular}


Damiano 2004 (Continued)

Interventions

Group 1: stented group

Group 2: unstented group

Surgical procedure: retrograde pyelography was performed in selected cases when ureteroscope progression was difficult. A semi-rigid ureteroscope (Wolf $8.9 \mathrm{Fr}$ ) was used in all cases. Ballistic intracorporeal lithotripsy was performed, and attempts were made to remove stone fragments in the ureter, although small fragments $(<3 \mathrm{~mm}$ ) were largely left to pass spontaneously. In all cases of fragmentation, the site of impaction was inspected for ureteral perforation. In the stented group following ureteroscopy, a double pigtail ureteral 4.8 or 6 Fr polyurethane stent was placed through a ureteroscopic operative channel or over a guidewire under fluoroscopic monitoring. No patients had a stent with a suture. Before surgery, participants were administered intravenous antibiotics, which were continued orally for 5 to 7 days postoperatively

Stent type: DJ stent, 4.8 Fr to 6 Fr (length: NR)

Time to stent removal: 2 weeks

Outcomes Primary outcomes

- Stone-free rate, postoperative patient pain, lower urinary tract symptoms, need for hospital care as a result of postoperative pain and late postoperative complications (ureteral stricture)

- How measured: questionnaire, urinalysis, urine culture, X-ray, renal sonography, IVP

- Time to measured: postoperative days 3, 7, and 15; postoperative 1 and 3 months for stone-free rate (KUB, renal ultrasound); postoperative 6 months for ureteral stricture (IVP)

- Time to reported: not reported

Secondary outcomes: not reported

Subgroup: participants requiring readmission to the hospital vs overall participants

\begin{tabular}{ll}
\hline Funding source & Not reported \\
\hline Declarations of interest & Not reported \\
\hline Notes & Language of publication: English
\end{tabular}

\section{Risk of bias}

Bias Authors' judgement Support for judgement

\begin{tabular}{ll}
\hline $\begin{array}{l}\text { Random sequence genera- } \\
\text { tion (selection bias) }\end{array}$ & Low risk \\
& $\begin{array}{l}\text { Comment: this method of random sequence generation was considered to } \\
\text { have low risk of bias }\end{array}$ \\
\hline
\end{tabular}

\begin{tabular}{|c|c|c|}
\hline $\begin{array}{l}\text { Allocation concealment } \\
\text { (selection bias) }\end{array}$ & Unclear risk & $\begin{array}{l}\text { Insufficient information to permit judgement } \\
\text { Comment: owing to insufficient information, risk of allocation concealment } \\
\text { was considered to be unclear }\end{array}$ \\
\hline
\end{tabular}

\begin{tabular}{|c|c|c|}
\hline $\begin{array}{l}\text { Blinding of participants } \\
\text { and personnel (perfor- } \\
\text { mance bias) } \\
\text { All outcomes }\end{array}$ & High risk & $\begin{array}{l}\text { No blinding was described } \\
\text { Comment: study was unlikely to have used blinding }\end{array}$ \\
\hline
\end{tabular}

\begin{tabular}{|c|c|c|}
\hline $\begin{array}{l}\text { Blinding of outcome as- } \\
\text { sessment (detection bias) } \\
\text { Subjective outcomes } \\
\text { (post-operative discom- }\end{array}$ & High risk & $\begin{array}{l}\text { Quote: "plain KUB X-ray and renal ultrasonography that were performed in the } \\
\text { immediate postoperative period" }\end{array}$ \\
\hline
\end{tabular}


Damiano 2004 (Continued) fort, UTI, ureteral stricture, QOL)
Comment: outcome assessor may be unblinded; therefore risk of detection bias was considered to be high
Blinding of outcome as- Low risk sessment (detection bias)

Objective outcomes (all others)

Low risk
Comment: objective outcomes were not likely affected by lack of blinding

$\begin{array}{ll}\begin{array}{l}\text { Incomplete outcome data } \\ \text { (attrition bias) }\end{array} & \begin{array}{l}\text { Comment: all participants who were randomised in each group were included } \\ \text { ill outcomes }\end{array}\end{array}$

All outcomes

Comment: objective outcomes were notlikely affected by lack of blinding

\begin{tabular}{ll}
\hline $\begin{array}{l}\text { Selective reporting (re- } \\
\text { porting bias) }\end{array}$ & Unclear risk \\
& $\begin{array}{l}\text { Protocol was not available } \\
\text { Comment: owing to insufficient information to permit judgement, risk of re- } \\
\text { porting bias was considered to be unclear }\end{array}$ \\
\hline
\end{tabular}

Other bias High risk
Quote: "For upper ureteral calculi removal, ureteroscopic treatment was main- ly suggested after failure of extracorporeal shock wave lithotripsy (ESWL) or upon the patient's specific request"

Comment: contamination of participants; therefore risk of other sources of bias was considered to be high

Denstedt 2001

\begin{tabular}{|c|c|}
\hline Methods & $\begin{array}{l}\text { Study design: parallel randomised controlled trial } \\
\text { Setting/Country: multi-centre/Canada } \\
\text { Dates of the study: not reported }\end{array}$ \\
\hline Participants & $\begin{array}{l}\text { Total number of participants randomised: } 58 \\
\text { Group 1, stented group: } 29 \\
\text { Group 2, unstented group: } 29 \\
\text { Stone location: proximal, mid, distal } \\
\text { Inclusion criteria: adults } 18 \text { years or older were considered eligible for study if they were scheduled for } \\
\text { ureteroscopy for ureteral calculus at any ureteral level } \\
\text { Exclusion criteria: stone size was greater than } 2 \mathrm{~cm} \text {; previous ureteroscopy had been performed and } \\
\text { had failed for treatment of the same stone, or there was a history of urinary tract infection, sepsis, re- } \\
\text { nal failure, solitary kidney, or pregnancy. Patients were also ineligible if a ureteral stent was in place at } \\
\text { the time of treatment, or if one had been indwelling up to } 30 \text { days before definitive ureteroscopy for the } \\
\text { same stone }\end{array}$ \\
\hline Interventions & $\begin{array}{l}\text { Group 1: stented group } \\
\text { Group 2: unstented group } \\
\text { Surgical procedure: surgery for the ureteral stone was performed in standard fashion using gener- } \\
\text { al anaesthesia and a } 6.9 \text { Fr semi-rigid or } 7.5 \mathrm{Fr} \text { flexible, actively deflectable ureteroscope with a safe- } \\
\text { ty guide wire within the ureter. Generally, rigid ureteroscopy was done for distal ureteral stones and } \\
\text { most mid ureteral stones, and the flexible ureteroscope was used for most calculi in the upper ureter. } \\
\text { Stones were fragmented with the holmium laser for all participants except } 1 \text { in the stented group, who } \\
\text { was treated with electrohydraulic lithotripsy. A holmium laser pulse energy of } 0.6 \text { to } 1.2 \mathrm{~J} \text { and pulse fre- } \\
\text { quency of } 5 \text { to } 10 \mathrm{~Hz} \text { were used for laser lithotripsy }\end{array}$ \\
\hline
\end{tabular}


Time to stent removal: 1 week

Primary outcomes
- Postoperative patient symptoms, postoperative analgesic requirements, stone-free status, early and
late postoperative complications
- How measured: visual analogue scale, plain X-ray, renal ultrasonography, urinalysis, urine culture
- Time to measured: postoperative days 1 and 6 and 12 weeks
- Time to reported: not reported

Secondary outcomes: not reported

Subgroup: not reported

\begin{tabular}{ll}
\hline Funding source & $\begin{array}{l}\text { Innovations for Patient Care Research Fund, St. Joseph's Health Care, London, Ontario, Canada, and } \\
\text { the R. Samuel McLaughlin Foundation of Canada }\end{array}$ \\
\hline Declarations of interest & $\begin{array}{l}\text { John D. Denstedt, Tim A. Wollin, and R. John D’A Honey; financial and/or other relationship with Boston } \\
\text { Scientific and Cook Urological }\end{array}$ \\
\hline Notes & Language of publication: English
\end{tabular}

Risk of bias

\begin{tabular}{lll}
\hline Bias & Authors' judgement & Support for judgement \\
\hline $\begin{array}{l}\text { Random sequence genera- } \\
\text { tion (selection bias) }\end{array}$ & Unclear risk & $\begin{array}{l}\text { Quote: "block randomization" } \\
\text { Comment: owing to insufficient information, risk of selection bias was consid- } \\
\text { ered to be unclear }\end{array}$ \\
\hline $\begin{array}{l}\text { Allocation concealment } \\
\text { (selection bias) }\end{array}$ & Unclear risk & $\begin{array}{l}\text { Insufficient information to permit judgement } \\
\text { Comment: owing to insufficient information, risk of allocation concealment } \\
\text { wlinding of participants } \\
\begin{array}{l}\text { and personnel (perfor- } \\
\text { mance bias) }\end{array}\end{array}$ \\
$\begin{array}{l}\text { All outcomes } \\
\text { wigh risk }\end{array}$ & No blinding was described \\
\hline
\end{tabular}

\begin{tabular}{lll}
\hline $\begin{array}{l}\text { Blinding of outcome as- } \\
\text { sessment (detection bias) }\end{array}$ & High risk & No blinding of outcome assessments was described \\
Subjective outcomes & Comment: study was unlikely to have used blinding
\end{tabular}

(post-operative discom-

fort, UTI, ureteral stricture, QOL)

\begin{tabular}{lll}
\hline $\begin{array}{l}\text { Blinding of outcome as- } \\
\text { sessment (detection bias) }\end{array}$ & Low risk & \\
Objective outcomes (all \\
others)
\end{tabular}


Denstedt 2001 (Continued)

Selective reporting (reporting bias)

Unclear risk
Protocol was not available

Comment: owing to insufficient information to permit judgement, risk of reporting bias was considered to be unclear

\begin{tabular}{ll}
\hline Other bias & Low risk \\
& $\begin{array}{l}\text { Study appears to be free of other sources of bias } \\
\text { Comment: no other sources of bias could be found; therefore risk of other bias } \\
\text { was considered to be low }\end{array}$
\end{tabular}

\section{ElHarrech 2014}

Study design: parallel randomised controlled trial
Setting/Country: single centre/Morocco
Dates of the study: January 2009 to January 2011

Participants

Total number of participants randomised: 117

Group 1, double J stented group: 42

Group 2, ureteral stented group: 37

Group 3, unstented group: 38

Stone location: not reported

Inclusion criteria: participants treated with successful ureteroscopy for distal ureteral stones

Exclusion criteria: stones $>2 \mathrm{~cm}$

Interventions

Group 1: double J stented group

Group 2: ureteral stented group

Group 3: unstented group

Surgical procedure: under epidural anaesthesia, ureteroscopy was done with a 7.5 Fr semi-rigid ureteroscope. The pneumatic lithoclast (Swiss LithoClast. Boston Scientific, Quincy, Massachusetts, USA) was used to fragment the offending calculus into pieces in all cases requiring lithotripsy

Stent type: ureteral stent $(n=37)$, DJ stent $(n=42)$; all: 7 Fr (length: NR)

Time to stent removal: ureteral stent: 24 hours; DJ stent: 3 weeks

\section{Outcomes}

\section{Primary outcomes}

- Stone-free rate, postoperative symptoms, complications, need for analgesics in postoperative time, rate of rehospitalisation, appearance of a ureteral stricture

- How measured: special questionnaire and a precise clinical exam

- Time to measured: not reported

- Time to reported: not reported

Secondary outcomes: not reported

Subgroup: not reported

Funding source Not reported


ElHarrech 2014 (Continued)

Declarations of interest None

Notes Language of publication: English

\section{Risk of bias}

\begin{tabular}{|c|c|c|}
\hline Bias & Authors' judgement & Support for judgement \\
\hline $\begin{array}{l}\text { Random sequence genera- } \\
\text { tion (selection bias) }\end{array}$ & Unclear risk & $\begin{array}{l}\text { Quote: "random" } \\
\text { Comment: owing to insufficient information, risk of selection bias was consid- } \\
\text { ered to be unclear }\end{array}$ \\
\hline $\begin{array}{l}\text { Allocation concealment } \\
\text { (selection bias) }\end{array}$ & Unclear risk & $\begin{array}{l}\text { Insufficient information to permit judgement } \\
\text { Comment: owing to insufficient information, risk of allocation concealment } \\
\text { was considered to be unclear }\end{array}$ \\
\hline $\begin{array}{l}\text { Blinding of participants } \\
\text { and personnel (perfor- } \\
\text { mance bias) } \\
\text { All outcomes }\end{array}$ & High risk & $\begin{array}{l}\text { No blinding was described } \\
\text { Comment: study was unlikely to have used blinding }\end{array}$ \\
\hline
\end{tabular}

\begin{tabular}{lll}
\hline Blinding of outcome as- & High risk & No blinding of outcome assessments was described \\
sessment (detection bias) & & Comment: study was unlikely to have used blinding \\
Subjective outcomes & &
\end{tabular}

(post-operative discom-

fort, UTI, ureteral stricture,

QOL)

\begin{tabular}{|c|c|c|}
\hline $\begin{array}{l}\text { Blinding of outcome as- } \\
\text { sessment (detection bias) } \\
\text { Objective outcomes (all } \\
\text { others) }\end{array}$ & Low risk & Comment: objective outcomes were not likely affected by lack of blinding \\
\hline $\begin{array}{l}\text { Incomplete outcome data } \\
\text { (attrition bias) } \\
\text { All outcomes }\end{array}$ & High risk & $\begin{array}{l}\text { Comment: only } 75 \% \text { of participants had follow-up imaging. Owing to a reason- } \\
\text { able number of participants lost to follow-up (> 20\%), risk of attrition bias was } \\
\text { considered to be high }\end{array}$ \\
\hline $\begin{array}{l}\text { Selective reporting (re- } \\
\text { porting bias) }\end{array}$ & Unclear risk & $\begin{array}{l}\text { Protocol was not available } \\
\text { Comment: owing to insufficient information to permit judgement, risk of re- } \\
\text { porting bias was considered to be unclear }\end{array}$ \\
\hline Other bias & Low risk & $\begin{array}{l}\text { Study appears to be free of other sources of bias } \\
\text { Comment: no other sources of bias could be found; therefore risk of other bias } \\
\text { was considered to be low }\end{array}$ \\
\hline
\end{tabular}

Study design: parallel randomised controlled trial
Setting/Country: multi-centre (likely 3 centres)/Italy
Dates of the study: July 2000 to September 2001


Grossi 2006 (Continued)

\section{Group 1, stented group: 28}

\section{Group 2, unstented group: 28}

Overall stone location: proximal, mid, distal

Inclusion criteria: participants with ureteral stones amenable to endoscopic treatment by ureterorenoscopy

Exclusion criteria: not reported

\begin{tabular}{ll}
\hline Interventions & Group 1: stented group \\
Group 2: unstented group \\
Surgical procedure: $8.5 \mathrm{Fr}$ rigid ureteroscope with a $5 \mathrm{Fr}$ working channel was used, and small stones \\
were removed with stone forceps or basket. Larger stones that could not be removed were disintegrat- \\
ed with ballistic lithotripter
\end{tabular}

Stent type: DJ stent, 6 Fr (length: NR)

Time to stent removal: 3 to 10 days

Primary outcomes
- Residual stones, infection, haematuria, postoperative pain
- How measured: urinalysis, X-ray, VAS, ultrasound
- Time to measured: postoperative day 7 and $1,2,3$, and 6 months
- Time to reported: not reported

Secondary outcomes: not reported

Subgroup: not reported

\begin{tabular}{|c|c|c|}
\hline Funding source & \multicolumn{2}{|l|}{ Not reported } \\
\hline Declarations of interest & \multicolumn{2}{|l|}{ Not reported } \\
\hline Notes & \multicolumn{2}{|c|}{ Language of publication: English } \\
\hline \multicolumn{3}{|l|}{ Risk of bias } \\
\hline Bias & Authors' judgement & Support for judgement \\
\hline $\begin{array}{l}\text { Random sequence genera- } \\
\text { tion (selection bias) }\end{array}$ & Unclear risk & $\begin{array}{l}\text { Quote: "random" } \\
\text { Comment: owing to insufficient information, risk of selection bias was consid- } \\
\text { ered to be unclear }\end{array}$ \\
\hline $\begin{array}{l}\text { Allocation concealment } \\
\text { (selection bias) }\end{array}$ & Unclear risk & $\begin{array}{l}\text { Insufficient information to permit judgement } \\
\text { Comment: owing to insufficient information, risk of allocation concealment } \\
\text { was considered to be unclear }\end{array}$ \\
\hline $\begin{array}{l}\text { Blinding of participants } \\
\text { and personnel (perfor- } \\
\text { mance bias) } \\
\text { All outcomes }\end{array}$ & High risk & $\begin{array}{l}\text { No blinding was described } \\
\text { Comment: study was unlikely to have used blinding }\end{array}$ \\
\hline $\begin{array}{l}\text { Blinding of outcome as- } \\
\text { sessment (detection bias) }\end{array}$ & High risk & $\begin{array}{l}\text { No blinding of outcome assessments was described } \\
\text { Comment: study was unlikely to have used blinding }\end{array}$ \\
\hline
\end{tabular}


Grossi 2006 (Continued)

Subjective outcomes

(post-operative discom-

fort, UTI, ureteral stricture,

QOL)

Blinding of outcome as- Low risk Comment: objective outcomes were not likely affected by lack of blinding
sessment (detection bias)

Objective outcomes (all others)

\begin{tabular}{|c|c|c|}
\hline $\begin{array}{l}\text { Incomplete outcome data } \\
\text { (attrition bias) } \\
\text { All outcomes }\end{array}$ & Unclear risk & $\begin{array}{l}\text { Comment: unclear whether all randomised participants were included in all } \\
\text { analyses }\end{array}$ \\
\hline
\end{tabular}

\begin{tabular}{lll}
\hline $\begin{array}{l}\text { Selective reporting (re- } \\
\text { porting bias) }\end{array}$ & Unclear risk & $\begin{array}{l}\text { Protocol was not available } \\
\text { Comment: owing to insufficient information to permit judgement, risk of re- } \\
\text { porting bias was considered to be unclear }\end{array}$ \\
\hline Other bias & Low risk & $\begin{array}{l}\text { Study appears to be free of other sources of bias } \\
\text { Comment: no other sources of bias could be found; therefore risk of other bias } \\
\text { was considered to be low }\end{array}$ \\
\hline
\end{tabular}

Hosseini 2009

Study design: parallel randomised controlled trial
Setting/Country: likely single centre/Iran
Dates of the study: not reported

Participants

\section{Total number of participants randomised: 39}

Group 1, stented group: 20

Group 2, unstented group: 19

Stone location: not reported

Inclusion criteria: 20 to 54 years old with $\mathrm{mid} /$ distal ureteral calculi $\leq 10 \mathrm{~mm}$

Exclusion criteria: not reported

Group 2: unstented group

Surgical procedure: not reported

Stent type: ureteral stent $5 \mathrm{Fr}$ (length: NR)

Time to stent removal: not reported

Outcomes Primary outcomes

- Postoperative pain, LUTS, fever, analgesic requirement, stone-free rate

- How measured: not reported

- Time to measured: not reported

- Time to reported: not reported 
Hosseini 2009 (Continued)

Secondary outcomes: not reported

Subgroup: not reported

\begin{tabular}{ll}
\hline Funding source & Not reported \\
\hline Declarations of interest & Not reported \\
\hline Notes & Abstract only \\
& Language of publication: English \\
\hline
\end{tabular}

\section{Risk of bias}

\begin{tabular}{|c|c|c|}
\hline Bias & Authors' judgement & Support for judgement \\
\hline $\begin{array}{l}\text { Random sequence genera- } \\
\text { tion (selection bias) }\end{array}$ & Unclear risk & $\begin{array}{l}\text { Quote: "randomized" } \\
\text { Comment: owing to insufficient information, risk of selection bias was consid- } \\
\text { ered to be unclear }\end{array}$ \\
\hline $\begin{array}{l}\text { Allocation concealment } \\
\text { (selection bias) }\end{array}$ & Unclear risk & $\begin{array}{l}\text { Insufficient information to permit judgement } \\
\text { Comment: owing to insufficient information, risk of allocation concealment } \\
\text { was considered to be unclear }\end{array}$ \\
\hline $\begin{array}{l}\text { Blinding of participants } \\
\text { and personnel (perfor- } \\
\text { mance bias) } \\
\text { All outcomes }\end{array}$ & Unclear risk & $\begin{array}{l}\text { Comment: owing to insufficient information, risk of performance bias was con- } \\
\text { sidered to be unclear; abstract only }\end{array}$ \\
\hline $\begin{array}{l}\text { Blinding of outcome as- } \\
\text { sessment (detection bias) } \\
\text { Subjective outcomes } \\
\text { (post-operative discom- } \\
\text { fort, UTI, ureteral stricture, } \\
\text { QOL) }\end{array}$ & Unclear risk & $\begin{array}{l}\text { Comment: owing to insufficient information, risk of detection bias was consid- } \\
\text { ered to be unclear; abstract only }\end{array}$ \\
\hline $\begin{array}{l}\text { Blinding of outcome as- } \\
\text { sessment (detection bias) } \\
\text { Objective outcomes (all } \\
\text { others) }\end{array}$ & Low risk & Comment: objective outcomes were not likely affected by lack of blinding \\
\hline $\begin{array}{l}\text { Incomplete outcome data } \\
\text { (attrition bias) } \\
\text { All outcomes }\end{array}$ & Unclear risk & $\begin{array}{l}\text { Comment: owing to insufficient information to permit judgement, risk of attri- } \\
\text { tion bias was considered to be unclear; abstract only }\end{array}$ \\
\hline $\begin{array}{l}\text { Selective reporting (re- } \\
\text { porting bias) }\end{array}$ & Unclear risk & $\begin{array}{l}\text { Comment: owing to insufficient information to permit judgement, risk of re- } \\
\text { porting bias was considered to be unclear; abstract only }\end{array}$ \\
\hline Other bias & Low risk & $\begin{array}{l}\text { Comment: no other sources of bias could be found; therefore risk of other bias } \\
\text { was considered to be low }\end{array}$ \\
\hline
\end{tabular}

Ibrahim 2008

Study design: parallel randomised controlled trial
Setting/Country: multi-centre/Kuwait and Egypt


Ibrahim 2008 (Continued)

Dates of the study: January 2004 to December 2006
Interventions

Total number of participants randomised: 220

Group 1, stented group: 110

Group 2, unstented group: 110

Stone location: not reported

Inclusion criteria: distal ureteric stone (defined as below iliac vessels on imaging) amenable to ureteroscopic management, age over 18

Exclusion criteria: ureteral stent placed preoperatively; stone removal not completed after procedure; evidence of ureteral perforation at the end of the procedure when ureteral stenting would normally be performed; complex ureteral stones expected to require prolonged intraoperative procedures, such as stones greater than $1.5 \mathrm{~cm}$; multiple large stones; evidence of active infection; solitary kidney; suspected additional ureteral pathology (e.g. ureteral stricture)

Group 1: stented group

Group 2: unstented group

Surgical procedure: when required, ureteral dilation was done to $15 \mathrm{Fr}$ using a UroMax balloon dilator (Boston Scientific, Quincy, Massachusetts, USA). Standard ureteroscopic stone extraction was done using a dormia basket or forceps with or without intracorporeal lithotripsy. A holmium:YAG laser (Lumenis Ltd., Yokneam, Israel) or Swiss LithoClast ballistic energy (Boston Scientific) was used through a 7 Fr to $10.5 \mathrm{Fr}$ graduated semi-rigid ureteroscope (Karl Storz, Tuttlingen, Germany). The stent used in the study was $6 \mathrm{Fr}$ in diameter with appropriate length determined by the surgeon intraoperatively based on participant height

Stent type: (likely) DJ stent, 6 Fr (length determined by the surgeon)

Time to stent removal: 2 weeks

\section{Outcomes Primary outcomes}

- Flank pain and dysuria at 48 hours and at 1 week, early postoperative complications, analgesia requirement, rehospitalisation, return to normal physical activity, stone-free rate, stone recurrence, late postoperative complications

- How measured: VAS, questionnaire, urinalysis, urine culture, X-ray, renal sonography, IVP

- Time to measured: 48 hours and 1 week, 4 weeks, every 3 months in year 1 , every 6 months in year 2 , once annually

- Time to reported

Secondary outcomes: not reported

Subgroup: not reported

\begin{tabular}{ll}
\hline Funding source & Not reported \\
\hline Declarations of interest & Not reported \\
\hline
\end{tabular}

Notes Language of publication: English

\section{Risk of bias}

\begin{tabular}{lll}
\hline Bias & Authors' judgement & Support for judgement \\
\hline $\begin{array}{l}\text { Random sequence genera- } \\
\text { tion (selection bias) }\end{array}$ & Low risk & Quote: "random number list" \\
& & \\
\hline
\end{tabular}


Ibrahim 2008 (Continued)

Comment: this method of random sequence generation was considered to have low risk of bias

Allocation concealment $\quad$ Low risk
(selection bias)

Quote: "patients and surgeons were blinded to the non stented and stented (selection bias) groups until the procedure was successfully completed in the operating room"

Comment: interpreted as allocation concealment to have taken place

\begin{tabular}{|c|c|c|}
\hline $\begin{array}{l}\text { Blinding of participants } \\
\text { and personnel (perfor- } \\
\text { mance bias) }\end{array}$ & High risk & $\begin{array}{l}\text { Quote: "patients and surgeons were blinded to the non stented and stented } \\
\text { groups until the procedure was successfully completed in the operating room" }\end{array}$ \\
\hline All outcomes & & Comment: assumed to have been unblinded once stent had been placed \\
\hline
\end{tabular}

\begin{tabular}{|c|c|c|}
\hline $\begin{array}{l}\text { Blinding of outcome as- } \\
\text { sessment (detection bias) } \\
\text { Subjective outcomes } \\
\text { (post-operative discom- } \\
\text { fort, UTI, ureteral stricture, } \\
\text { QOL) }\end{array}$ & High risk & $\begin{array}{l}\text { No blinding of outcome assessments was described } \\
\text { Comment: study was unlikely to have used blinding }\end{array}$ \\
\hline
\end{tabular}

Blinding of outcome as- Low risk Comment: objective outcomes were not likely affected by lack of blinding
sessment (detection bias)

Objective outcomes (all others)

\begin{tabular}{lll}
\hline $\begin{array}{l}\text { Incomplete outcome data } \\
\text { (attrition bias) } \\
\text { All outcomes }\end{array}$ & Low risk & Comment: all participants randomised in each group were included in analysis \\
\hline $\begin{array}{l}\text { Selective reporting (re- } \\
\text { porting bias) }\end{array}$ & Unclear risk & Protocol was not available \\
& $\begin{array}{l}\text { Comment: owing to insufficient information to permit judgement, risk of re- } \\
\text { porting bias was considered to be unclear }\end{array}$ \\
\hline Other bias & Low risk & $\begin{array}{l}\text { Study appears to be free of other sources of bias } \\
\text { Comment: no other sources of bias could be found; therefore risk of other bias } \\
\text { was considered to be low }\end{array}$ \\
\hline
\end{tabular}

Isen 2008

$\begin{array}{ll}\text { Methods } & \text { Study design: parallel randomised controlled trial } \\ \text { Setting/Country: single centre/Turkey } \\ \text { Dates of the study: July } 2004 \text { to January } 2007\end{array}$

Participants

\title{
Total number of participants randomised: 43
}

\author{
Group 1, stented group: 21
}

Group 2, unstented group: 22

Stone location: not reported

Inclusion criteria: lower ureteral stone larger than $1 \mathrm{~cm}$ who underwent ureteroscopy (stone was localised below the inferior part of the sacroiliac joint) 
Isen 2008 (Continued)

Exclusion criteria: patients with a history of sepsis, renal failure, bilateral ureteral stones, solitary kidney, multiple ureteral stones, or pregnancy. Patients detected intraoperatively with severe mucosal injury, ureteral perforation, migration of large stone fragment to the kidney, and failed access

Group 1: stented group
Group 2: unstented group
Surgical procedure: $8 / 9.8 \mathrm{Fr}$ Wolf semi-rigid ureteroscope with a 5 Fr working channel was used in all
participants under general anaesthesia. The stone was fragmented with a pneumatic lithotripter (Cal-
cusplit, Karl Storz, Tuttlingen, Germany). Additional forceps application (AFA) was used to remove frag-
ments < $4 \mathrm{~mm}$. Endoscopic inspection was done at the end of the procedure to rule out any residual
calculi < $4 \mathrm{~mm}$ or trauma. In the stented group, a DJ stent (4.8 Fr) was placed through the ureteroscopic
operative channel or over a guidewire via the cystoscope
Stent type: DJ stent, $4.8 \mathrm{Fr}$ (length: NR)
Time to stent removal: 3 weeks
Primary outcomes
- Stone-free rate, stone size, operative time, additional forceps application, hospitalisation time, rehos-
pitalisation, postoperative pain, irritative voiding symptoms, haematuria, stricture formation
- How measured: pain: questionnaire specific to the study, IVP (3 months)
- Time to measured: not reported

Secondary outcomes: not reported

Subgroup: not reported

\begin{tabular}{ll}
\hline Funding source & Not reported \\
\hline Declarations of interest & Not reported \\
\hline
\end{tabular}

Notes Language of publication: English

\section{Risk of bias}

\begin{tabular}{lll}
\hline Bias & Authors' judgement & Support for judgement \\
\hline $\begin{array}{ll}\text { Random sequence genera- } \\
\text { tion (selection bias) }\end{array}$ & Unclear risk & Quote: "random" \\
& & $\begin{array}{l}\text { Comment: owing to insufficient information, risk of selection bias was consid- } \\
\text { ered to be unclear }\end{array}$
\end{tabular}

\begin{tabular}{ll}
\hline $\begin{array}{l}\text { Allocation concealment } \\
\text { (selection bias) }\end{array}$ & Unclear risk \\
& $\begin{array}{l}\text { Insufficient information to permit judgement } \\
\text { Comment: owing to insufficient information, risk of allocation concealment } \\
\text { was considered to be unclear }\end{array}$ \\
\hline
\end{tabular}

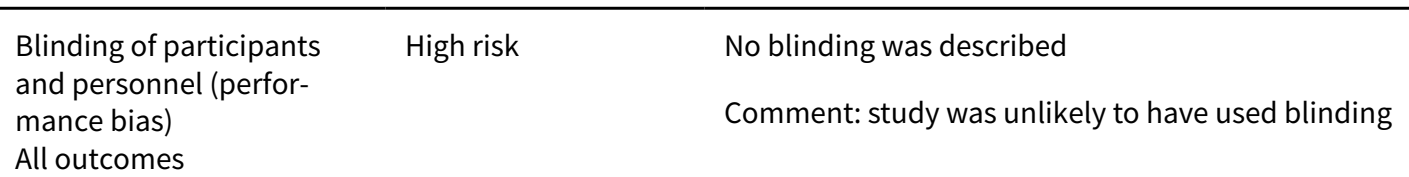

Blinding of outcome as-
sessment (detection bias)

Subjective outcomes

(post-operative discom-
High risk

No blinding of outcome assessments was described

Comment: study was unlikely to have used blinding 
Isen 2008 (Continued)

fort, UTI, ureteral stricture,

QOL)

\begin{tabular}{lll}
$\begin{array}{l}\text { Blinding of outcome as- } \\
\text { sessment (detection bias) } \\
\text { Objective outcomes (all } \\
\text { others) }\end{array}$ & Low risk & Comment: objective outcomes were not likely affected by lack of blinding \\
\hline $\begin{array}{l}\text { Incomplete outcome data } \\
\text { (attrition bias) } \\
\text { All outcomes }\end{array}$ & Low risk & Comment: all participants randomised in each group were included in analysis \\
\hline $\begin{array}{l}\text { Selective reporting (re- } \\
\text { porting bias) }\end{array}$ & Unclear risk & Protocol was not available \\
& $\begin{array}{l}\text { Comment: owing to insufficient information to permit judgement, risk of re- } \\
\text { porting bias was considered to be unclear }\end{array}$ \\
\hline Other bias & Low risk & $\begin{array}{l}\text { Study appears to be free of other sources of bias } \\
\text { Comment: no other sources of bias could be found; therefore risk of other bias } \\
\text { was considered to be low }\end{array}$
\end{tabular}

Jeong 2004

Methods Study design: parallel randomised controlled trial

Setting/Country: single centre/South Korea

Dates of the study: April 2000 to January 2001

Participants

Total number of participants randomised: 45

Group 1, stented group: 23

Group 2, unstented group: 22

Stone location: proximal, mid, distal

Inclusion criteria: patients with ureteric calculi treated by ureteroscopic lithotripsy

Exclusion criteria: previous surgical management (e.g. ESWL, urinary stenting/diversion)

Interventions

Group 1: stented group

Group 2: unstented group

Surgical procedure: treatment was delivered under spinal anaesthesia or intravenous sedation. An 8.5 Fr rigid ureteroscope with a $5 \mathrm{Fr}$ working channel was used, and stones were removed with stone forceps or basket. Large stones that could not be removed were disintegrated with an electromechanical lithotripter

Stent type: DJ stent, 7 Fr (length: NR)

Time to stent removal: 7 days

\section{Outcomes}

\section{Primary outcomes}

- Pain and urinary symptoms

- Pain: absent (score 1), mild (symptoms within 0 to 3 days of operation, bearable with no medication; score 2), moderate (symptoms persisting for 3 to 7 days, painful enough for medication; score 3), and severe (symptoms for 7 days, requiring the use of analgesic; score 4) 
Jeong 2004 (Continued)

- Time to measured: not reported

- Time to reported: not reported

Secondary outcomes: not reported

Subgroup: not reported

\begin{tabular}{ll}
\hline Funding source & Not reported \\
\hline Declarations of interest & Not reported \\
\hline Notes & Language of publication: English
\end{tabular}

\section{Risk of bias}

\begin{tabular}{|c|c|c|}
\hline Bias & Authors' judgement & Support for judgement \\
\hline $\begin{array}{l}\text { Random sequence genera- } \\
\text { tion (selection bias) }\end{array}$ & Unclear risk & $\begin{array}{l}\text { Quote: "random" } \\
\text { Comment: owing to insufficient information, risk of selection bias was consid- } \\
\text { ered to be unclear }\end{array}$ \\
\hline $\begin{array}{l}\text { Allocation concealment } \\
\text { (selection bias) }\end{array}$ & Unclear risk & $\begin{array}{l}\text { Insufficient information to permit judgement } \\
\text { Comment: owing to insufficient information, risk of allocation concealment } \\
\text { was considered to be unclear }\end{array}$ \\
\hline $\begin{array}{l}\text { Blinding of participants } \\
\text { and personnel (perfor- } \\
\text { mance bias) } \\
\text { All outcomes }\end{array}$ & High risk & $\begin{array}{l}\text { No blinding was described } \\
\text { Comment: study was unlikely to have used blinding }\end{array}$ \\
\hline $\begin{array}{l}\text { Blinding of outcome as- } \\
\text { sessment (detection bias) } \\
\text { Subjective outcomes } \\
\text { (post-operative discom- } \\
\text { fort, UTI, ureteral stricture, } \\
\text { QOL) }\end{array}$ & High risk & $\begin{array}{l}\text { No blinding of outcome assessments was described } \\
\text { Comment: study was unlikely to have used blinding }\end{array}$ \\
\hline $\begin{array}{l}\text { Blinding of outcome as- } \\
\text { sessment (detection bias) } \\
\text { Objective outcomes (all } \\
\text { others) }\end{array}$ & Low risk & Comment: objective outcomes were not likely affected by lack of blinding \\
\hline $\begin{array}{l}\text { Incomplete outcome data } \\
\text { (attrition bias) } \\
\text { All outcomes }\end{array}$ & Low risk & Comment: all participants randomised in each group were included in analysis \\
\hline $\begin{array}{l}\text { Selective reporting (re- } \\
\text { porting bias) }\end{array}$ & Unclear risk & $\begin{array}{l}\text { Protocol was not available } \\
\text { Comment: owing to insufficient information to permit judgement, risk of re- } \\
\text { porting bias was considered to be unclear }\end{array}$ \\
\hline Other bias & Low risk & $\begin{array}{l}\text { Study appears to be free of other sources of bias } \\
\text { Comment: no other sources of bias could be found; therefore risk of other bias } \\
\text { was considered to be low }\end{array}$ \\
\hline
\end{tabular}


Netto 2001

\begin{tabular}{|c|c|}
\hline Methods & $\begin{array}{l}\text { Study design: parallel randomised controlled trial } \\
\text { Setting/Country: single centre/Brazil } \\
\text { Dates of the study: February } 1997 \text { to June } 2000\end{array}$ \\
\hline Participants & $\begin{array}{l}\text { Total number of participants randomised: } 295 \\
\text { Group 1, stented group: } 133 \\
\text { Group 2, unstented group: } 162 \\
\text { Stone location: proximal, mid, distal } \\
\text { Inclusion criteria: patients underwent rigid ureteroscopy for ureteral calculi } \\
\text { Exclusion criteria: not reported }\end{array}$ \\
\hline Interventions & $\begin{array}{l}\text { Group 1: stented group } \\
\text { Group 2: unstented group } \\
\text { Surgical procedure: all procedures were done using intravenous sedation and epidural anaesthesia } \\
\text { with patients in the dorsal lithotomy position on a fluoroscopy table. Ureteroscopy was done with a } 7.5 \\
\text { Fr rigid ureteroscope. No participants required dilation of the ureteral orifice or intramural ureter. Ret- } \\
\text { rograde pyelography was performed in select cases when ureteroscope progression was difficult. Large } \\
\text { calculi were fragmented with ultrasonic lithotrites and smaller calculi were extracted with helical or flat } \\
\text { wire baskets. Endoscopic inspection was done at the end of the procedure to rule out any residual cal- } \\
\text { culi or trauma }\end{array}$ \\
\hline
\end{tabular}

Stent type: not reported

Time to stent removal: not reported

Primary outcomes
Outcomes
- Stone-free rate (visual or radiographic assessment), operative time, postoperative pain, complica-
- How measured: analgesic use, modified International Prostate Symptom Score, X-ray, renal ultra-
sonography
- Time to measured: immediate postoperative period, 2 to 3 months
- Time to reported: not reported

Secondary outcomes: not reported

Subgroup: not reported

\begin{tabular}{lll}
\hline Funding source & Not reported \\
\hline Declarations of interest & Not reported & \\
\hline Notes & Language of publication: English \\
\hline Risk of bias & & \\
\hline Bias & Authors' judgement & Support for judgement \\
\hline $\begin{array}{l}\text { Random sequence genera- } \\
\text { tion (selection bias) }\end{array}$ & Unclear risk & $\begin{array}{l}\text { Quote: "random" } \\
\text { Comment: owing to insufficient information, risk of selection bias was consid- } \\
\end{array}$ \\
\hline
\end{tabular}


Netto 2001 (Continued)

$\begin{array}{ll}\begin{array}{l}\text { Allocation concealment } \\ \text { (selection bias) }\end{array} & \text { Insufficient information to permit judgement } \\ & \begin{array}{l}\text { Comment: owing to insufficient information, risk of allocation concealment } \\ \text { was considered to be unclear }\end{array}\end{array}$

\begin{tabular}{|c|c|c|}
\hline $\begin{array}{l}\text { Blinding of participants } \\
\text { and personnel (perfor- } \\
\text { mance bias) } \\
\text { All outcomes }\end{array}$ & High risk & $\begin{array}{l}\text { Quote: "a stent with a suture was placed only in } 30 \text { female patients" } \\
\text { Comment: participants were not blinded, and risk of performance bias was } \\
\text { considered to be high }\end{array}$ \\
\hline
\end{tabular}

Quote: "a stent with a suture was placed only in 30 female patients"

Blinding of outcome as- High risk sessment (detection bias)

Subjective outcomes (post-operative discom-

Comment: outcome assessor may be unblinded; therefore risk of detection fort, UTI, ureteral stricture, $\mathrm{QOL})$

\begin{tabular}{lll}
\hline $\begin{array}{l}\text { Blinding of outcome as- } \\
\text { sessment (detection bias) } \\
\begin{array}{l}\text { Objective outcomes (all } \\
\text { others) }\end{array}\end{array}$ & Low risk & \\
\hline $\begin{array}{l}\text { Incomplete outcome data } \\
\text { (attrition bias) } \\
\text { All outcomes }\end{array}$ & Low risk & Comment: all participants randomised in each group were included in analysis \\
\hline $\begin{array}{l}\text { Selective reporting (re- } \\
\text { porting bias) }\end{array}$ & Unclear risk & Protocol was not available \\
& $\begin{array}{l}\text { Comment: owing to insufficient information to permit judgement, risk of re- } \\
\text { porting bias was considered to be unclear }\end{array}$ \\
\hline $\begin{array}{l}\text { Other bias } \\
\text { High risk }\end{array}$ & $\begin{array}{l}\text { Comment: baseline imbalance in age; therefore risk of other bias was consid- } \\
\text { ered to be high }\end{array}$ \\
\hline
\end{tabular}

Shao 2008

$\begin{array}{ll}\text { Methods } & \text { Study design: parallel randomised controlled trial } \\ \text { Setting/Country: single centre/China } \\ \text { Dates of the study: June } 2005 \text { to March } 2006\end{array}$

Participants

\section{Total number of participants randomised: 115}

\section{Group 1, stented group: 58}

Group 2, unstented group: 57

Stone location: distal, mid

Inclusion criteria: patients with distal or middle ureteral calculi smaller than $2 \mathrm{~cm}$ undergoing ureteroscopy with holmium laser lithotripsy

Exclusion criteria: stone size larger than $2 \mathrm{~cm}$, previous failure in performance of ureteroscopy for treatment of the same stone, a history of sepsis, renal failure, solitary kidney, pregnancy, suspicion of urothelial cancer, preoperative ureteral stenting, stricture in the ureter and mucosal perforation during operation 
Shao 2008 (Continued)

\section{Group 2: unstented group}

Surgical procedure: all procedures were done using epidural anaesthesia. Ureteroscopy was done with an $8 \mathrm{Fr} / 9.8 \mathrm{Fr}$ Wolf semi-rigid ureteroscope. The ureteroscope was introduced without dilation of the ureteral orifice. Stones were fragmented with the holmium laser in all participants. Holmium laser pulse energy of 1.0 to $1.2 \mathrm{~J}$ and pulse frequency of $10 \mathrm{to} 12 \mathrm{~Hz}$ were used for laser lithotripsy. Stones in the ureters were completely fragmented to particles smaller than $2 \mathrm{~mm}$, and no attempt was made to remove stone fragments with graspers; instead stone fragments were left in situ for spontaneous passage

Stent type: DJ stent, $4.8 \mathrm{Fr}(26 \mathrm{~cm})$

Time to stent removal: 2 weeks

Primary outcomes
- Operative time, postoperative patient symptoms, stone-free status, early and late postoperative com-
plications, quality of life, cost-effectiveness
- How measured: ureteric stent symptoms questionnaires, urinalysis, plain X-ray, postoperative renal
ultrasound, incidence of stent migration, IVP
- Time to be measured: 2 weeks postoperatively, 12 weeks for ureteral stricture
- Time to reported: not reported

Secondary outcomes: not reported

Subgroup: not reported

\begin{tabular}{ll}
\hline Funding source & Not reported \\
\hline Declarations of interest & Not reported \\
\hline Notes & Language of publication: English
\end{tabular}

\section{Risk of bias}

\begin{tabular}{lll}
\hline Bias & Authors' judgement & Support for judgement \\
\hline $\begin{array}{ll}\text { Random sequence genera- } \\
\text { tion (selection bias) }\end{array}$ & Unclear risk & Quote: "random" \\
& & $\begin{array}{l}\text { Comment: owing to insufficient information, risk of selection bias was consid- } \\
\text { ered to be unclear }\end{array}$
\end{tabular}

\begin{tabular}{ll}
\hline $\begin{array}{l}\text { Allocation concealment } \\
\text { (selection bias) }\end{array}$ & Unclear risk \\
& $\begin{array}{l}\text { Insufficient information to permit judgement } \\
\text { Commet: owing to insufficient information, risk of allocation concealment } \\
\text { was considered to be unclear }\end{array}$ \\
\hline
\end{tabular}

\begin{tabular}{|c|c|c|}
\hline $\begin{array}{l}\text { Blinding of participants } \\
\text { and personnel (perfor- } \\
\text { mance bias) } \\
\text { All outcomes }\end{array}$ & High risk & $\begin{array}{l}\text { No blinding was described } \\
\text { Comment: study was unlikely to have used blinding }\end{array}$ \\
\hline
\end{tabular}

\begin{tabular}{|c|c|c|}
\hline $\begin{array}{l}\text { Blinding of outcome as- } \\
\text { sessment (detection bias) } \\
\text { Subjective outcomes } \\
\text { (post-operative discom- } \\
\text { fort, UTI, ureteral stricture, } \\
\text { QOL) }\end{array}$ & High risk & $\begin{array}{l}\text { No blinding was described } \\
\text { Comment: study was unlikely to have used blinding }\end{array}$ \\
\hline
\end{tabular}


Shao 2008 (Continued)

Blinding of outcome as- Low risk Comment: objective outcomes were not likely affected by lack of blinding sessment (detection bias)

Objective outcomes (all others)

\begin{tabular}{lll}
\hline $\begin{array}{l}\text { Incomplete outcome data } \\
\text { (attrition bias) } \\
\text { All outcomes }\end{array}$ & Low risk & Comment: all participants randomised in each group were included in analysis \\
\hline $\begin{array}{l}\text { Selective reporting (re- } \\
\text { porting bias) }\end{array}$ & Unclear risk & Protocol was not available \\
& Low risk & $\begin{array}{l}\text { Comment: owing to insufficient information to permit judgement, risk of re- } \\
\text { porting bias was considered to be unclear }\end{array}$ \\
\hline Other bias & $\begin{array}{l}\text { Study appears to be free of other sources of bias } \\
\text { Comment: no other sources of bias could be found; therefore risk of other bias } \\
\text { was considered to be low }\end{array}$ \\
\hline
\end{tabular}

Sirithanaphol 2017

Study design: parallel randomised controlled trial
Setting/Country: single centre/Thailand
Dates of the study: April 2014 to December 2014

Participants Total number of participants randomised: 38

Group 1, stented group: 19

Group 2, unstented group: 19

Stone location: proximal, renal

Inclusion criteria: 18 years or older, patients undergoing flexible ureteroscopy with ureteral access sheath placement

Exclusion criteria: patients who had indications for postoperative ureteral stent or patients who required pre-stent were excluded

Interventions

Group 1: stented group

Group 2: unstented group

Surgical procedure: the procedure was performed under general anaesthesia. Ureteral access sheath (12/14 Fr) was utilised. Access sheath length was $35 \mathrm{~cm}$ for women and $45 \mathrm{~cm}$ for men. Holmium:YAG laser was used for laser lithotripsy. Stone fragments were removed with a stone basket. The fragments smaller than $2 \mathrm{~mm}$ were left in situ to pass spontaneously. At the end of the procedure, ureter was visualised to evaluate degree of ureteric injury

Stent type: (likely) DJ stent, NR Fr (length: NR)

Time to stent removal: 2 weeks

Outcomes Primary outcomes

- Operative time, pain score, unplanned hospital visit, irritative voiding symptom, analgesic usage, perioperative complications, duration of indwelled urethral catheter, length of hospital stay 
- How measured: visual analogue scale, irritative domains of International Prostate Symptom Score, record of events

- Time to measured: not reported

- Time to reported: not reported

Secondary outcomes: not reported

Subgroup: not reported

\begin{tabular}{ll}
\hline Funding source & Not reported \\
\hline Declarations of interest & Not reported \\
\hline
\end{tabular}

Notes Language of publication: English

\section{Risk of bias}

\begin{tabular}{|c|c|c|}
\hline Bias & Authors' judgement & Support for judgement \\
\hline $\begin{array}{l}\text { Random sequence genera- } \\
\text { tion (selection bias) }\end{array}$ & Low risk & $\begin{array}{l}\text { Comment: study investigator provided random sequence generation method: } \\
\text { "block randomization by nQuery Advisor version 6.0.1" }\end{array}$ \\
\hline $\begin{array}{l}\text { Allocation concealment } \\
\text { (selection bias) }\end{array}$ & High risk & Commnet: study investigator provided "no allocation concealment" \\
\hline $\begin{array}{l}\text { Blinding of participants } \\
\text { and personnel (perfor- } \\
\text { mance bias) } \\
\text { All outcomes }\end{array}$ & High risk & Comment: study investigator provided "participants were not blinded" \\
\hline $\begin{array}{l}\text { Blinding of outcome as- } \\
\text { sessment (detection bias) } \\
\text { Subjective outcomes } \\
\text { (post-operative discom- } \\
\text { fort, UTI, ureteral stricture, } \\
\text { QOL) }\end{array}$ & High risk & $\begin{array}{l}\text { Comment: study investigator provided "Surgeons were unblinded after proce- } \\
\text { dure" }\end{array}$ \\
\hline $\begin{array}{l}\text { Blinding of outcome as- } \\
\text { sessment (detection bias) } \\
\text { Objective outcomes (all } \\
\text { others) }\end{array}$ & Low risk & Comment: objective outcomes were not likely affected by lack of blinding \\
\hline $\begin{array}{l}\text { Incomplete outcome data } \\
\text { (attrition bias) } \\
\text { All outcomes }\end{array}$ & Low risk & Comment: all participants randomised in each group were included in analysis \\
\hline $\begin{array}{l}\text { Selective reporting (re- } \\
\text { porting bias) }\end{array}$ & Unclear risk & $\begin{array}{l}\text { Protocol was not available } \\
\text { Comment: owing to insufficient information to permit judgement, risk of re- } \\
\text { porting bias was considered to be unclear }\end{array}$ \\
\hline Other bias & Low risk & $\begin{array}{l}\text { Study appears to be free of other sources of bias } \\
\text { Comment: no other sources of bias could be found; therefore risk of other bias } \\
\text { was considered to be low }\end{array}$ \\
\hline
\end{tabular}


Srivastava 2003

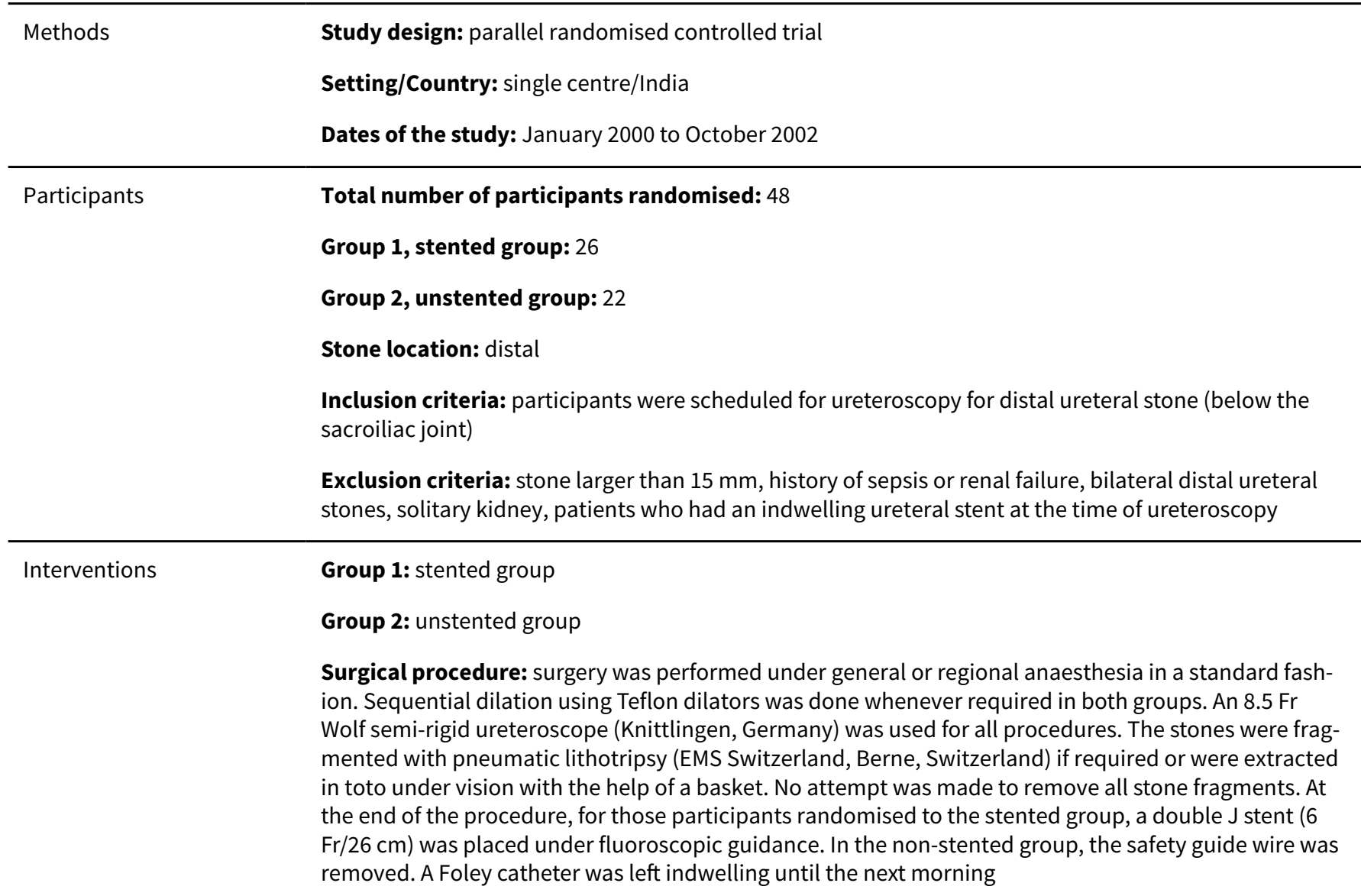

Stent type: DJ stent, $6 \mathrm{Fr}(26 \mathrm{~cm})$

Time to stent removal: 3 weeks

Primary outcomes
- Stone-free rate, pain, stent-related symptoms (suprapubic or flank pain with voiding), urgency, dy-
suria, fever, need for analgesics, any postoperative complications
- How measured: visual analogue scale, KUB, urine culture, IVP
- Time to measured: postoperative 1 day, 3 weeks, 3 months
- Time to reported: not reported

Secondary outcomes: not reported

Subgroup: not reported

\begin{tabular}{|c|c|c|}
\hline Funding source & \multicolumn{2}{|l|}{ Not reported } \\
\hline Declarations of interest & \multicolumn{2}{|l|}{ Not reported } \\
\hline Notes & \multicolumn{2}{|c|}{ Language of publication: English } \\
\hline \multicolumn{3}{|l|}{ Risk of bias } \\
\hline Bias & Authors' judgement & Support for judgement \\
\hline $\begin{array}{l}\text { Random sequence genera- } \\
\text { tion (selection bias) }\end{array}$ & Low risk & Quote: "random number table" \\
\hline
\end{tabular}




\begin{tabular}{ll}
\hline $\begin{array}{l}\text { Allocation concealment } \\
\text { (selection bias) }\end{array}$ & Unclear risk \\
& $\begin{array}{l}\text { Insufficient information to permit judgement } \\
\text { Comment: owing to insufficient information, risk of allocation concealment } \\
\text { was considered to be unclear }\end{array}$ \\
\hline
\end{tabular}

\begin{tabular}{|c|c|c|}
\hline $\begin{array}{l}\text { Blinding of participants } \\
\text { and personnel (perfor- } \\
\text { mance bias) }\end{array}$ & High risk & $\begin{array}{l}\text { No blinding was described } \\
\text { Comment: study was unlikely to have used blinding }\end{array}$ \\
\hline
\end{tabular}

All outcomes

\begin{tabular}{lll}
\hline Blinding of outcome as- & High risk & No blinding was described \\
sessment (detection bias) & & Comment: study was unlikely to have used blinding \\
Subjective outcomes & & Com
\end{tabular}

(post-operative discom-

fort, UTI, ureteral stricture, $\mathrm{QOL})$

\begin{tabular}{|c|c|c|}
\hline $\begin{array}{l}\text { Blinding of outcome as- } \\
\text { sessment (detection bias) } \\
\text { Objective outcomes (all } \\
\text { others) }\end{array}$ & Low risk & Comment: objective outcomes were not likely affected by lack of blinding \\
\hline $\begin{array}{l}\text { Incomplete outcome data } \\
\text { (attrition bias) } \\
\text { All outcomes }\end{array}$ & Unclear risk & $\begin{array}{l}\text { Comment: } 80.76 \% \text { in the stented group and } 86.36 \% \text { in the non-stented group } \\
\text { were followed at } 3 \text { months, owing to the moderate number of participants lost } \\
\text { to follow-up (> } 10 \%) \text {; risk of attrition bias was considered to be unclear }\end{array}$ \\
\hline $\begin{array}{l}\text { Selective reporting (re- } \\
\text { porting bias) }\end{array}$ & Unclear risk & $\begin{array}{l}\text { Protocol was not available } \\
\text { Comment: owing to insufficient information to permit judgement, risk of re- } \\
\text { porting bias was considered to be unclear }\end{array}$ \\
\hline Other bias & Low risk & $\begin{array}{l}\text { Study appears to be free of other sources of bias } \\
\text { Comment: no other sources of bias could be found; therefore risk of other bias } \\
\text { was considered to be low }\end{array}$ \\
\hline
\end{tabular}

Wang 2009

Study design: parallel randomised controlled trial
Setting/Country: single centre/Taiwan
Dates of the study: January 2004 to December 2007

Participants

Total number of participants randomised: 228

Group 1, stented group: 71

Group 2, unstented group: 67

Group 3, uncomplicated, unstented: 90

Stone location: proximal, mid, distal

Inclusion criteria: adult patients were included if they were scheduled for ureteroscopy for ureteral stones; Groups 1 and 2 were deemed complicated based on appearance of ureter postop, defined as 
Wang 2009 (Continued)

marked oedema or polypoid formation. Uncomplicated control group defined as smooth mucosa, with no oedema or polyp formation postop

Exclusion criteria: patients were excluded from the study if stone diameter was greater than $15 \mathrm{~mm}$, there was a history of sepsis or renal failure, there were bilateral ureteral stones, or the patient had a solitary kidney

Group 1: stented group
Group 2: unstented group
Group 3: control group
Surgical procedure: A 7.0 Fr Wolf semi-rigid ureteroscope (Knittlingen, Germany) was used for all pro-
cedures without ureteral dilation, under direct vision and intravenous general anaesthesia. The stones
were fragmented with pneumatic lithotripsy (EMS Switzerland, Berne, Switzerland), if required or ex-
tracted under vision with the help of a basket

Stent type: DJ stent, 7 Fr (length used by body height)

Time to stent removal: 1 week

Primary outcomes
- Pain, stent-related symptoms, fever, need for analgesics, any postoperative complications
- How measured: visual analogue scale, International Prostate Symptom Scale, X-ray
- Time to measured: first postoperative day, 6 weeks, and 12 weeks
- Time to reported: not reported

Secondary outcomes: not reported

Subgroup: not reported

\begin{tabular}{ll}
\hline Funding source & Not reported \\
\hline Declarations of interest & Not reported \\
\hline Notes & Language of publication: English \\
\hline
\end{tabular}

\section{Risk of bias}

\begin{tabular}{lll}
\hline Bias & Authors' judgement & Support for judgement \\
\hline $\begin{array}{l}\text { Random sequence genera- } \\
\text { tion (selection bias) }\end{array}$ & Low risk & Quote: "random number table" \\
& & $\begin{array}{l}\text { Comment: this method of random sequence generation was considered to } \\
\text { have low risk of bias }\end{array}$
\end{tabular}

\begin{tabular}{ll}
\hline $\begin{array}{l}\text { Allocation concealment } \\
\text { (selection bias) }\end{array}$ & Unclear risk \\
& $\begin{array}{l}\text { Insufficient information to permit judgement } \\
\text { Comment: owing to insufficient information, risk of allocation concealment } \\
\text { was considered to be unclear }\end{array}$ \\
\hline
\end{tabular}

\begin{tabular}{|c|c|c|}
\hline $\begin{array}{l}\text { Blinding of participants } \\
\text { and personnel (perfor- } \\
\text { mance bias) } \\
\text { All outcomes }\end{array}$ & Unclear risk & $\begin{array}{l}\text { Comment: nothing to indicate that patients or personnel were blinded, but in- } \\
\text { vestigators claim blinding took place }\end{array}$ \\
\hline
\end{tabular}

\begin{tabular}{|c|c|c|}
\hline $\begin{array}{l}\text { Blinding of outcome as- } \\
\text { sessment (detection bias) }\end{array}$ & Unclear risk & $\begin{array}{l}\text { Comment: nothing to indicate that outcome assessors were blinded, but in- } \\
\text { vestigators claim blinding took place }\end{array}$ \\
\hline
\end{tabular}


Wang 2009 (Continued)

Subjective outcomes

(post-operative discom-

fort, UTI, ureteral stricture,

$\mathrm{QOL})$

Blinding of outcome as- Low risk $\quad$ Comment: objective outcomes were not likely affected by lack of blinding
sessment (detection bias)

ment (detection bias)

Objective outcomes (all

others)

Incomplete outcome data Low risk Comment: all participants randomised in each group were included in analysis
(attrition bias)
All outcomes

\begin{tabular}{lll}
\hline $\begin{array}{l}\text { Selective reporting (re- } \\
\text { porting bias) }\end{array}$ & Unclear risk & $\begin{array}{l}\text { Protocol was not available } \\
\text { Comment: owing to insufficient information to permit judgement, risk of re- } \\
\text { porting bias was considered to be unclear }\end{array}$ \\
\hline Other bias & Low risk & $\begin{array}{l}\text { Study appears to be free of other sources of bias } \\
\text { Comment: no other sources of bias could be found; therefore risk of other bias } \\
\text { was considered to be low }\end{array}$ \\
\hline
\end{tabular}

Xu 2009

$\begin{array}{ll}\text { Methods } & \text { Study design: parallel randomised controlled trial } \\ \text { Setting/Country: single centre/China } \\ \text { Dates of the study: May } 2005 \text { to May } 2006\end{array}$

Participants

\section{Total number of participants randomised: 110}

Group 1, stented group: 55

Group 2, unstented group: 55

Stone location: distal, mid

Inclusion criteria: adults, 18 years or older, were considered eligible for the study if they were scheduled for ureteroscopy for distal and middle ureteral calculi

Exclusion criteria: stone size larger than $2 \mathrm{~cm}$; history of sepsis, renal failure, solitary kidney, multiple ureteral stones, pregnancy, or previous ureteroscopic lithotripsy in the same position; patients with intraoperatively detected severe mucosal injury and/or ureteral perforation

Group 2: unstented group

Surgical procedure: a $7 \mathrm{Fr}$ Wolf semi-rigid ureteroscope (Yong Xu, Chengdu, China) was used in all patients under general anaesthesia. Laser lithotripsy was delivered using a pulsed 100-watt holmium laser. A 365- $\mu \mathrm{m}$ laser fibre was used. The laser energy was generally applied at a setting of 1.0 to 1.2 Joules, and pulse frequency was used at a setting of 10 to $12 \mathrm{Hertz}$. All stones were completely fragmented to particles smaller than $2 \mathrm{~mm}$. Instead, stone fragments were left in situ, allowing spontaneous passage. If the stone cannot be fragmented to bits smaller than $2 \mathrm{~mm}$, additional forceps application should be used to remove the remaining fragments. In the stented group, a double J stent (4.8 $\mathrm{Fr} / 26 \mathrm{~cm}$ ) was used

Stent type: DJ stent, $4.8 \mathrm{Fr}(26 \mathrm{~cm})$ 
Time to stent removal: 3 weeks

\section{Outcomes Primary outcomes}

- Operative time, pain score, postoperative analgesic requirements, complications, stone-free rate

- How measured: symptom and event questionnaire; complications were measured by the questionnaire; urinalysis; plain X-ray of the kidney, ureters, and bladder (KUB); renal ultrasound; stone-free status was determined by KUB, IVP, for ureteral stricture

- Time to measured: postoperative 48 hours, 1 week, 4 weeks, 3 months

- Time to reported: not reported

Secondary outcomes: not reported

Subgroup: not reported

\begin{tabular}{ll}
\hline Funding source & Not reported \\
\hline Declarations of interest & Not reported \\
\hline Notes & Language of publication: English
\end{tabular}

\section{Risk of bias}

\begin{tabular}{lll}
\hline Bias & Authors' judgement & Support for judgement \\
\hline $\begin{array}{ll}\text { Random sequence genera- } \\
\text { tion (selection bias) }\end{array}$ & Unclear risk & Quote: "random" \\
& & $\begin{array}{l}\text { Comment: owing to insufficient information, risk of selection bias was consid- } \\
\text { ered to be unclear }\end{array}$ \\
\hline
\end{tabular}

\begin{tabular}{ll}
$\begin{array}{l}\text { Allocation concealment } \\
\text { (selection bias) }\end{array}$ & Unclear risk \\
& $\begin{array}{l}\text { Insufficient information to permit judgement } \\
\text { Comment: owing to insufficient information, risk of allocation concealment } \\
\text { was considered to be unclear }\end{array}$ \\
\hline
\end{tabular}

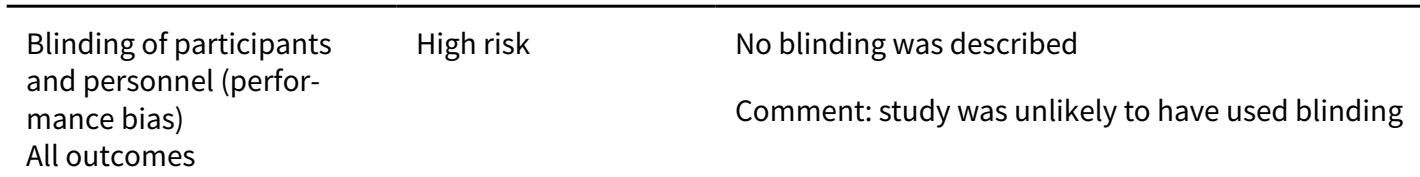

Blinding of outcome assessment (detection bias)

Subjective outcomes (post-operative discomfort, UTI, ureteral stricture, $\mathrm{QOL})$

\section{High risk}

No blinding of outcome assessments was described

Comment: study was unlikely to have used blinding

Blinding of outcome as- Low risk Comment: objective outcomes were not likely affected by lack of blinding
sessment (detection bias)
Objective outcomes (all
others)

Incomplete outcome data Low risk Comment: all participants randomised in each group were included in analysis
(attrition bias)
All outcomes

\begin{tabular}{ll}
\hline $\begin{array}{l}\text { Selective reporting (re- } \\
\text { porting bias) }\end{array}$ & Unclear risk $\quad$ Protocol was not available
\end{tabular}


Xu 2009 (Continued)

Comment: owing to insufficient information to permit judgement, risk of reporting bias was considered to be unclear

\begin{tabular}{|c|c|c|}
\hline Other bias & Low risk & $\begin{array}{l}\text { Study appears to be free of other sources of bias } \\
\text { Comment: no other sources of bias could be found; therefore risk of other bias } \\
\text { was considered to be low }\end{array}$ \\
\hline
\end{tabular}

Yari 2010

\begin{tabular}{ll}
\hline Study design: parallel randomised controlled trial \\
Setting/Country: single centre//ran \\
Dates of the study: September 2006 to February 2007 \\
\hline
\end{tabular}

Participants

Total number of participants randomised: 80

Group 1, stented group: 44

Group 2, unstented group: 36

Stone location: not reported

Inclusion criteria: distal ureteral calculi amenable to ureteroscopic stone removal

Exclusion criteria: not reported

\begin{tabular}{|c|c|}
\hline Interventions & $\begin{array}{l}\text { Group 1: stented group } \\
\text { Group 2: unstented group } \\
\text { Surgical procedure: not reported } \\
\text { Stent type: not reported } \\
\text { Time to stent removal: not reported }\end{array}$ \\
\hline Outcomes & $\begin{array}{l}\text { Primary outcomes } \\
\text { - Urinary and gastrointestinal symptoms, postoperative pain score, analgesic requirement, time of } \\
\text { anaesthesia } \\
\text { - How measured: not reported } \\
\text { - Time to measured: not reported } \\
\text { - Time to reported: not reported } \\
\text { Secondary outcomes: not reported } \\
\text { Subgroup: not reported }\end{array}$ \\
\hline Funding source & Not reported \\
\hline Declarations of interest & Not reported \\
\hline Notes & $\begin{array}{l}\text { Abstract only } \\
\text { Language of publication: English }\end{array}$ \\
\hline
\end{tabular}

\section{Risk of bias}


Yari 2010 (Continued)

\begin{tabular}{lll} 
Bias & Authors' judgement & Support for judgement \\
\hline $\begin{array}{ll}\text { Random sequence genera- } \\
\text { tion (selection bias) }\end{array}$ & Unclear risk & $\begin{array}{l}\text { Quote: "randomized" } \\
\text { Comment: owing to insufficient information, risk of selection bias was consid- } \\
\text { ered to be unclear }\end{array}$ \\
\hline
\end{tabular}

\begin{tabular}{lll}
\hline $\begin{array}{l}\text { Allocation concealment } \\
\text { (selection bias) }\end{array}$ & Unclear risk & $\begin{array}{l}\text { Comment: owing to insufficient information, risk of allocation concealment } \\
\text { was considered to be unclear; abstract only }\end{array}$ \\
\hline $\begin{array}{l}\text { Blinding of participants } \\
\text { and personnel (perfor- } \\
\text { mance bias) }\end{array}$ & Unclear risk & $\begin{array}{l}\text { Comment: owing to insufficient information, risk of performance bias was con- } \\
\text { sidered to be unclear; abstract only }\end{array}$ \\
All outcomes & \\
\hline
\end{tabular}

\begin{tabular}{|c|c|c|}
\hline $\begin{array}{l}\text { Blinding of outcome as- } \\
\text { sessment (detection bias) } \\
\text { Subjective outcomes } \\
\text { (post-operative discom- } \\
\text { fort, UTI, ureteral stricture, } \\
\text { QOL) }\end{array}$ & Unclear risk & $\begin{array}{l}\text { Comment: owing to insufficient information, risk of detection bias was consid- } \\
\text { ered to be unclear; abstract only }\end{array}$ \\
\hline
\end{tabular}

Blinding of outcome as- Low risk Comment: objective outcomes were not likely affected by lack of blinding
sessment (detection bias)

Objective outcomes (all others)

\begin{tabular}{lll}
\hline $\begin{array}{l}\text { Incomplete outcome data } \\
\text { (attrition bias) } \\
\text { All outcomes }\end{array}$ & Unclear risk & $\begin{array}{l}\text { Comment: owing to insufficient information to permit judgement, risk of attri- } \\
\text { tion bias was considered to be unclear; abstract only }\end{array}$ \\
\hline $\begin{array}{l}\text { Selective reporting (re- } \\
\text { porting bias) }\end{array}$ & Unclear risk & $\begin{array}{l}\text { Comment: owing to insufficient information to permit judgement, risk of re- } \\
\text { porting bias was considered to be unclear; abstract only }\end{array}$ \\
\hline Other bias & Low risk & $\begin{array}{l}\text { Comment: no other sources of bias could be found; therefore risk of other bias } \\
\text { was considered to be low }\end{array}$ \\
\hline
\end{tabular}

\section{Zaki 2011}

Study design: parallel randomised controlled trial
Setting/Country: single centre/Pakistan
Dates of the study: March 2008 to March 2010

Participants Total number of participants randomised: 198

Group 1, stented group: 99

Group 2: unstented group: 99

Stone location: not reported

Inclusion criteria: patients underwent uncomplicated ureteroscopic stone disintegration in ureteric stones irrespective of size and site 
Zaki 2011 (Continued)

Exclusion criteria: patients having bilateral ureteric stones, renal failure, solitary kidney, previous failed ureteroscopy, or pregnancy were excluded from our study. Patients who had significant mucosal injury or ureteral perforation intraoperatively were also excluded

Group 1: stented group
Group 2: unstented group
Surgical procedure: intracorporeal lithotripsy was done with $8.9 \mathrm{Fr}$ rigid ureteroscopy, and stone frag-
mentation was done with Swiss lithoclast under general anaesthesia. Stones were fragmented with
pneumatic lithotripsy during the procedure. At the end of the procedure, participants were randomised
into 2 groups. In the stented group, a DJ stent $6 \mathrm{Fr}, 25 \mathrm{~cm}$ was placed under fluoroscopic guidance
through ureteroscopic operative channel or via cystoscopy. All participants received prophylactic in-
travenous third-generation cephalosporin at the time of induction, and continued 5 days on an oral
quinolone

Stent type: DJ stent, $6 \operatorname{Fr}(25 \mathrm{~cm})$

Time to stent removal: 2 weeks

Primary outcomes
- Postoperative pain, irritative urinary symptoms, haematuria, number of visits to emergency room,
late complications, stone-free status
- How measured: stone-free rate: X-ray, IVP for ureteral stricture
- Time to measured: stone-free rate: 2 weeks, ureteral stricture: 3 months

Secondary outcomes: not reported

Subgroup: not reported

\begin{tabular}{|c|c|c|}
\hline Funding source & \multicolumn{2}{|l|}{ Not reported } \\
\hline Declarations of interest & \multicolumn{2}{|l|}{ Not reported } \\
\hline Notes & \multicolumn{2}{|c|}{ Language of publication: English } \\
\hline \multicolumn{3}{|l|}{ Risk of bias } \\
\hline Bias & Authors' judgement & Support for judgement \\
\hline \multirow{2}{*}{$\begin{array}{l}\text { Random sequence genera- } \\
\text { tion (selection bias) }\end{array}$} & Unclear risk & Quote: "random" \\
\hline & & $\begin{array}{l}\text { Comment: owing to insufficient information, risk of selection bias was consid- } \\
\text { ered to be unclear }\end{array}$ \\
\hline \multirow{2}{*}{$\begin{array}{l}\text { Allocation concealment } \\
\text { (selection bias) }\end{array}$} & Unclear risk & Insufficient information to permit judgement \\
\hline & & $\begin{array}{l}\text { Comment: owing to insufficient information, risk of allocation concealment } \\
\text { was considered to be unclear }\end{array}$ \\
\hline \multirow{3}{*}{$\begin{array}{l}\text { Blinding of participants } \\
\text { and personnel (perfor- } \\
\text { mance bias) } \\
\text { All outcomes }\end{array}$} & High risk & No blinding was described \\
\hline & & \\
\hline & & \\
\hline \multirow{2}{*}{$\begin{array}{l}\text { Blinding of outcome as- } \\
\text { sessment (detection bias) } \\
\text { Subjective outcomes } \\
\text { (post-operative discom- }\end{array}$} & High risk & No blinding of outcome assessments was described \\
\hline & & Comment: study was unlikely to have used blinding \\
\hline
\end{tabular}

Ureteral stent versus no ureteral stent for ureteroscopy in the management of renal and ureteral calculi (Review) 
Zaki 2011 (Continued)

fort, UTI, ureteral stricture,

QOL)

\begin{tabular}{|c|c|c|}
\hline $\begin{array}{l}\text { Blinding of outcome as- } \\
\text { sessment (detection bias) } \\
\text { Objective outcomes (all } \\
\text { others) }\end{array}$ & Low risk & Comment: objective outcomes were not likely affected by lack of blinding \\
\hline $\begin{array}{l}\text { Incomplete outcome data } \\
\text { (attrition bias) } \\
\text { All outcomes }\end{array}$ & Low risk & Comment: all participants randomised in each group were included in analysis \\
\hline $\begin{array}{l}\text { Selective reporting (re- } \\
\text { porting bias) }\end{array}$ & Unclear risk & $\begin{array}{l}\text { Protocol was not available } \\
\text { Comment: owing to insufficient information to permit judgement, risk of re- } \\
\text { porting bias was considered to be unclear }\end{array}$ \\
\hline Other bias & Low risk & $\begin{array}{l}\text { Study appears to be free of other sources of bias } \\
\text { Comment: no other sources of bias could be found; therefore risk of other bias } \\
\text { was considered to be low }\end{array}$ \\
\hline
\end{tabular}

AFA: additional forceps application.

DJ: double J.

ESWL: extracorporeal shock wave lithotripsy.

$\mathrm{Fr}$ : 1 French (Fr), equivalent to $0.33 \mathrm{~mm}$ of diameter.

IVP: intravenous pyelography.

KUB: kidneys, ureter, bladder.

LUTS: lower urinary tract symptoms.

NR: not reported.

VAS: visual analogue scale.

Characteristics of excluded studies [ordered by study ID]

\begin{tabular}{|c|c|}
\hline Study & Reason for exclusion \\
\hline Ali 2001 & Ineligible study design \\
\hline Bolat 2017 & Ineligible comparator \\
\hline Byrne 2002 & Ineligible intervention \\
\hline Chauhan 2015 & Ineligible comparator \\
\hline Clayman 2005 & Ineligible study design \\
\hline Hussein 2006 & Ineligible population \\
\hline Manu 2015 & Ineligible study design \\
\hline Mittakanti 2018 & Ineligible study design \\
\hline Muslumanoglu 2017 & Ineligible study design \\
\hline Schoenthaler 2013 & Ineligible study design \\
\hline Tu 2015 & Ineligible study design \\
\hline
\end{tabular}




\begin{tabular}{ll}
\hline Study & Reason for exclusion \\
\hline Turker 2009 & Ineligible study design \\
\hline Wang 2017 & Ineligible study design \\
\hline Zhang 2014 & Ineligible study design \\
\hline
\end{tabular}

Characteristics of ongoing studies [ordered by study ID]

NCT03130907

Trial name or title

The role of ureteral stenting following uncomplicated ureteroscopy for ureteral and renal stones: a randomized, controlled trial

\begin{tabular}{ll}
\hline Methods & Randomised parallel-group trial \\
\hline Participants & Inclusion criteria \\
- Adult patients age 18 to 89 with solitary or multiple proximal ureteral or renal stones $1.5 \mathrm{~cm}$ \\
or smaller measured in the longest dimension on preoperative imaging (CT or X-ray). Proximal \\
ureteral stones are those proximal to the pelvic brim in the ureter \\
Exclusion criteria \\
- Stone larger than $1.5 \mathrm{~cm}$ on preoperative imaging \\
- Pregnancy \\
- Stent placement before ureteroscopy ("pre-stented patients") \\
- Patients with solitary kidney
\end{tabular}

Group A: stent

Group B: no stent

CT: computed tomography. 
DATA AND ANALYSES

Comparison 1. URS with stent placement vs URS with no stent placement

\begin{tabular}{|c|c|c|c|c|}
\hline Outcome or subgroup title & No. of studies & $\begin{array}{l}\text { No. of partici- } \\
\text { pants }\end{array}$ & Statistical method & Effect size \\
\hline $\begin{array}{l}1 \text { Unplanned return visit to emer- } \\
\text { gency/urgent care department }\end{array}$ & 16 & 1970 & Risk Ratio (M-H, Random, 95\% Cl) & $0.69[0.40,1.21]$ \\
\hline 2 Postoperative pain day 0 & 4 & 346 & $\begin{array}{l}\text { Mean Difference (IV, Random, } \\
95 \% \mathrm{Cl})\end{array}$ & $0.32[-0.13,0.78]$ \\
\hline $\begin{array}{l}3 \text { Postoperative pain day } 1 \text { to day } \\
3\end{array}$ & 8 & 683 & $\begin{array}{l}\text { Std. Mean Difference (IV, Random, } \\
95 \% \mathrm{CI} \text { ) }\end{array}$ & $0.25[-0.32,0.82]$ \\
\hline $\begin{array}{l}4 \text { Postoperative pain day } 4 \text { to day } \\
30\end{array}$ & 8 & 903 & $\begin{array}{l}\text { Std. Mean Difference (IV, Random, } \\
95 \% \mathrm{CI} \text { ) }\end{array}$ & $0.62[0.08,1.16]$ \\
\hline 5 Secondary interventions & 10 & 1435 & Risk Ratio (M-H, Random, 95\% Cl) & $1.15[0.39,3.33]$ \\
\hline 6 Narcotic requirement & 7 & 830 & Risk Ratio (M-H, Random, 95\% Cl) & $0.80[0.48,1.36]$ \\
\hline $\begin{array}{l}7 \mathrm{UTI} \text { (positive urine culture as } \\
\text { well as symptoms) up to } 90 \text { days }\end{array}$ & 10 & 1207 & Risk Ratio (M-H, Random, 95\% Cl) & $0.94[0.59,1.51]$ \\
\hline $\begin{array}{l}8 \text { Operating room time (in min- } \\
\text { utes) }\end{array}$ & 17 & 1981 & $\begin{array}{l}\text { Mean Difference (IV, Random, } \\
95 \% \mathrm{Cl} \text { ) }\end{array}$ & $3.72[2.30,5.14]$ \\
\hline 9 Ureteral stricture up to 90 days & 14 & 1625 & Risk Ratio (M-H, Random, 95\% Cl) & $0.58[0.23,1.47]$ \\
\hline 10 Quality of life & 1 & 115 & $\begin{array}{l}\text { Mean Difference (IV, Random, } \\
95 \% \mathrm{CI})\end{array}$ & $2.9[2.52,3.28]$ \\
\hline 11 Hospital admission & 13 & 1647 & Risk Ratio (M-H, Random, 95\% Cl) & $0.70[0.32,1.55]$ \\
\hline
\end{tabular}

Analysis 1.1. Comparison 1 URS with stent placement vs URS with no stent placement, Outcome 1 Unplanned return visit to emergency/urgent care department.

\begin{tabular}{|c|c|c|c|c|c|}
\hline \multirow[t]{2}{*}{ Study or subgroup } & $\begin{array}{l}\text { URS with stent } \\
\text { placement }\end{array}$ & $\begin{array}{l}\text { URS with } \\
\text { no stent } \\
\text { placement }\end{array}$ & \multirow[b]{2}{*}{ M-H, Random, $95 \% \mathrm{Cl}$} & \multirow[t]{2}{*}{ Weight } & \multirow{2}{*}{$\begin{array}{c}\text { Risk Ratio } \\
\text { M-H, Random, } 95 \% \mathrm{Cl}\end{array}$} \\
\hline & $n / N$ & $n / N$ & & & \\
\hline Borboroglu 2001 & $0 / 53$ & $4 / 54$ & & $3.15 \%$ & $0.11[0.01,2.05]$ \\
\hline Cevik 2010 & $3 / 30$ & $6 / 30$ & 1 & $10.27 \%$ & $0.5[0.14,1.82]$ \\
\hline Chen 2002 & $0 / 30$ & $1 / 30$ & $\downarrow$ & $2.7 \%$ & $0.33[0.01,7.87]$ \\
\hline Cheung 2003 & $6 / 29$ & $5 / 29$ & 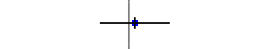 & $12.46 \%$ & $1.2[0.41,3.5]$ \\
\hline Damiano 2004 & $0 / 52$ & $12 / 52$ & - & $3.34 \%$ & $0.04[0,0.66]$ \\
\hline Denstedt 2001 & $1 / 29$ & $1 / 29$ & & $3.5 \%$ & $1[0.07,15.24]$ \\
\hline ElHarrech 2014 & $0 / 42$ & $1 / 38$ & 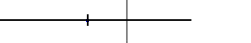 & $2.69 \%$ & $0.3[0.01,7.21]$ \\
\hline Ibrahim 2008 & $2 / 110$ & $5 / 110$ & $\longrightarrow+$ & $7.78 \%$ & $0.4[0.08,2.02]$ \\
\hline Isen 2008 & $1 / 21$ & $1 / 22$ & & $3.54 \%$ & $1.05[0.07,15.69]$ \\
\hline
\end{tabular}




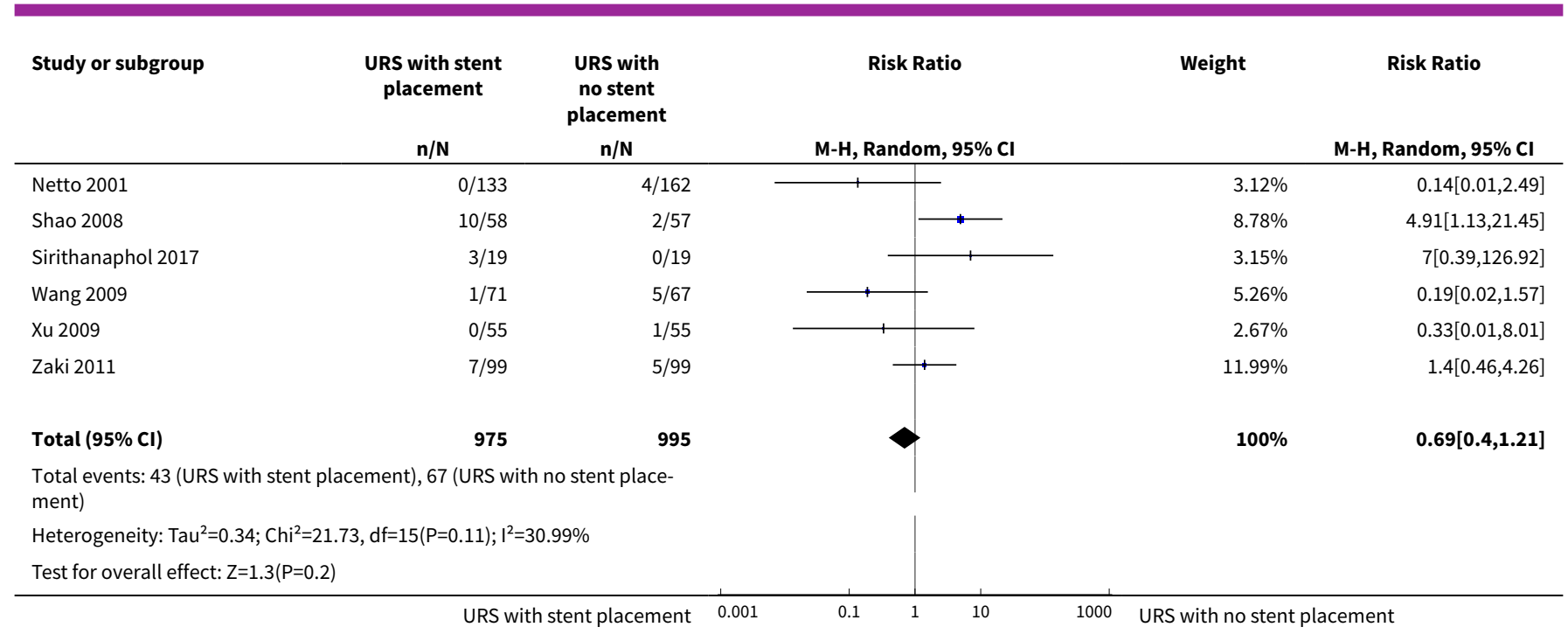

Analysis 1.2. Comparison 1 URS with stent placement vs URS with no stent placement, Outcome 2 Postoperative pain day 0.

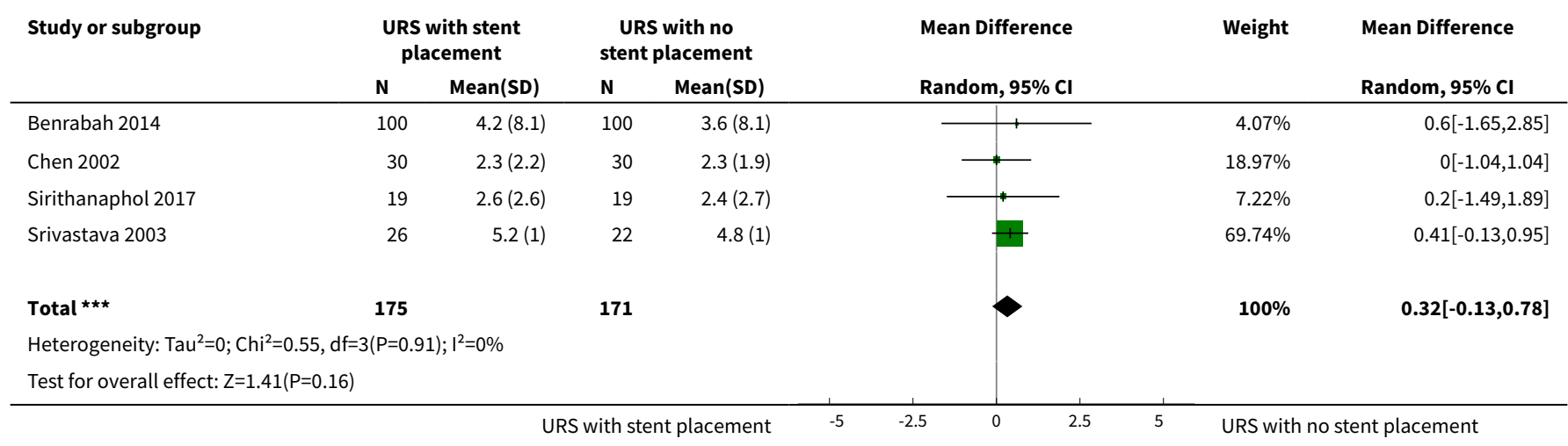

Analysis 1.3. Comparison 1 URS with stent placement vs URS with no stent placement, Outcome 3 Postoperative pain day 1 to day 3.

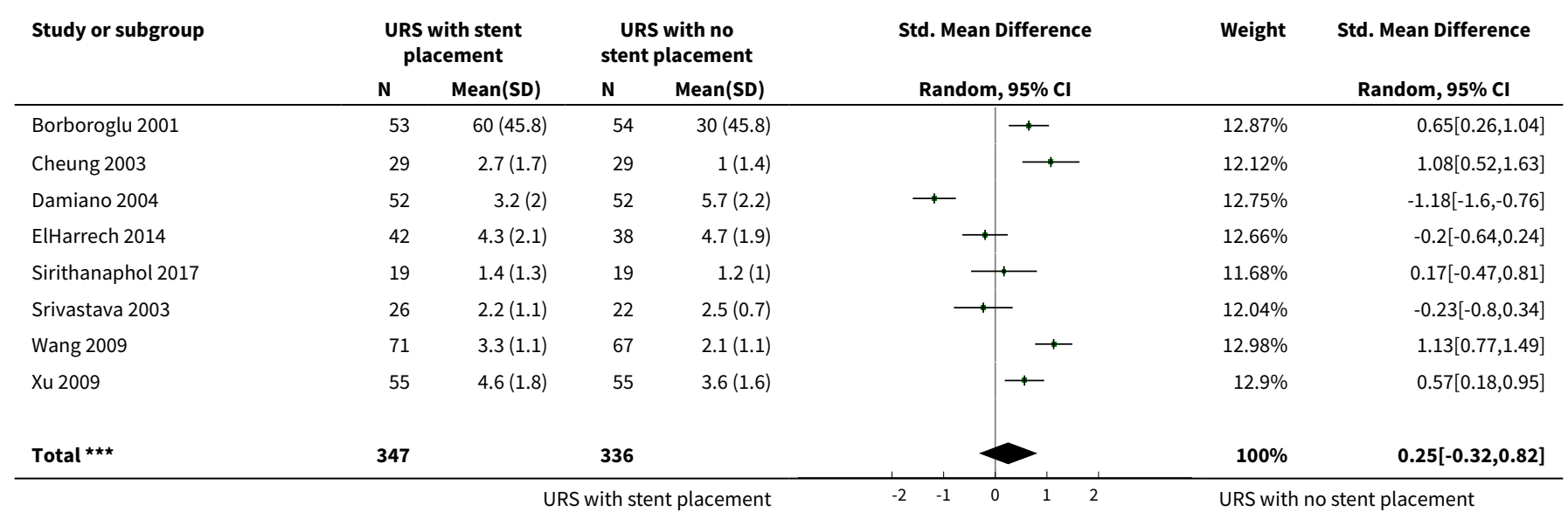




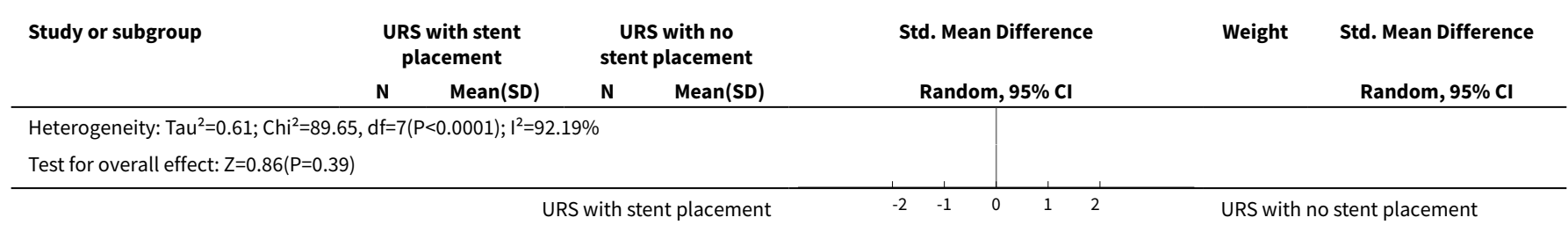

Analysis 1.4. Comparison 1 URS with stent placement vs URS with no stent placement, Outcome 4 Postoperative pain day 4 to day 30.

\begin{tabular}{|c|c|c|c|c|c|c|c|}
\hline \multirow[t]{2}{*}{ Study or subgroup } & \multicolumn{2}{|c|}{$\begin{array}{l}\text { URS with stent } \\
\text { placement }\end{array}$} & \multicolumn{2}{|c|}{$\begin{array}{c}\text { URS with no } \\
\text { stent placement }\end{array}$} & \multirow{2}{*}{$\begin{array}{l}\text { Std. Mean Difference } \\
\text { Random, } 95 \% \mathrm{Cl}\end{array}$} & \multirow[t]{2}{*}{ Weight } & \multirow{2}{*}{$\begin{array}{l}\text { Std. Mean Difference } \\
\text { Random, } 95 \% \mathrm{CI} \\
\end{array}$} \\
\hline & $\mathbf{N}$ & $\operatorname{Mean}(\mathrm{SD})$ & $\mathbf{N}$ & $\operatorname{Mean}(\mathrm{SD})$ & & & \\
\hline Başeskioğlu 2011 & 144 & $2.9(1.3)$ & 142 & $2.8(1.1)$ & + & $13.32 \%$ & $0.12[-0.12,0.35]$ \\
\hline Borboroglu 2001 & 53 & $10(7.6)$ & 54 & $5(7.6)$ & 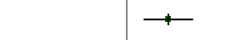 & $12.75 \%$ & $0.65[0.26,1.04]$ \\
\hline Damiano 2004 & 52 & $2.7(1.8)$ & 52 & $2.9(1.7)$ & $\rightarrow$ & $12.77 \%$ & $-0.11[-0.5,0.27]$ \\
\hline Denstedt 2001 & 29 & $4.1(2.9)$ & 29 & $1.7(2.5)$ & $\longrightarrow$ & $12.01 \%$ & $0.87[0.33,1.41]$ \\
\hline Isen 2008 & 21 & $2(0.8)$ & 22 & $1.8(0.6)$ & + & $11.68 \%$ & $0.25[-0.35,0.85]$ \\
\hline Shao 2008 & 58 & $16.8(3.6)$ & 57 & $4.1(5.3)$ & & $12.13 \%$ & $2.79[2.27,3.31]$ \\
\hline Xu 2009 & 55 & $0.5(0.5)$ & 55 & $0.4(0.5)$ & + & $12.82 \%$ & $0.15[-0.22,0.53]$ \\
\hline 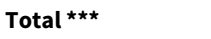 & 454 & & 449 & & & $100 \%$ & $0.62[0.08,1.16]$ \\
\hline \multicolumn{8}{|c|}{ Heterogeneity: $\mathrm{Tau}^{2}=0.55 ; \mathrm{Chi}^{2}=100.83, \mathrm{df}=7(\mathrm{P}<0.0001) ; \mathrm{I}^{2}=93.06 \%$} \\
\hline
\end{tabular}

Analysis 1.5. Comparison 1 URS with stent placement vs URS with no stent placement, Outcome 5 Secondary interventions.

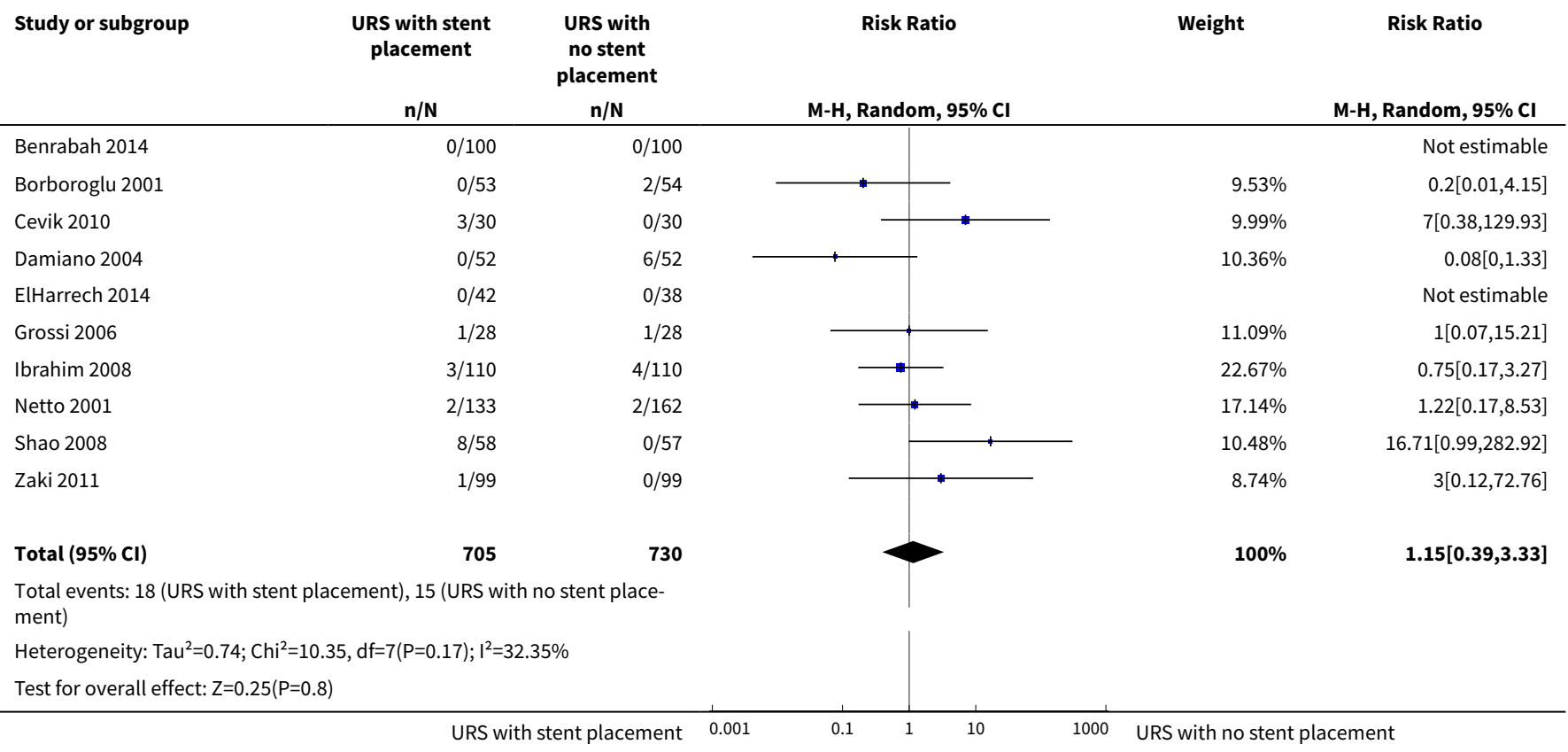


Analysis 1.6. Comparison 1 URS with stent placement vs URS with no stent placement, Outcome 6 Narcotic requirement.

\begin{tabular}{|c|c|c|c|c|c|}
\hline \multirow[t]{2}{*}{ Study or subgroup } & $\begin{array}{l}\text { URS with stent } \\
\text { placement }\end{array}$ & $\begin{array}{l}\text { URS with } \\
\text { no stent } \\
\text { placement }\end{array}$ & \multirow[b]{2}{*}{ M-H, Random, 95\% Cl } & \multirow[t]{2}{*}{ Weight } & \multirow{2}{*}{$\begin{array}{c}\text { Risk Ratio } \\
\text { M-H, Random, } 95 \% \mathrm{Cl}\end{array}$} \\
\hline & $n / N$ & $n / N$ & & & \\
\hline Cevik 2010 & $19 / 30$ & $29 / 30$ & \# & $27.08 \%$ & $0.66[0.5,0.87]$ \\
\hline Damiano 2004 & $0 / 52$ & $6 / 52$ & & $3.04 \%$ & $0.08[0,1.33]$ \\
\hline Netto 2001 & $5 / 133$ & $7 / 162$ & $\longrightarrow$ & $12.5 \%$ & $0.87[0.28,2.68]$ \\
\hline Sirithanaphol 2017 & $5 / 19$ & $11 / 19$ & $\rightarrow$ & $16.68 \%$ & $0.45[0.2,1.06]$ \\
\hline Wang 2009 & $48 / 71$ & $31 / 67$ & - & $26.72 \%$ & $1.46[1.08,1.98]$ \\
\hline Xu 2009 & $6 / 55$ & $4 / 55$ & 1 & $11.48 \%$ & $1.5[0.45,5.02]$ \\
\hline Total $(95 \% \mathrm{Cl})$ & 400 & 430 & & $100 \%$ & $0.8[0.48,1.36]$ \\
\hline \multicolumn{6}{|c|}{$\begin{array}{l}\text { Total events: } 83 \text { (URS with stent placement), } 89 \text { (URS with no stent place- } \\
\text { ment) }\end{array}$} \\
\hline Test for overall effect & & & & & \\
\hline
\end{tabular}

Analysis 1.7. Comparison 1 URS with stent placement vs URS with no stent placement, Outcome 7 UTI (positive urine culture as well as symptoms) up to 90 days.

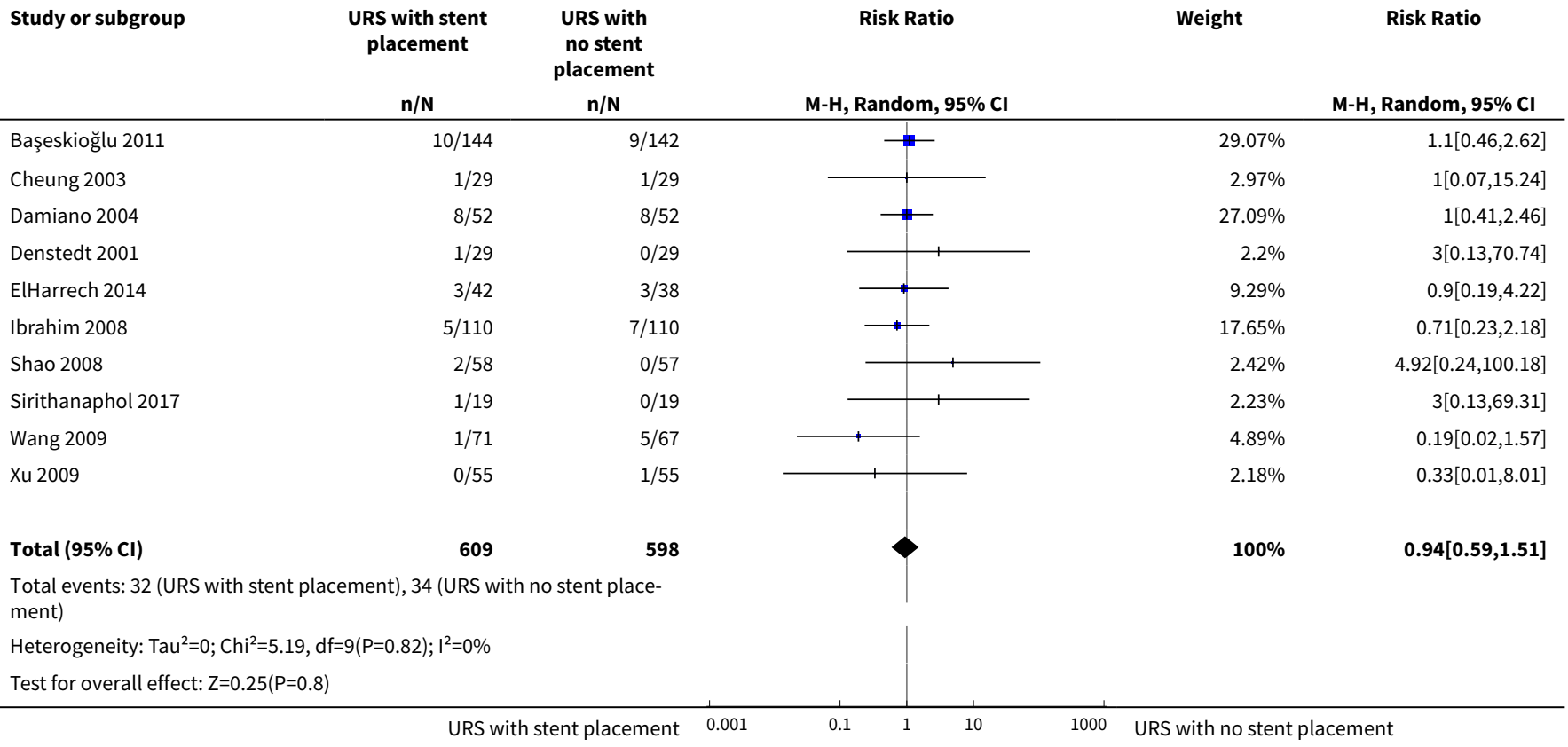


Analysis 1.8. Comparison 1 URS with stent placement vs URS with no stent placement, Outcome 8 Operating room time (in minutes).

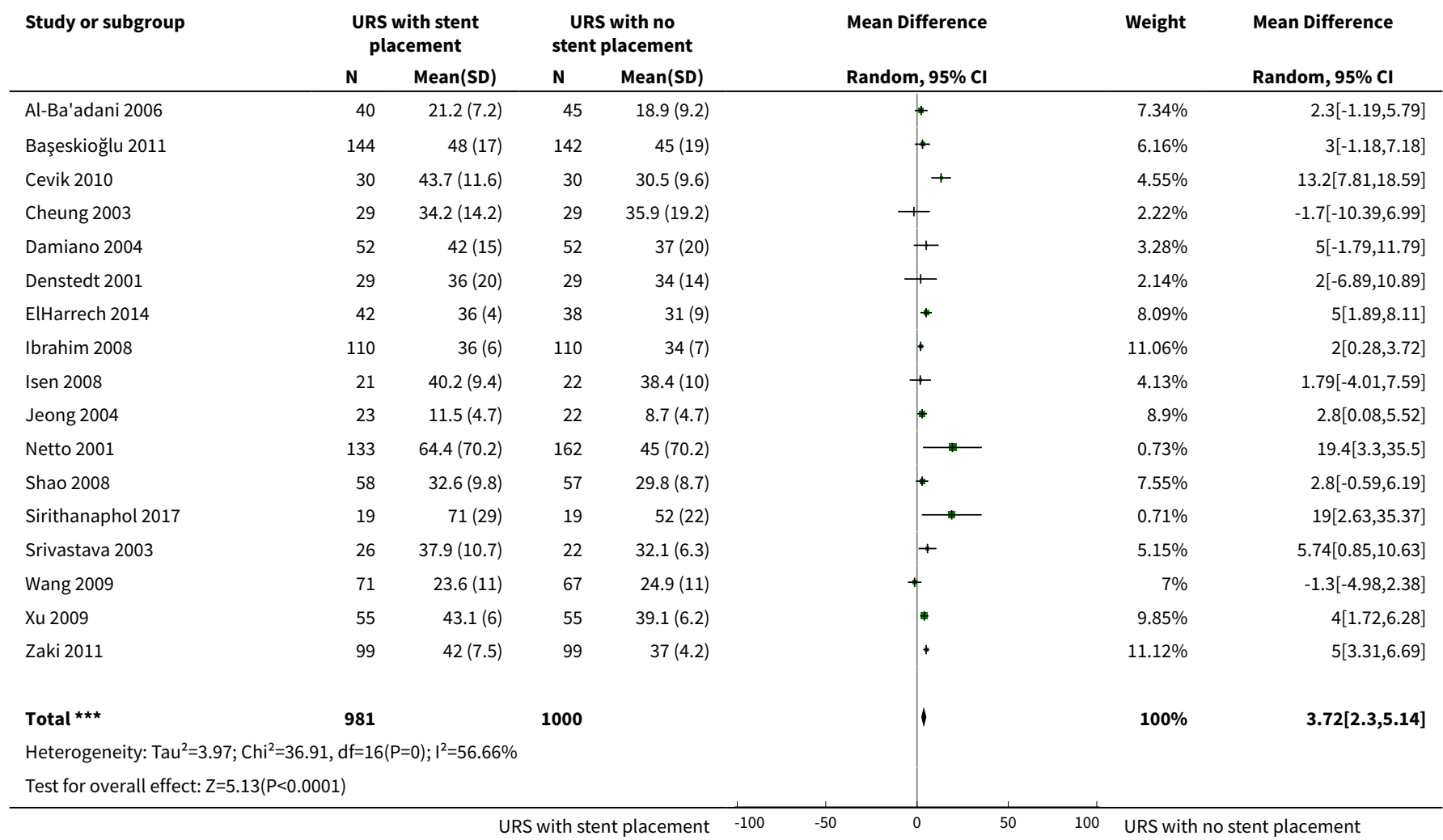

Analysis 1.9. Comparison 1 URS with stent placement vs URS with no stent placement, Outcome 9 Ureteral stricture up to 90 days.

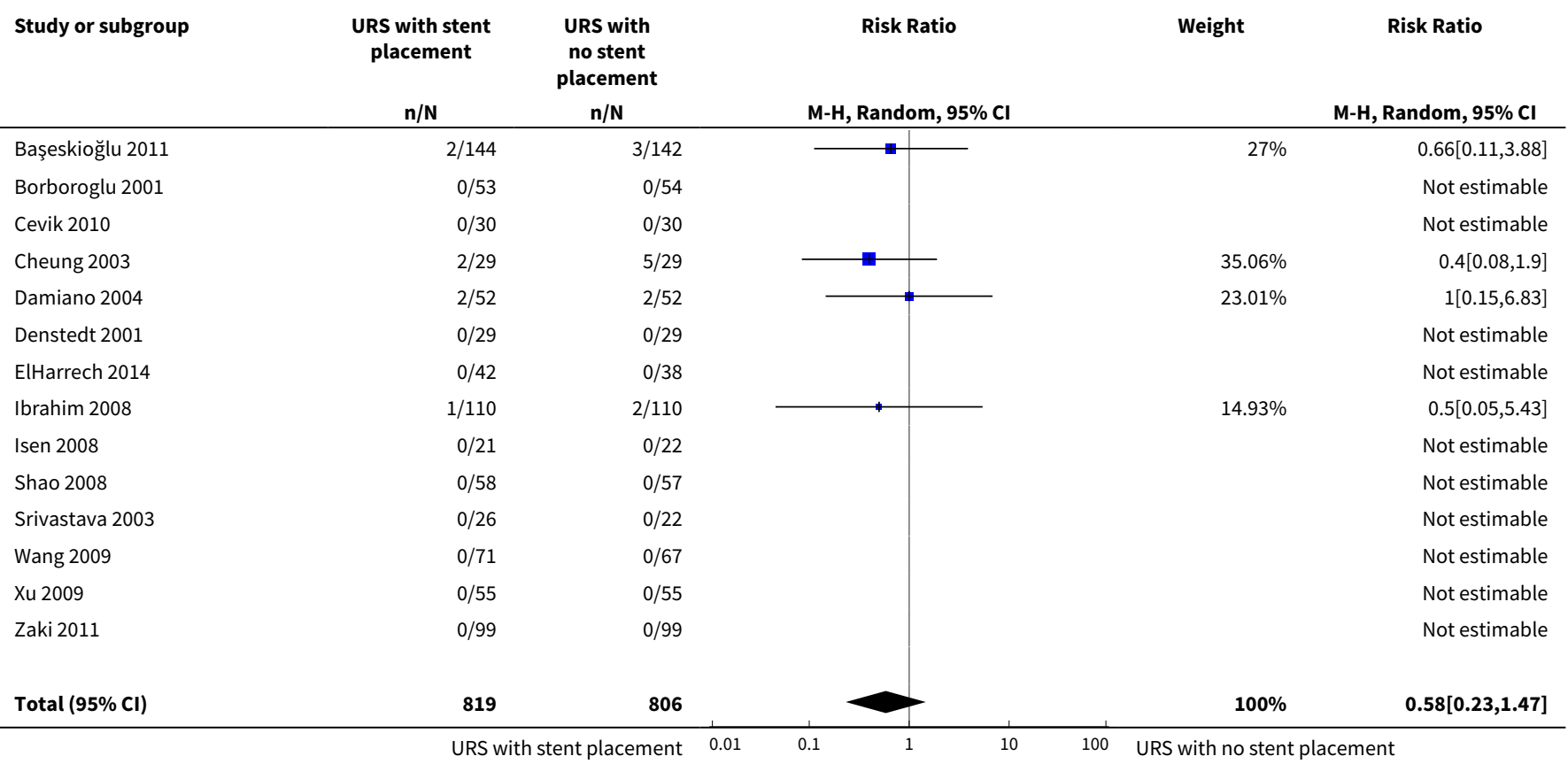




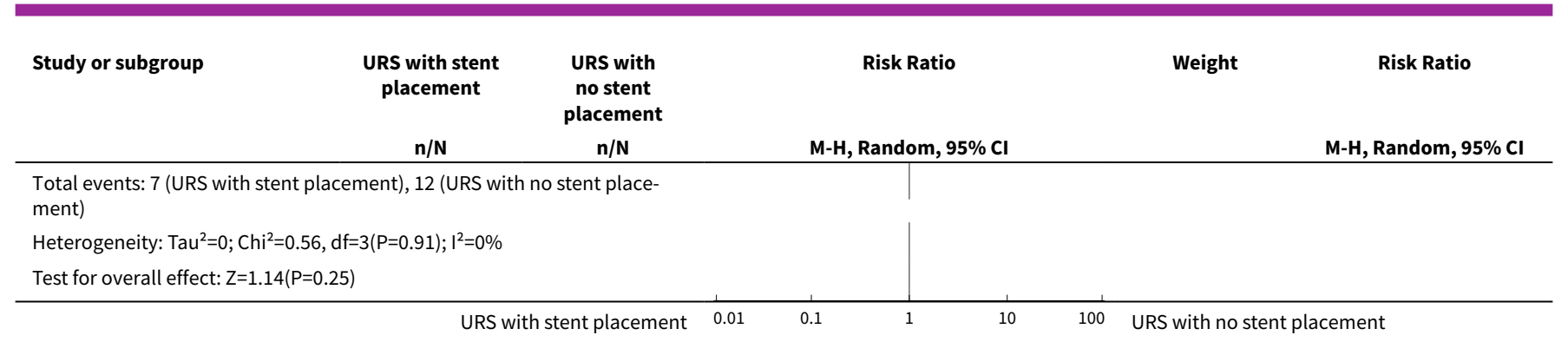

Analysis 1.10. Comparison 1 URS with stent placement vs URS with no stent placement, Outcome 10 Quality of life.

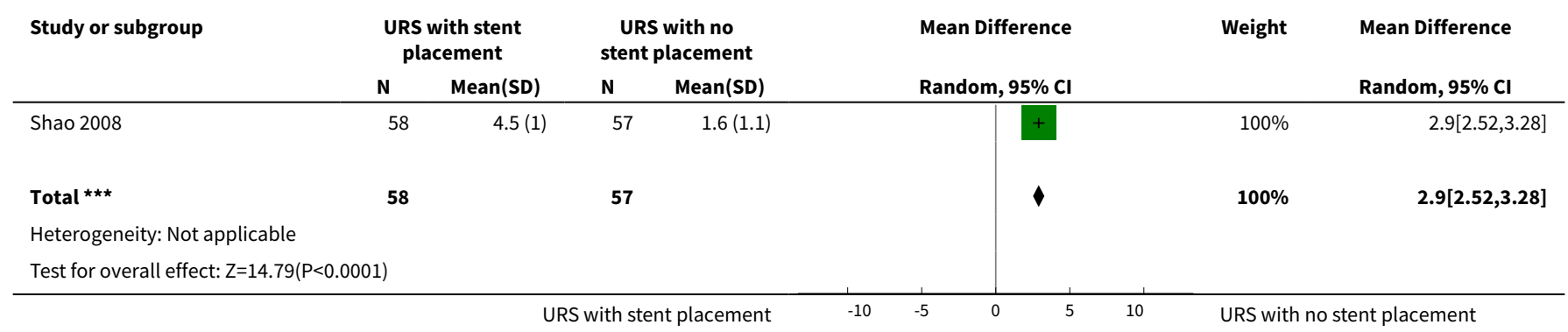

Analysis 1.11. Comparison 1 URS with stent placement vs URS with no stent placement, Outcome 11 Hospital admission.

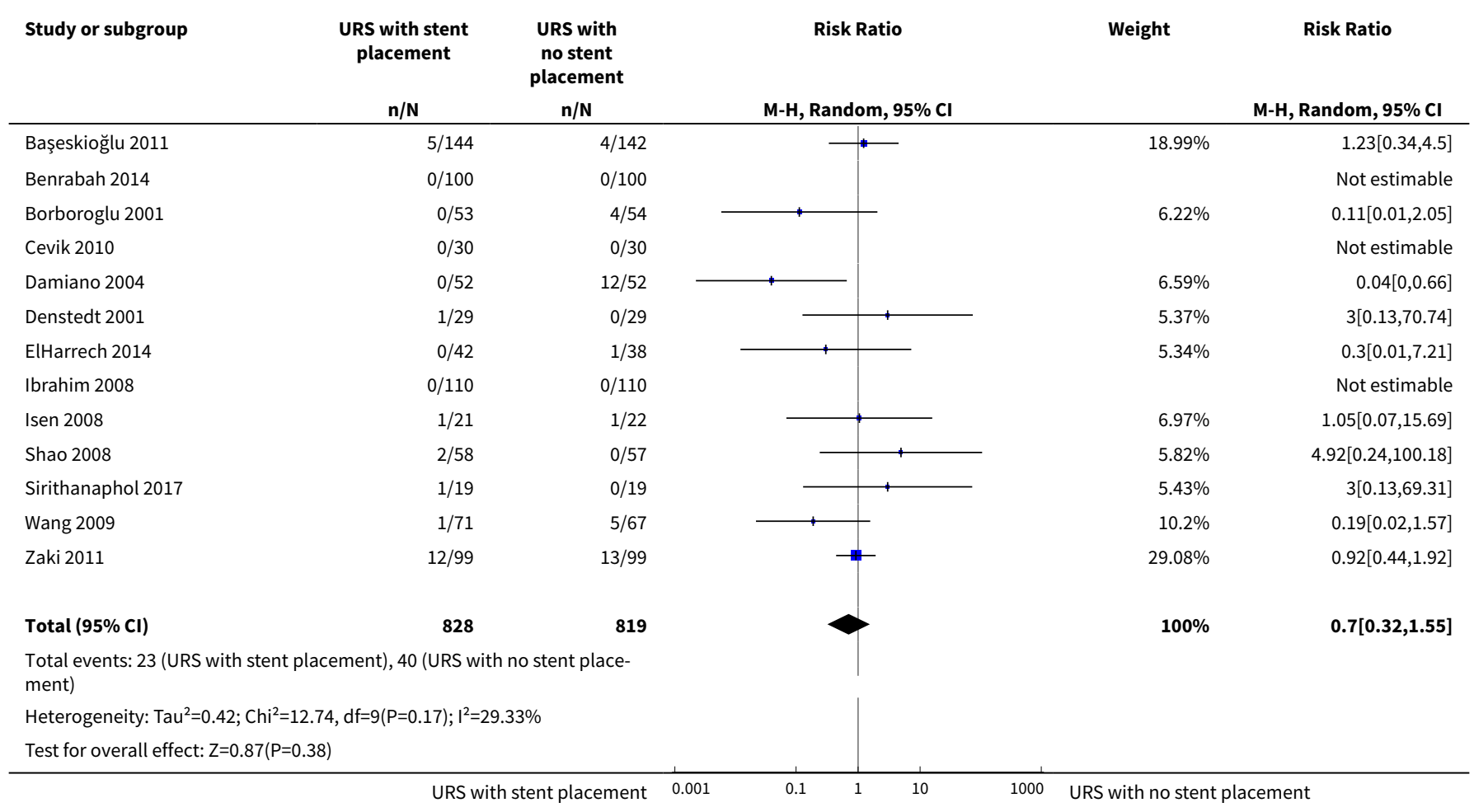




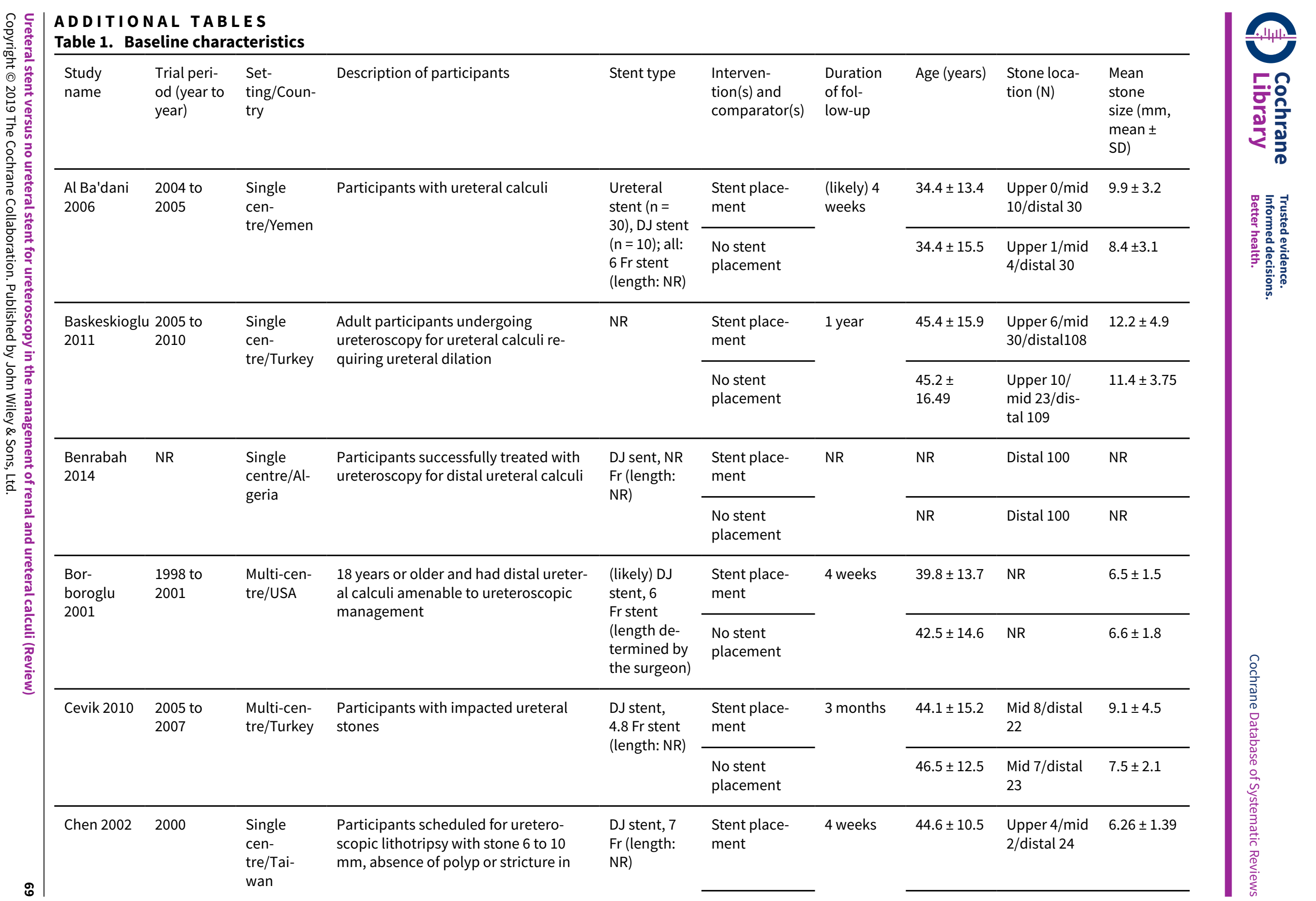




\begin{tabular}{|c|c|c|c|c|c|c|c|c|c|}
\hline & & & $\begin{array}{l}\text { the ureter, and no mucosal injury or } \\
\text { perforation during operation }\end{array}$ & & $\begin{array}{l}\text { No stent } \\
\text { placement }\end{array}$ & & $38.8 \pm 1.8$ & $\begin{array}{l}\text { Upper } 4 / \text { mid } \\
\text { 2/distal } 24\end{array}$ & $6.17 \pm 1.44$ \\
\hline \multirow[t]{2}{*}{$\begin{array}{l}\text { Cheung } \\
2003\end{array}$} & \multirow[t]{2}{*}{$\begin{array}{l}2001 \text { to } \\
2002\end{array}$} & \multirow{2}{*}{$\begin{array}{l}\text { Single } \\
\text { cen- } \\
\text { tre/Hong } \\
\text { Kong }\end{array}$} & \multirow{2}{*}{$\begin{array}{l}\text { Participants with unilateral ureteral } \\
\text { stones, irrespective of stone burden, } \\
\text { location and severity of obstruction }\end{array}$} & \multirow{2}{*}{$\begin{array}{l}\text { DJ stent, } 6 \\
\mathrm{Fr}(24 \text { or } 26 \\
\mathrm{cm})\end{array}$} & $\begin{array}{l}\text { Stent place- } \\
\text { ment }\end{array}$ & \multirow[t]{2}{*}{3 months } & $51.2 \pm 15.3$ & $\begin{array}{l}\text { Upper 6/mid } \\
\text { 2/distal } 21\end{array}$ & $9.8 \pm 3.7$ \\
\hline & & & & & $\begin{array}{l}\text { No stent } \\
\text { placement }\end{array}$ & & $53.1 \pm 13.0$ & $\begin{array}{l}\text { Upper 12/ } \\
\text { mid 5/distal } \\
12\end{array}$ & $9.6 \pm 4.7$ \\
\hline \multirow[t]{2}{*}{$\begin{array}{l}\text { Damiano } \\
2004\end{array}$} & \multirow[t]{2}{*}{$\begin{array}{l}2000 \text { to } \\
2002\end{array}$} & \multirow[t]{2}{*}{$\begin{array}{l}\text { Multi-cen- } \\
\text { tre/Italy }\end{array}$} & \multirow{2}{*}{$\begin{array}{l}\text { Ureteroscopy for treatment of ureter- } \\
\text { al lithiasis, absence of polyp sugges- } \\
\text { tive of urothelial cancer, no evidence } \\
\text { of stricture, no mucosal perforation } \\
\text { during the operation }\end{array}$} & \multirow{2}{*}{$\begin{array}{l}\text { DJ stent, } \\
4.8 \text { Fr to } 6 \text { Fr } \\
\text { (length: NR) }\end{array}$} & $\begin{array}{l}\text { Stent place- } \\
\text { ment }\end{array}$ & \multirow[t]{2}{*}{6 months } & $44 \pm 16$ & $\begin{array}{l}\text { Upper } 7 / \text { mid } \\
\text { 14/distal } 31\end{array}$ & $11 \pm 0.9$ \\
\hline & & & & & $\begin{array}{l}\text { No stent } \\
\text { placement }\end{array}$ & & $43 \pm 14$ & $\begin{array}{l}\text { Upper } 9 / \text { mid } \\
15 / \text { distal } 28\end{array}$ & $10 \pm 1.2$ \\
\hline \multirow[t]{2}{*}{$\begin{array}{l}\text { Denstedt } \\
2001\end{array}$} & \multirow[t]{2}{*}{ NR } & \multirow{2}{*}{$\begin{array}{l}\text { Multi-cen- } \\
\text { tre/Cana- } \\
\text { da }\end{array}$} & \multirow[t]{2}{*}{$\begin{array}{l}\text { Adults } 18 \text { years or older scheduled for } \\
\text { ureteroscopy for ureteral calculus }\end{array}$} & \multirow{2}{*}{$\begin{array}{l}\text { DJ stent, NR } \\
\text { Fr (length: } \\
\text { NR) }\end{array}$} & $\begin{array}{l}\text { Stent place- } \\
\text { ment }\end{array}$ & \multirow[t]{2}{*}{12 weeks } & $49 \pm 15$ & $\begin{array}{l}\text { Upper } 4 / \text { mid } \\
\text { 5/distal } 20\end{array}$ & NR \\
\hline & & & & & $\begin{array}{l}\text { No stent } \\
\text { placement }\end{array}$ & & $54 \pm 15$ & $\begin{array}{l}\text { Upper } 3 / \text { mid } \\
3 / \text { distal } 23\end{array}$ & NR \\
\hline \multirow[t]{3}{*}{$\begin{array}{l}\text { ElHarrech } \\
2014\end{array}$} & \multirow[t]{3}{*}{$\begin{array}{l}2009 \text { to } \\
2011\end{array}$} & \multirow{3}{*}{$\begin{array}{l}\text { Single } \\
\text { cen- } \\
\text { tre/Moroc- } \\
\text { co }\end{array}$} & \multirow[t]{3}{*}{$\begin{array}{l}\text { Participants treated with successful } \\
\text { ureteroscopy for distal ureteral stones }\end{array}$} & \multirow{3}{*}{$\begin{array}{l}\text { Ureteral } \\
\text { stent }(\mathrm{n}= \\
37), \text { DJ stent } \\
(\mathrm{n}=42) \text {; all: } \\
7 \mathrm{Fr} \text { (length: } \\
\text { NR) }\end{array}$} & $\begin{array}{l}\text { Double J stent } \\
\text { placement }\end{array}$ & \multirow{3}{*}{$\begin{array}{l}\text { Minimum } \\
3 \text { months } \\
\text { (mean } 12 \\
\text { months) }\end{array}$} & $44.1 \pm 12.5$ & NR & $8.6 \pm 3.4$ \\
\hline & & & & & $\begin{array}{l}\text { Ureteral stent } \\
\text { placement }\end{array}$ & & $39.6 \pm 11.3$ & NR & $10.1 \pm 2.7$ \\
\hline & & & & & $\begin{array}{l}\text { No stent } \\
\text { placement }\end{array}$ & & $43.2 \pm 14$ & NR & $9.6 \pm 3.4$ \\
\hline \multirow[t]{2}{*}{$\begin{array}{l}\text { Grossi } \\
2006\end{array}$} & \multirow[t]{2}{*}{$\begin{array}{l}2000 \text { to } \\
2001\end{array}$} & \multirow[t]{2}{*}{$\begin{array}{l}\text { Multi-cen- } \\
\text { tre/Italy }\end{array}$} & \multirow[t]{2}{*}{$\begin{array}{l}\text { Participants with ureteral stones } \\
\text { amenable to endoscopic treatment by } \\
\text { ureterorenoscopy }\end{array}$} & \multirow[t]{2}{*}{$\begin{array}{l}\text { DJ stent, } 6 \\
\text { Fr (length: } \\
\text { NR) }\end{array}$} & $\begin{array}{l}\text { Stent place- } \\
\text { ment }\end{array}$ & \multirow[t]{2}{*}{6 months } & \multirow[t]{2}{*}{$\begin{array}{l}48 \pm 12 \\
\text { (total) }\end{array}$} & \multirow[t]{2}{*}{$\begin{array}{l}\text { Total only; } \\
\text { upper } 8 / \text { mid } \\
21 / \text { distal } 27\end{array}$} & $\begin{array}{l}9.17 \times 6.91 \\
\text { (total) }\end{array}$ \\
\hline & & & & & $\begin{array}{l}\text { No stent } \\
\text { placement }\end{array}$ & & & & \\
\hline \multirow[t]{2}{*}{$\begin{array}{l}\text { Hosseini } \\
2009\end{array}$} & \multirow[t]{2}{*}{ NR } & \multirow{2}{*}{$\begin{array}{l}\text { Single } \\
\text { cen- } \\
\text { tre/Iran }\end{array}$} & \multirow[t]{2}{*}{$\begin{array}{l}20 \text { to } 54 \text { years old with } \mathrm{mid} / \text { distal } \\
\text { ureteral calculi } \leq 10 \mathrm{~mm}\end{array}$} & \multirow{2}{*}{$\begin{array}{l}\text { Ureteral } \\
\text { stent } 5 \mathrm{Fr} \\
\text { (length: NR) }\end{array}$} & $\begin{array}{l}\text { Stent place- } \\
\text { ment }\end{array}$ & NR & NR & NR & NR \\
\hline & & & & & $\begin{array}{l}\text { No stent } \\
\text { placement }\end{array}$ & & $\mathrm{NR}$ & NR & NR \\
\hline
\end{tabular}




\begin{tabular}{|c|c|c|c|c|c|c|c|c|c|}
\hline \multirow[t]{2}{*}{$\begin{array}{l}\text { Ibrahim } \\
2008\end{array}$} & \multirow[t]{2}{*}{$\begin{array}{l}2004 \text { to } \\
2006\end{array}$} & \multirow[t]{2}{*}{$\begin{array}{l}\text { Multi-cen- } \\
\text { tre/Kuwait } \\
\text { and Egypt }\end{array}$} & \multirow{2}{*}{$\begin{array}{l}\text { Distal ureteric stone (defined as below } \\
\text { iliac vessels on imaging) amenable to } \\
\text { ureteroscopic management - age over } \\
18\end{array}$} & \multirow{2}{*}{$\begin{array}{l}\text { (likely) DJ } \\
\text { stent; } 6 \text { Fr } \\
\text { (length de- } \\
\text { termined by } \\
\text { the surgeon) }\end{array}$} & $\begin{array}{l}\text { Stent place- } \\
\text { ment }\end{array}$ & \multirow[t]{2}{*}{49 months } & $39 \pm 11$ & NR & \multirow[t]{2}{*}{$12.4 \pm 2.9$} \\
\hline & & & & & $\begin{array}{l}\text { No stent } \\
\text { placement }\end{array}$ & & $36 \pm 9$ & NR & \\
\hline \multirow[t]{2}{*}{ Isen 2008} & \multirow[t]{2}{*}{$\begin{array}{l}2004 \text { to } \\
2007\end{array}$} & \multirow[t]{2}{*}{$\begin{array}{l}\text { Single } \\
\text { cen- } \\
\text { tre/Turkey }\end{array}$} & \multirow{2}{*}{$\begin{array}{l}\text { Lower ureteral stone larger than } 1 \\
\mathrm{~cm} \text { who underwent ureteroscopic } \\
\text { lithotripsy (stone was localised below } \\
\text { the inferior part of the sacroiliac joint) }\end{array}$} & \multirow[t]{2}{*}{$\begin{array}{l}\text { DJ stent, } 4.8 \\
\text { Fr (length: } \\
\text { NR) }\end{array}$} & $\begin{array}{l}\text { Stent place- } \\
\text { ment }\end{array}$ & \multirow[t]{2}{*}{3 months } & $35.28 \pm 9.0$ & NR & $13.28 \pm 2.5$ \\
\hline & & & & & $\begin{array}{l}\text { No stent } \\
\text { placement }\end{array}$ & & $36.09 \pm 9.7$ & NR & $12.90 \pm 2.4$ \\
\hline \multirow[t]{2}{*}{$\begin{array}{l}\text { Jeong } \\
2004\end{array}$} & \multirow[t]{2}{*}{$\begin{array}{l}2000 \text { to } \\
2001\end{array}$} & \multirow{2}{*}{$\begin{array}{l}\text { Single } \\
\text { cen- } \\
\text { tre/South } \\
\text { Korea }\end{array}$} & \multirow[t]{2}{*}{$\begin{array}{l}\text { Participants with ureteric calculi treat- } \\
\text { ed by ureteroscopic lithotripsy }\end{array}$} & \multirow[t]{2}{*}{$\begin{array}{l}\text { DJ stent, } 7 \\
\text { Fr (length: } \\
\text { NR) }\end{array}$} & $\begin{array}{l}\text { Stent place- } \\
\text { ment }\end{array}$ & \multirow[t]{2}{*}{4 weeks } & $50.5 \pm 12.6$ & $\begin{array}{l}\text { Upper } 4 / \text { mid } \\
\text { 2/distal } 17\end{array}$ & $7.1 \pm 2.9$ \\
\hline & & & & & $\begin{array}{l}\text { No stent } \\
\text { placement }\end{array}$ & & $42.9 \pm 12.6$ & $\begin{array}{l}\text { Upper } 1 / \text { mid } \\
0 / \text { distal } 21\end{array}$ & $5.3 \pm 2.9$ \\
\hline \multirow[t]{2}{*}{ Netto 2001} & \multirow[t]{2}{*}{$\begin{array}{l}1997 \text { to } \\
2000\end{array}$} & \multirow[t]{2}{*}{$\begin{array}{l}\text { Single } \\
\text { cen- } \\
\text { tre/Brazil }\end{array}$} & \multirow[t]{2}{*}{$\begin{array}{l}\text { Participants underwent rigid } \\
\text { ureteroscopy for ureteral calculi }\end{array}$} & \multirow[t]{2}{*}{ NR } & $\begin{array}{l}\text { Stent place- } \\
\text { ment }\end{array}$ & \multirow{2}{*}{$\begin{array}{l}\text { Minimum } \\
3 \text { months } \\
\text { (medi- } \\
\text { an } 12 \\
\text { months) }\end{array}$} & $65 \pm 9.5$ & $\begin{array}{l}\text { Upper } 10 / \\
\text { mid } 20 / \text { dis- } \\
\text { tal } 103\end{array}$ & $8.4 \pm 3.5$ \\
\hline & & & & & $\begin{array}{l}\text { No stent } \\
\text { placement }\end{array}$ & & $39 \pm 9.6$ & $\begin{array}{l}\text { Upper } 8 / \text { mid } \\
\text { 20/distal } \\
134\end{array}$ & $10.3 \pm 9.4$ \\
\hline \multirow[t]{2}{*}{ Shao 2008} & \multirow[t]{2}{*}{$\begin{array}{l}2005 \text { to } \\
2006\end{array}$} & \multirow[t]{2}{*}{$\begin{array}{l}\text { Single } \\
\text { cen- } \\
\text { tre/China }\end{array}$} & \multirow{2}{*}{$\begin{array}{l}\text { Participants with distal or middle } \\
\text { ureteral calculi smaller than } 2 \mathrm{~cm} \text { were } \\
\text { performed by ureteroscopic holmium } \\
\text { laser lithotripsy }\end{array}$} & \multirow[t]{2}{*}{$\begin{array}{l}\text { DJ stent, } 4.8 \\
\operatorname{Fr}(26 \mathrm{~cm})\end{array}$} & $\begin{array}{l}\text { Stent place- } \\
\text { ment }\end{array}$ & \multirow[t]{2}{*}{12 weeks } & $47.0 \pm 10.9$ & $\begin{array}{l}\text { Mid 16/dis- } \\
\text { tal } 42\end{array}$ & $9.5 \pm 2.5$ \\
\hline & & & & & $\begin{array}{l}\text { No stent } \\
\text { placement }\end{array}$ & & $45.3 \pm 13.2$ & $\begin{array}{l}\text { Mid } 12 / \text { dis- } \\
\text { tal } 45\end{array}$ & $9.3 \pm 2.4$ \\
\hline \multirow{2}{*}{\multicolumn{2}{|c|}{$\begin{array}{l}\text { Sirithanaphol } 2014 \\
2017\end{array}$}} & \multirow{2}{*}{$\begin{array}{l}\text { Single } \\
\text { cen- } \\
\text { tre/Thai- } \\
\text { land }\end{array}$} & \multirow{2}{*}{$\begin{array}{l}18 \text { years or older, flexible ureteroscopy } \\
\text { to do retrograde intrarenal stone } \\
\text { surgery (RIRS), to do ureterolithotripsy } \\
\text { in upper ureter (URSL), and to manage } \\
\text { upper urinary tract tumour }\end{array}$} & \multirow{2}{*}{$\begin{array}{l}\text { (likely) DJ } \\
\text { stent, NR Fr } \\
\text { (length: NR) }\end{array}$} & $\begin{array}{l}\text { Stent place- } \\
\text { ment }\end{array}$ & $\begin{array}{l}\text { (likely) } 2 \\
\text { weeks }\end{array}$ & $45.8 \pm 12.2$ & NR & NR \\
\hline & & & & & $\begin{array}{l}\text { No stent } \\
\text { placement }\end{array}$ & & $50.1 \pm 10.3$ & NR & NR \\
\hline \multirow[t]{2}{*}{$\begin{array}{l}\text { Srivastava } \\
2003\end{array}$} & $\begin{array}{l}2000 \text { to } \\
2002\end{array}$ & $\begin{array}{l}\text { Single } \\
\text { centre/In- } \\
\text { dia }\end{array}$ & $\begin{array}{l}\text { Participants were scheduled for } \\
\text { ureteroscopy for distal ureteral stone } \\
\text { (below the sacroiliac joint) }\end{array}$ & $\begin{array}{l}\text { DJ stent, } 6 \\
\text { Fr }(26 \mathrm{~cm})\end{array}$ & $\begin{array}{l}\text { Stent place- } \\
\text { ment }\end{array}$ & 3 months & $\begin{array}{l}36.12 \pm \\
10.66\end{array}$ & NR & $7.58 \pm 1.92$ \\
\hline & & & & & $\begin{array}{l}\text { No stent } \\
\text { placement }\end{array}$ & & $\begin{array}{l}32.05 \pm \\
8.49\end{array}$ & NR & $7.82 \pm 1.53$ \\
\hline
\end{tabular}




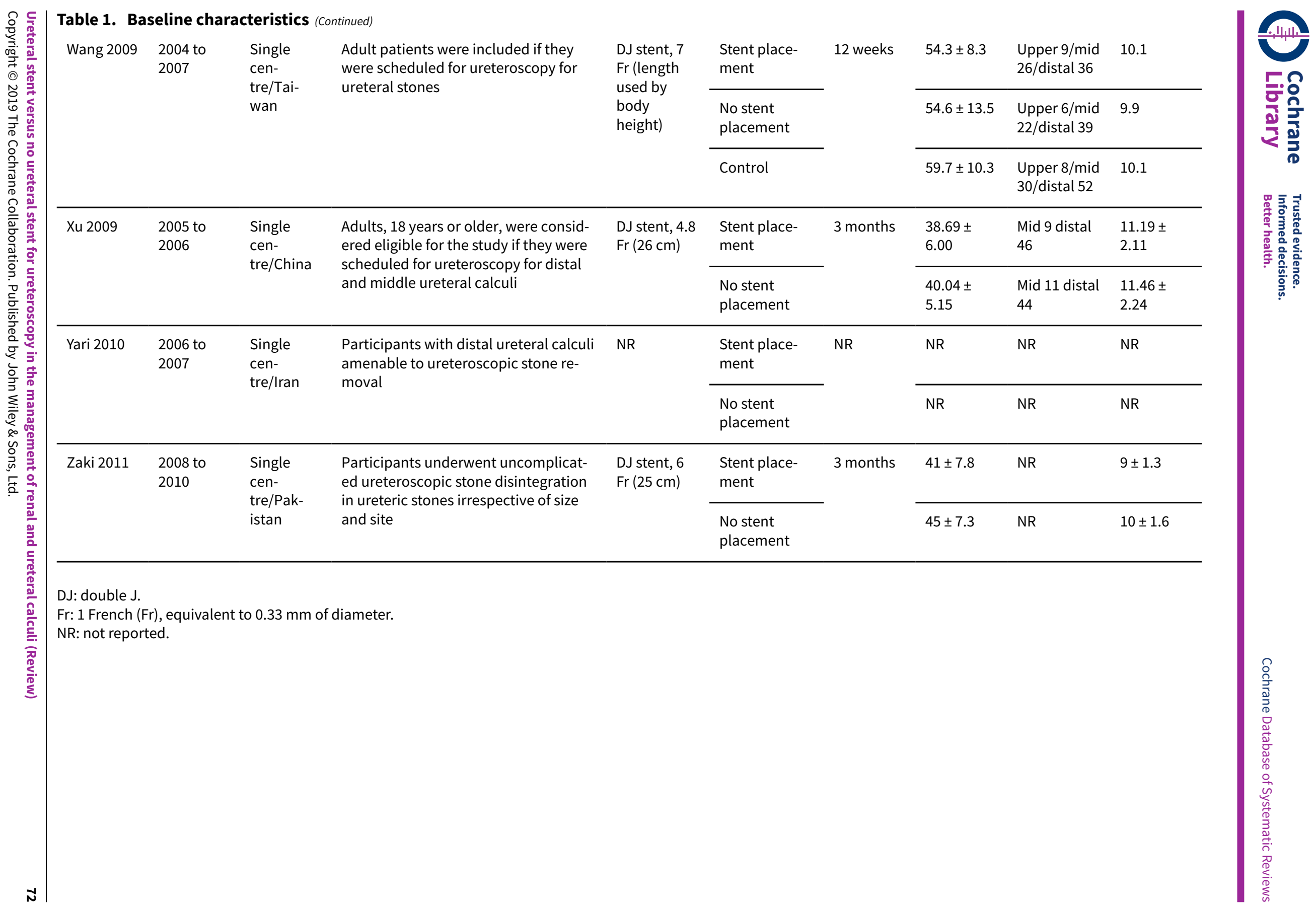




\section{Table 2. Participants' disposition}

\begin{tabular}{|c|c|c|c|c|c|}
\hline Study name & Intervention(s) and comparator(s) & $\begin{array}{l}\text { Screened/eli- } \\
\text { gible (N) }\end{array}$ & $\begin{array}{l}\text { Randomised } \\
\text { (N) }\end{array}$ & Analysed (N) & Finishing trial $(\mathrm{N}(\%))$ \\
\hline \multirow{3}{*}{$\begin{array}{l}\text { Al Ba'dani } \\
2006\end{array}$} & Stent placement & NR/85 & 40 & 40 & $40(100)$ \\
\hline & No stent placement & & 45 & 45 & $45(100)$ \\
\hline & Total & & 85 & 85 & $85(100)$ \\
\hline \multirow{3}{*}{$\begin{array}{l}\text { Baskeskioglu } \\
2011\end{array}$} & Stent placement & $505 / 286$ & 144 & 144 & $144(100)$ \\
\hline & No stent placement & & 142 & 142 & $142(100)$ \\
\hline & Total & & 286 & 286 & $286(100)$ \\
\hline \multirow{3}{*}{$\begin{array}{l}\text { Benrabah } \\
2014\end{array}$} & Stent placement & $N R / 200$ & 100 & NR & NR \\
\hline & No stent placement & & 100 & NR & NR \\
\hline & Total & & 200 & NR & NR \\
\hline \multirow{3}{*}{$\begin{array}{l}\text { Borboroglu } \\
2001\end{array}$} & Stent placement & $\mathrm{NR} / 113$ & 53 & 53 & $53(100)$ \\
\hline & No stent placement & & 60 & 54 & $54(90)$ \\
\hline & Total & & 113 & 107 & $107(94.6)$ \\
\hline \multirow[t]{3}{*}{ Cevik 2010} & Stent placement & $64 / 60$ & 30 & 30 & $30(100)$ \\
\hline & No stent placement & & 30 & 30 & $30(100)$ \\
\hline & Total & & 60 & 60 & $60(100)$ \\
\hline \multirow[t]{3}{*}{ Chen 2002} & Stent placement & $N R / 60$ & 30 & 30 & $30(100)$ \\
\hline & No stent placement & & 30 & 30 & $30(100)$ \\
\hline & Total & & 60 & 60 & $60(100)$ \\
\hline \multirow[t]{3}{*}{ Cheung 2003} & Stent placement & $62 / 58$ & 29 & 29 & $29(100)$ \\
\hline & No stent placement & & 29 & 29 & $29(100)$ \\
\hline & Total & & 58 & 58 & $58(100)$ \\
\hline \multirow[t]{3}{*}{ Damiano 2004} & Stent placement & $\mathrm{NR} / 104$ & 52 & 52 & $52(100)$ \\
\hline & No stent placement & & 52 & 52 & $52(100)$ \\
\hline & Total & & 104 & 104 & $104(100)$ \\
\hline \multirow[t]{2}{*}{ Denstedt 2001} & Stent placement & $71 / 58$ & 29 & 29 & $29(100)$ \\
\hline & No stent placement & & 29 & 29 & $29(100)$ \\
\hline
\end{tabular}


Table 2. Participants' disposition (Continued)

\begin{tabular}{|c|c|c|c|c|c|}
\hline & Total & & 58 & 58 & $58(100)$ \\
\hline \multirow{4}{*}{$\begin{array}{l}\text { ElHarrech } \\
2014\end{array}$} & DJ stent placement & $\mathrm{NR} / 117$ & 42 & 42 & $42(100)$ \\
\hline & Ureteral stent placement & & 37 & 37 & $37(100)$ \\
\hline & No stent placement & & 38 & 38 & $38(100)$ \\
\hline & Total & & 117 & $\begin{array}{l}117 \text { ( } 75 \% \text { of } \\
\text { participants } \\
\text { had follow-up } \\
\text { imaging } \\
\text { minimum } 3 \\
\text { months (mean } \\
\text { follow-up } 12 \\
\text { months)) }\end{array}$ & $117(100)$ \\
\hline \multirow[t]{3}{*}{ Grossi 2006} & Stent placement & $N R / 56$ & 28 & NR & NR \\
\hline & No stent placement & & 28 & NR & NR \\
\hline & Total & & 56 & NR & NR \\
\hline \multirow[t]{3}{*}{ Hosseini 2009} & Stent placement & $N R / 39$ & 20 & NR & NR \\
\hline & No stent placement & & 19 & NR & NR \\
\hline & Total & & 39 & NR & NR \\
\hline \multirow[t]{3}{*}{ Ibrahim 2008} & Stent placement & $\mathrm{NR} / 220$ & 110 & 110 & $110(100)$ \\
\hline & No stent placement & & 110 & 110 & $110(100)$ \\
\hline & Total & & 220 & 220 & $220(100)$ \\
\hline \multirow[t]{3}{*}{ Isen 2008} & Stent placement & $N R / 43$ & 21 & 21 & $21(100)$ \\
\hline & No stent placement & & 22 & 22 & $22(100)$ \\
\hline & Total & & 43 & 43 & $43(100)$ \\
\hline \multirow[t]{3}{*}{ Jeong 2004} & Stent placement & $52 / 45$ & 23 & 23 & $23(100)$ \\
\hline & No stent placement & & 22 & 22 & $22(100)$ \\
\hline & Total & & 45 & 45 & $45(100)$ \\
\hline \multirow[t]{3}{*}{ Netto 2001} & Stent placement & NR/295 & 133 & 133 & $133(100)$ \\
\hline & No stent placement & & 162 & 162 & $162(100)$ \\
\hline & Total & & 295 & 295 & $295(100)$ \\
\hline \multirow[t]{2}{*}{ Shao 2008} & Stent placement & $118 / 115$ & 58 & 58 & $58(100)$ \\
\hline & No stent placement & & 57 & 57 & $57(100)$ \\
\hline
\end{tabular}


Table 2. Participants' disposition (Continued)

\begin{tabular}{|c|c|c|c|c|c|}
\hline & Total & & 115 & 115 & $115(100)$ \\
\hline \multirow{3}{*}{$\begin{array}{l}\text { Sirithanaphol } \\
2017\end{array}$} & Stent placement & $50 / 38$ & 19 & 19 & $19(100)$ \\
\hline & No stent placement & & 19 & 19 & $19(100)$ \\
\hline & Total & & 38 & 38 & $38(100)$ \\
\hline \multirow{3}{*}{$\begin{array}{l}\text { Srivastava } \\
2003\end{array}$} & Stent placement & $\mathrm{NR} / 48$ & 26 & 26 & $26(100)$ \\
\hline & No stent placement & & 22 & 22 & $22(100)$ \\
\hline & Total & & 48 & $\begin{array}{l}48 \text { ( } 83.33 \% \text { of } \\
\text { participants } \\
\text { had follow-up } \\
\text { imaging at } 3 \\
\text { months) }\end{array}$ & $48(100)$ \\
\hline \multirow[t]{4}{*}{ Wang 2009} & Stent placement & $\mathrm{NR} / 228$ & 71 & 71 & $71(100)$ \\
\hline & No stent placement & & 67 & 67 & $67(100)$ \\
\hline & Control & & 90 & 90 & $90(100)$ \\
\hline & Total & & 228 & 228 & $228(100)$ \\
\hline \multirow[t]{3}{*}{ Xu 2009} & Stent placement & $120 / 110$ & 55 & 55 & $55(100)$ \\
\hline & No stent placement & & 55 & 55 & $55(100)$ \\
\hline & Total & & 110 & 110 & $110(100)$ \\
\hline \multirow[t]{3}{*}{ Yari 2010} & Stent placement & $\mathrm{NR} / 80$ & 44 & NR & NR \\
\hline & No stent placement & & 36 & NR & NR \\
\hline & Total & & 80 & NR & NR \\
\hline \multirow[t]{3}{*}{ Zaki 2011} & Stent placement & $204 / 198$ & 99 & 99 & $99(100)$ \\
\hline & No stent placement & & 99 & 99 & $99(100)$ \\
\hline & Total & & 198 & 198 & $198(100)$ \\
\hline Grand total & & & 2656 & $2275^{\star}$ & $2275^{\star}$ \\
\hline
\end{tabular}

Benrabah 2014, Hosseini 2009, Grossi 2006, Yari 2010; analysed and finished trial numbers were not reported.

DJ: double J.

NR: not reported. 


\section{A P P E N D I CES}

\section{Appendix 1. Cochrane Library via Wiley}

1. MeSH descriptor: [Nephrolithiasis] explode all trees

2. MeSH descriptor: [Kidney Calculi] explode all trees

3. MeSH descriptor: [Ureterolithiasis] explode all trees

4. MeSH descriptor: [Urolithiasis] explode all trees

5. MeSH descriptor: [Ureteral Calculi] explode all trees

6. MeSH descriptor: [Urinary Calculi] explode all trees

7. ("Kidney Calculi" or "Kidney Calculus" or "Kidney Stones" or "Kidney Stone" or "Renal Calculus" or "Renal Calculi" or Nephrolith or Nephrolithasis or "Staghorn Calculi" or "Staghorn Calculus" or "Ureteral Calculus" or "Ureteral Calculi" or "Urinary Calculi" or "Urinary Calculus" or "Urinary Lithiasis" or "Calyceal calculi" or calyces or "ureteric calculi" or "ureteric calculus" or "bladder stone" or "bladder stones" or "ureter stone" or "ureter stones" or ureterolithiasis or urolithiasis):ti,ab,kw (Word variations have been searched)

8. \#1 or \#2 or \#3 or \#4 or \#5 or \#6 or \#7

9. MeSH descriptor: [Ureteroscopy] explode all trees

10. (Ureteroscop* or "Ureteroscopic Surgical Procedure*" or "Ureteroscopic Surgery" or "Ureteroscopic Surgeries" or pyeloureteroscopy or ureteropyeloscopy):ti,ab,kw (Word variations have been searched)

11. \#9 or \#10

12. MeSH descriptor: [Stents] explode all trees

13. (stent ${ }^{\star}$ or "non-stent ${ }^{\star}$ " or unstent ${ }^{\star}$ or nonstent $\left.{ }^{\star}\right): t i, a b, k w$ (Word variations have been searched)

14. \#12 or \#13

15. \#8 and \#11 and \#14

16. MeSH descriptor: [Adult] explode all trees

17. MeSH descriptor: [Child] explode all trees

18. MeSH descriptor: [Adolescent] explode all trees

19. MeSH descriptor: [Infant] explode all trees

20. \#17 OR \#18 OR\#19

21. \#20 NOT \#16

22. \#15 NOT \#21

23. MeSH descriptor: [Animals] explode all trees

24. MeSH descriptor: [Humans] explode all trees

25. \#23 NOT \#24

26. \#22 NOT \#25

\section{Appendix 2. MEDLINE (via OVID) search strategy}

1. exp Nephrolithiasis/

2. exp Kidney Calculi/

3. exp Ureterolithiasis/

4. exp Urolithiasis/

5. exp Ureteral Calculi/

6. exp Urinary Calculi/

7. ("Kidney Calculi" or "Kidney Calculus" or "Kidney Stones" or "Kidney Stone" or "Renal Calculus" or "Renal Calculi" or Nephrolith or Nephrolithasis or "Staghorn Calculi" or "Staghorn Calculus" or "Ureteral Calculus" or "Ureteral Calculi" or "Urinary Calculi" or "Urinary Calculus" or "Urinary Lithiasis" or "Calyceal calculi" or calyces or "ureteric calculi" or "ureteric calculus" or "bladder stone" OR "bladder stones" OR "ureter stone" OR "ureter stones" OR ureterolithiasis OR urolithiasis).tw

8. OR/1-7

9. $\exp$ Ureteroscopy/

10. (Ureteroscop* or "Ureteroscopic Surgical Procedure*" or "Ureteroscopic Surgery" or "Ureteroscopic Surgeries" OR pyeloureteroscopy OR ureteropyeloscopy).tw

11. OR/9-10

12. exp Stents/

13. (stent ${ }^{\star}$ or "non-stent ${ }^{\star} "$ or unstent ${ }^{\star}$ or nonstent $\left.{ }^{\star}\right)$.tw.

14. OR/12-13

15. 8 AND 11 AND 14

16. exp Adult/

17. $\exp$ Child/

18. Adolescent/

19. exp Infant/

20. OR/17-19

21. 20 NOT 16

22. 15 NOT 21

Ureteral stent versus no ureteral stent for ureteroscopy in the management of renal and ureteral calculi (Review) 
23. exp Animals/

24. Humans/

25. 23 NOT 24

26. 22 NOT 25

\section{Appendix 3. Embase (via OVID) search strategy}

1. exp urolithiasis/

2. ("Kidney Calculi" or "Kidney Calculus" or "Kidney Stones" or "Kidney Stone" or "Renal Calculus" or "Renal Calculi" or Nephrolith or Nephrolithasis or "Staghorn Calculi" or "Staghorn Calculus" or "Ureteral Calculus" or "Ureteral Calculi" or "Urinary Calculi" or "Urinary Calculus" or "Urinary Lithiasis" or "Calyceal calculi" or calyces or "ureteric calculi" or "ureteric calculus" or "bladder stone" OR "bladder stones" OR "ureter stone" OR "ureter stones" OR ureterolithiasis OR urolithiasis).tw

3. $\mathrm{OR} / 1-2$

4. exp Ureteroscopy/

5. (Ureteroscop* or "Ureteroscopic Surgical Procedure*" or "Ureteroscopic Surgery" or "Ureteroscopic Surgeries" OR pyeloureteroscopy OR ureteropyeloscopy).tw

6. OR/4-5

7. exp stent/

8. exp urologic stent/

9. exp ureter stent/

10. (stent ${ }^{\star}$ or "non-stent ${ }^{\star}$ " or unstent ${ }^{\star}$ or nonstent $\left.^{\star}\right)$.tw

11. OR/7-10

12. 3 AND 6 AND 11

13. exp adult/

14. exp child/

15. exp adolescent/

16. OR/14-15

17. 16 NOT 13

18. 12 NOT 17

19. exp animals/

20. exp humans/

21. 19 NOT 20

22. 18 NOT 21

Appendix 4. Survey of trial investigators providing information on included and excluded trials

\begin{tabular}{llll}
\hline & $\begin{array}{l}\text { Date trial author } \\
\text { contacted (first) }\end{array}$ & $\begin{array}{l}\text { Date trial author } \\
\text { provided data (lat- } \\
\text { est) }\end{array}$ & Data trial author provided (short summary) \\
\hline Sirithanaphol 2017 & 27 Jun 2018 & 20 Sep 2018 & $\begin{array}{l}\text { Method of random sequence generation and blinding. } \\
\text { Number of participants who received analgesics (in morphine } \\
\text { equivalents) }\end{array}$ \\
\hline Wang 2009 & 27 Jun 2018 & 3 Jul 2018 & Method of random sequence generation and blinding \\
\hline Bolat 2017 & & $\begin{array}{l}\text { Number of participants who received analgesics (in morphine } \\
\text { equivalents) }\end{array}$ \\
\hline
\end{tabular}

\section{CONTRIBUTIONS OF AUTHORS}

Maria Ordonez (MO): conception and study design, writing of the protocol, study selection, data extraction, assessment of risk of bias, performance of data analysis. 
EC Hwang (ECH): data extraction, performance of data analysis, interpretation of data.

Michael Borofsky (MB): provision of clinical advice and critical content.

Caitlin J Bakker (CB): creation of the search strategy.

Shreyas Gandhi: data extraction.

Philipp Dahm (PD): conception and study design, provision of clinical and methodological advice on the review, drafting of the review, and final approval.

\section{DECLARATIONS OF INTEREST}

MO: none known.

$\mathrm{ECH}$ : none known.

MB: Boston Scientific (consultant for endourology and stone management), Auris Health (consultant for robotic surgery and endourology).

CB: none known.

SG: none known.

PD: serves as Co-ordinating Editor of Cochrane Urology. However, he was not involved in editorial processing or decision-making for this review. Other editors of Cochrane Urology managed the editorial process, including final sign-off for this review.

\section{SOURCES OF SUPPORT}

\section{Internal sources}

- Department of Urology, University of Minnesota, USA. salary support

- Department of Urology, Chonnam National University Medical School and Hwasun Hospital, Korea, South. salary support

\section{External sources}

- No sources of support supplied

\section{DIFFERENCES BETWEEN PROTOCOLANDREVIEW}

This review is based on a published protocol (Ordonez 2017), with differences as described here.

- We found no study that reported narcotic requirements as mean morphine equivalents. Instead, studies reported the number of patients who required any narcotics (in addition to non-steroidal analgesics). We therefore elected to report this outcome instead.

- Postoperative pain assessment by included trials varied greatly in terms of location of the pain and timing of assessment. The latter prompted us to split this outcome into three outcomes (day of the procedure, postoperative days 1 through 3 , and postoperative days 4 through 30). Given the addition of two outcomes and the GRADE requirement to limit outcomes in the 'Summary of findings' table to seven, we elected to report the pain on days 4 to 30 because we perceived it as the most important time interval among the three.

- Because reporting quality did not allow a meaningful distinction per outcome, we assessed attrition bias for all outcomes.

- We changed the 'Summary of findings' table to include the outcome of postoperative pain split into three time intervals. Based on reviewers' views of their perceived importance to patient care, we also added ureteral stricture and hospital admission.

\section{NOTES}

We have based parts of the methods section of this protocol on a standard template developed by the Cochrane Metabolic and Endocrine Disorders Group, which has been modified and adapted for use by the Cochrane Urology Group.

\section{IN DEX TERMS}

\section{Medical Subject Headings (MeSH)}

*Stents; *Ureter; Analgesics, Opioid [administration \& dosage]; Emergency Service, Hospital [statistics \& numerical data]; Hospitalization [statistics \& numerical data]; Kidney Calculi [ ${ }^{*}$ surgery]; Pain Measurement; Pain, Postoperative [diagnosis] 
[prevention \& control]; Postoperative Complications [diagnosis] [prevention \& control]; Randomized Controlled Trials as Topic; Ureteral Calculi [* ${ }^{\star}$ surgery]; Ureteral Obstruction [prevention \& control]; Ureteroscopy [adverse effects] [*methods]; Urinary Tract Infections [epidemiology] [prevention \& control]

\section{MeSH check words}

Humans 